Supplement of Clim. Past Discuss., 11, 873-932, 2015

http://www.clim-past-discuss.net/11/873/2015/

doi:10.5194/cpd-11-873-2015-supplement

(C) Author(s) 2015. CC Attribution 3.0 License.

(c) (i)

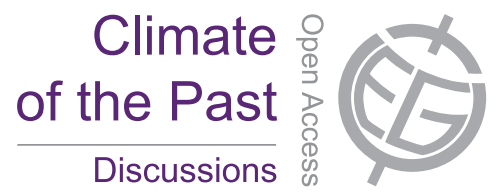

Supplement of

\title{
Early-Holocene warming in Beringia and its mediation by sea-level and vegetation changes
}

\section{P. J. Bartlein et al.}

Correspondence to: P. J. Bartlein (bartlein@uoregon.edu) 


\section{Supplementary Material}

This supplement contains figures displaying 10-year long-term means or long-term mean differences (anomalies) from the various simulations. Each simulation is described by two pages of figures (A \& B): Page A displays net radiation $\left(\mathrm{Wm}^{-2}\right), 2-\mathrm{m}$ air temperature $\left({ }^{\circ} \mathrm{C}\right)$, $500 \mathrm{mb}$ heights (gpm) and winds $\left(\mathrm{m} \mathrm{s}^{-1}\right)$, sea-level pressure $(\mathrm{hPa})$ and surface winds $\left(\mathrm{m} \mathrm{s}^{-1}\right)$, total cloud (fraction), precipitation rate $\left(\mathrm{mm} \mathrm{d}^{-1}\right)$, and soil moisture (\%). Page B displays surface energy-balance components including net shortwave radiation, net longwave radiation, net radiation, sensible heat flux, latent heat flux, and the heat flux into the substrate (or change in heat storage), all in $\mathrm{Wm}^{-2}$, and 2-m air temperature ( ${ }^{\circ} \mathrm{C}$ ). (Net radiation and 2-m air temperature appear on both figures for convenience.) The sign convention for the energy-balance components is described below.

\section{Figures:}

1) Present-Day Simulation (with modern continental outlines)

2) Present-Day Simulation (with 11 ka continental outlines)

3) Present-Day Simulation (with modern continental outlines) minus Present-Day Simulation (with 11 ka continental outlines)

4) $11 \mathrm{ka}$ Control Simulation

5) $11 \mathrm{ka}$ Control Simulation minus Present-Day Simulation

6) $11 \mathrm{ka}$ Control Simulation minus Present-Day Simulation (with 11 ka continental outlines)

7) 11 ka Sea-Level Simulation

8) $11 \mathrm{ka}$ Sea-Level Simulation minus $11 \mathrm{ka}$ Control Simulation

9) 11 ka Vegetation Simulation

10) 11 ka Vegetation Simulation minus 11 ka Control Simulation

11) 11 ka Lakes Simulation

12) 11 ka Lakes Simulation minus 11 ka Control Simulation

13) $11 \mathrm{ka}$ All Simulation

14) 11 ka All Simulation minus 11 ka Control Simulation

15) $11 \mathrm{ka}$ All Simulation minus Present-Day Simulation (with modern continental outlines)

16) 6 ka Simulation

17) 6 ka Simulation minus Present-Day Simulation (with modern continental outlines)

18) 6 ka Simulation minus $11 \mathrm{ka}$ All Simulation 
where

\section{Surface energy-balance components}

The surface energy balance is given by

$$
\begin{aligned}
& K \downarrow-K \uparrow+L \downarrow-L \uparrow-Q_{H}-Q_{E}-Q_{G}=0 \text {, or } \\
& Q_{\text {net }}=K \downarrow-K \uparrow+L \downarrow-L \uparrow, \text { or } \\
&=K_{\text {net }}+L_{\text {net }}, \text { and } \\
&=Q_{H}+Q_{E}+Q_{G}, \text { or } \\
&=Q_{H}+Q_{E}+\Delta Q_{S}
\end{aligned}
$$

$K \downarrow=$ incoming shortwave radiation (all terms in $\mathrm{Wm}^{-2}$ ),

$K \uparrow=$ outgoing shortwave radiation,

$K_{\text {net }}=K \downarrow-K \uparrow$, net shortwave radiation, or $(1-\alpha) K \downarrow$ where $\alpha$ is the albedo of the surface,

$L \downarrow=$ incoming longwave radiation,

$L \uparrow=$ outgoing longwave radiation ( $\sim T_{s f c}^{4}$ where $T_{s f c}$ is the temperature of the surface),

$L_{\text {net }}=L \downarrow-L \uparrow$, or net longwave radiation,

$Q_{H}=$ sensible heat flux,

$Q_{E}=$ latent heat flux ( $\sim E$ or $\sim E T$, where $E$ is evaporation and $E T$ is evapotranspiration), and

$Q_{G}=\Delta Q_{S}$, heat flux into or out of the substrate (land or water) or change in heat storage 


\author{
Radiative \\ components \\ Net shortwave \\ radiation, $K_{\text {net }}$ \\ positive: toward surface \\ (i.e., surface heating) \\ negative: 0.0 \\ Net longwave \\ radiation, $L_{\text {net }}$

\section{components} \\ Non-radiative \\ Sensible heat \\ flux, $Q_{H}$ \\ Latent heat flux, \\ $Q_{E}$ \\ positive: toward surface \\ negative: from surface (i.e., \\ surface cooling) \\ positive: heat flow from surface \\ to atmosphere \\ negative: heat flow from \\ atmosphere to surface \\ positive: heat flow (via $E$ or $E T$ ) \\ from surface to atmosphere \\ negative: heat flow (via \\ condensation) from \\ atmosphere to surface \\ Substrate heat positive: heat flow from surface \\ flux, $Q_{G}=\Delta Q_{S} \quad$ into substrate (land or water), \\ i.e., into storage \\ negative: heat flow from \\ substrate to surface, i.e., from \\ storage
}

\section{Long-term mean difference (anomalies)}

positive: increased $K \downarrow$ or decreased albedo (e.g. seaice replaced by land)

negative: decreased $K \downarrow$ or increased albedo (e.g. land replaced by sea-ice)

positive: increased $L \downarrow$ or decreased $L \uparrow$

negative: decreased $L \downarrow$ or increased $L \uparrow$

positive: increased heating of atmosphere by surface or decreased heating of surface by atmosphere negative: decreased heating of atmosphere by surface or increased heating of surface by atmosphere

positive: increased $E$ or $E T$ (or decreased condensation)

negative: decreased $E$ or $E T$ (or increased condensation)

positive: increased heat flow from surface to substrate (or increased flow into storage)

negative: decreased heat flow from surface to substrate (or decreased flow into storage) 


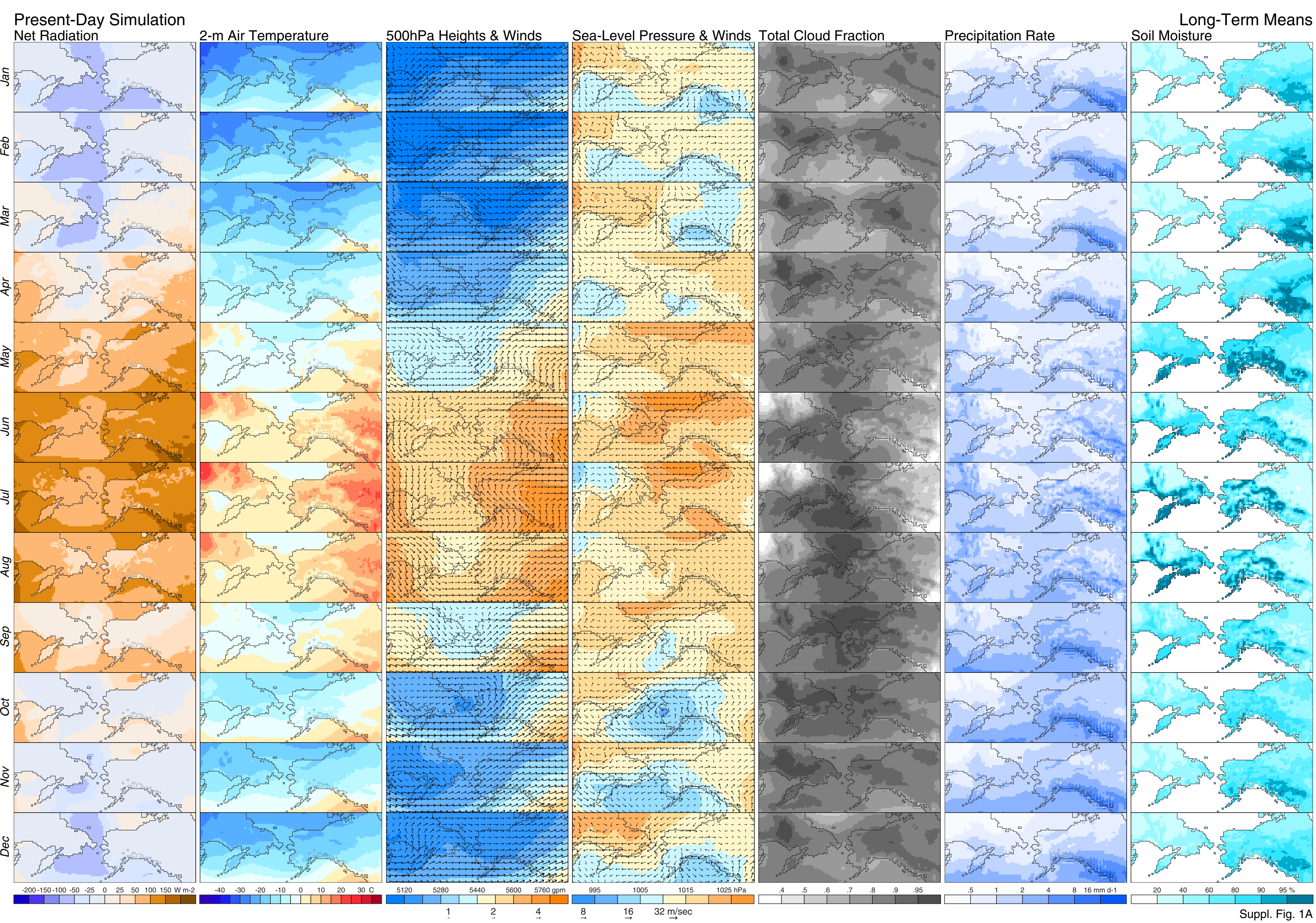




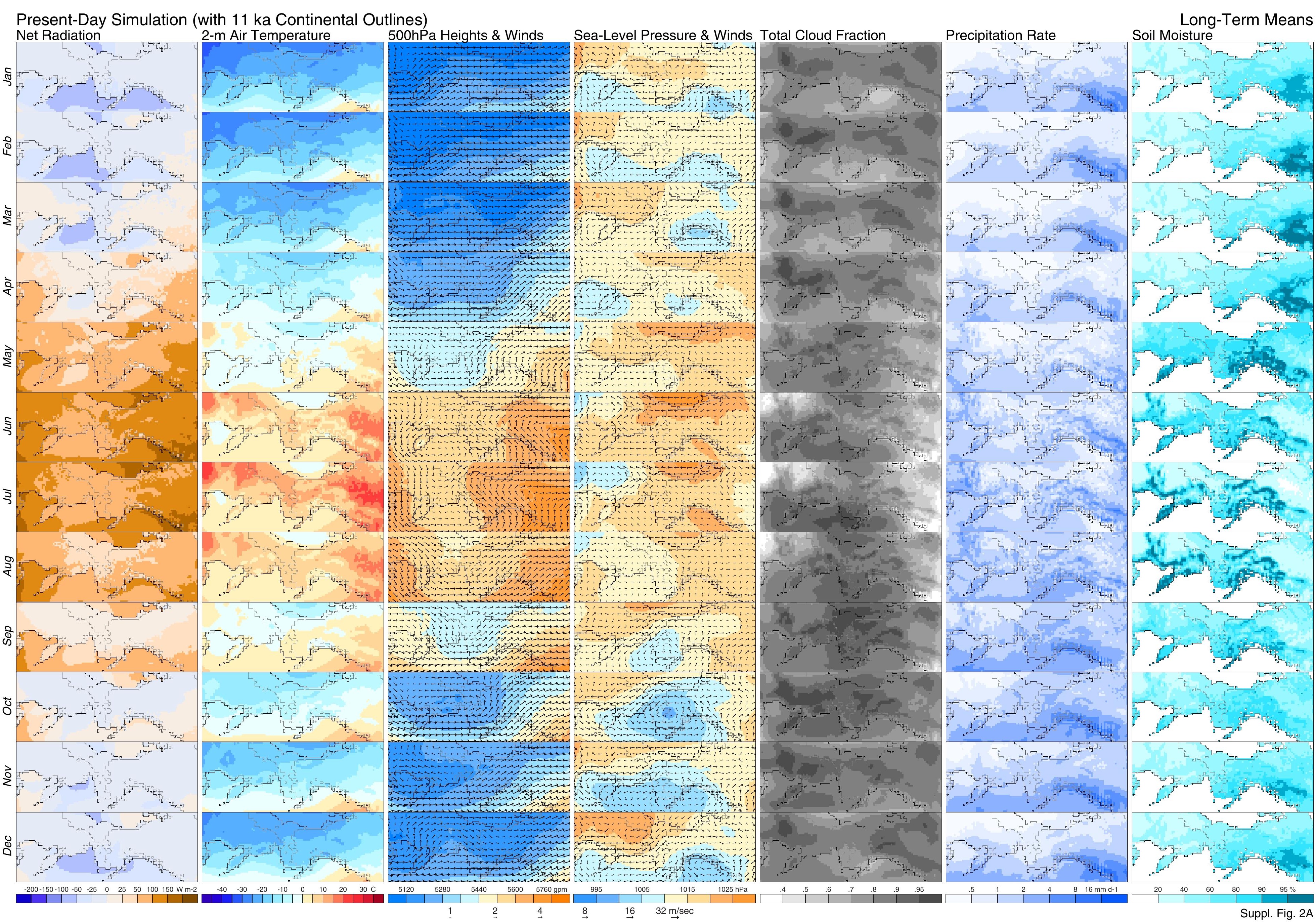




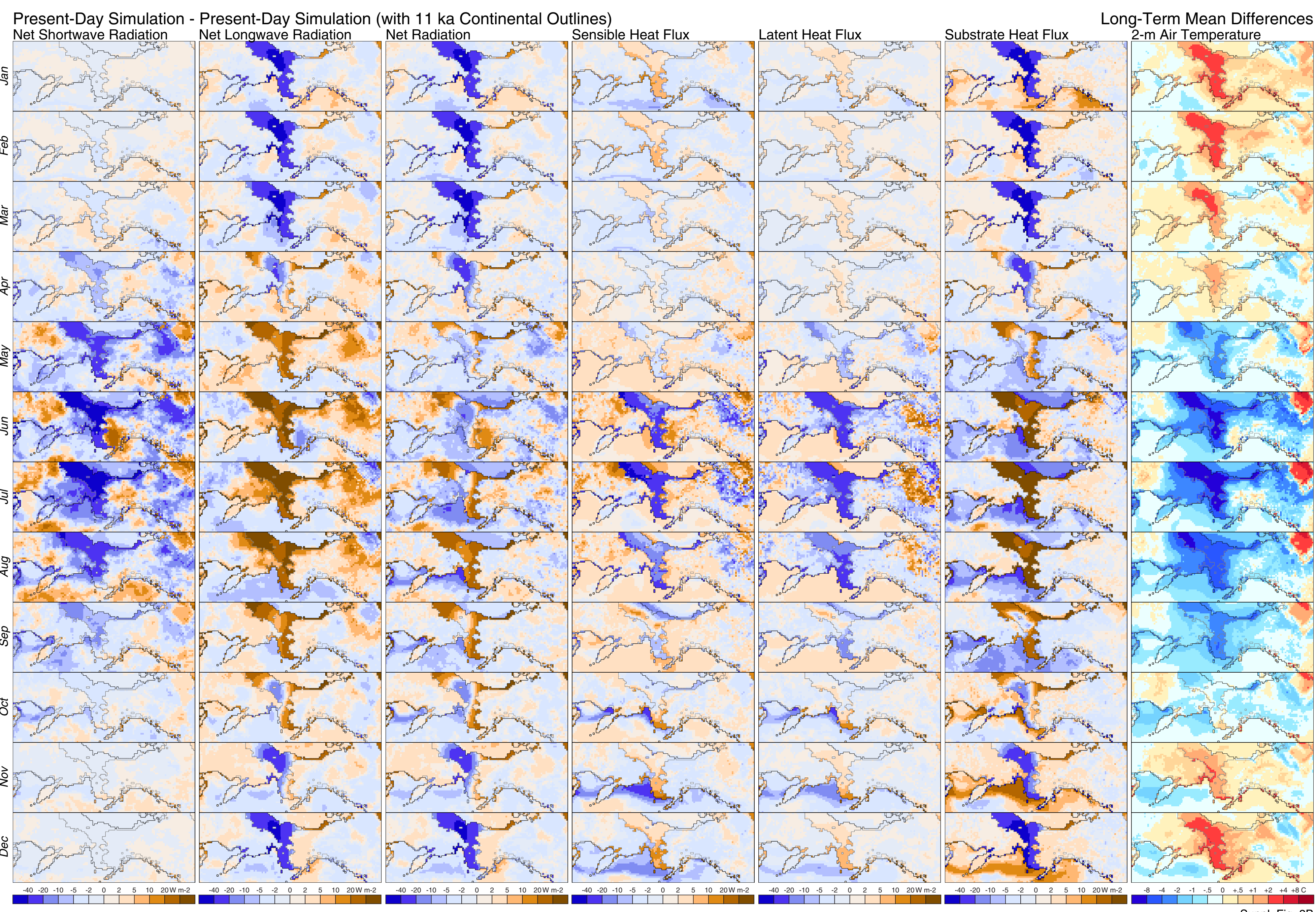

pppl. Fig. 3B 

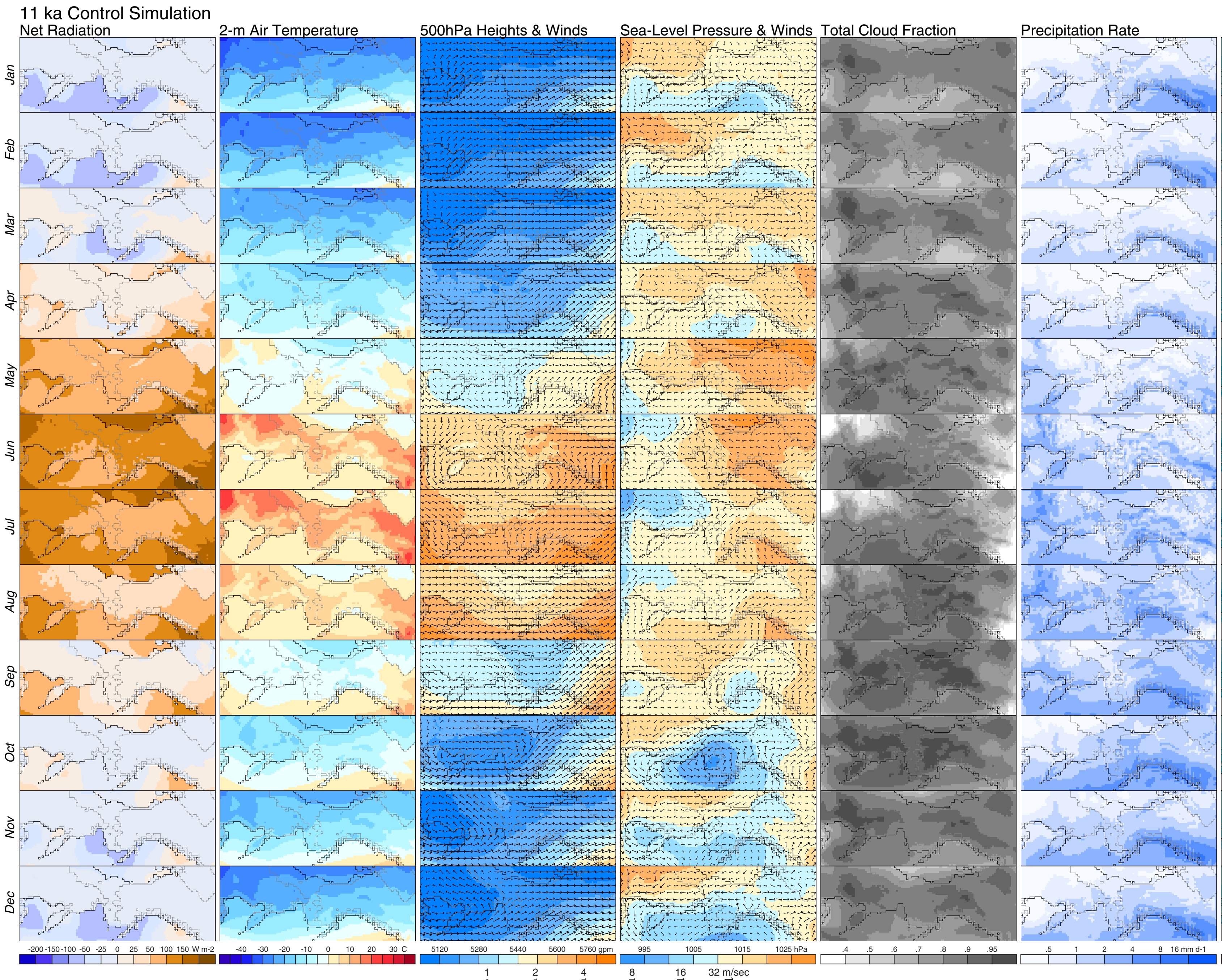

Long-Term Means Soil Moisture

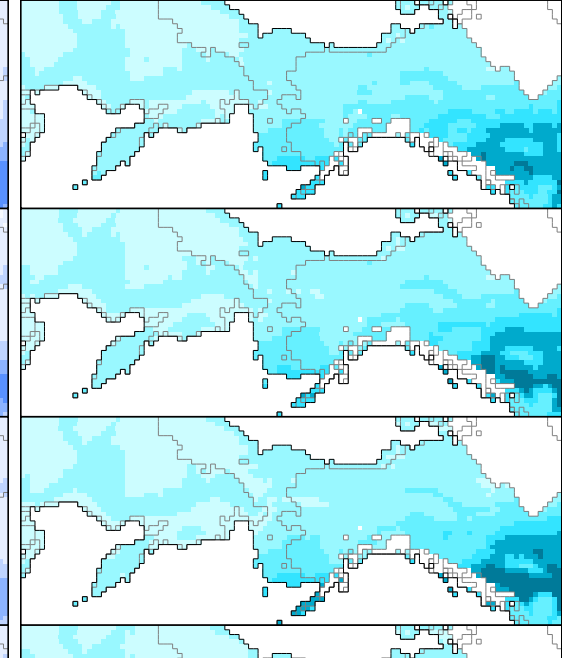

.

. $\frac{4}{P^{2}}=$ at

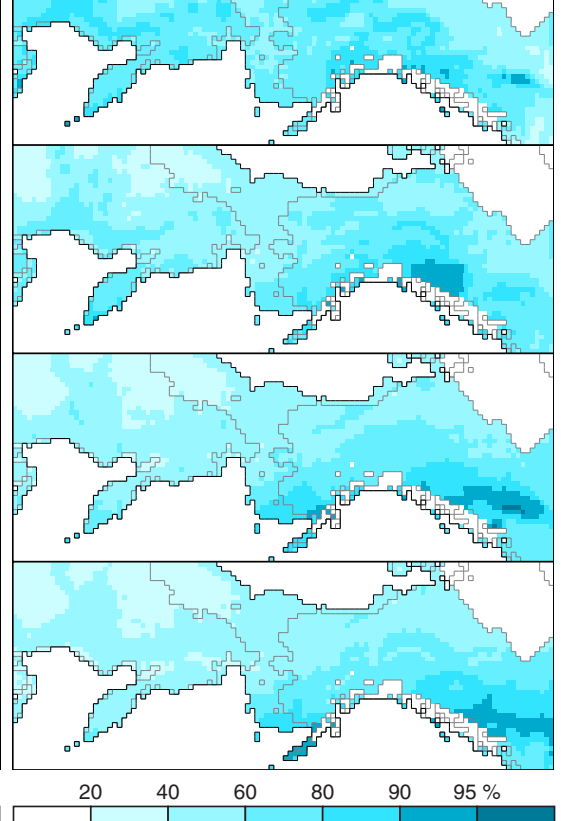
Suppl. Fig. 4A 
11 ka Control Simulation

Net Shortwave Radiation Net Longwave Radiation

Net Radiation

Sensible Heat Flux

Flux

\&

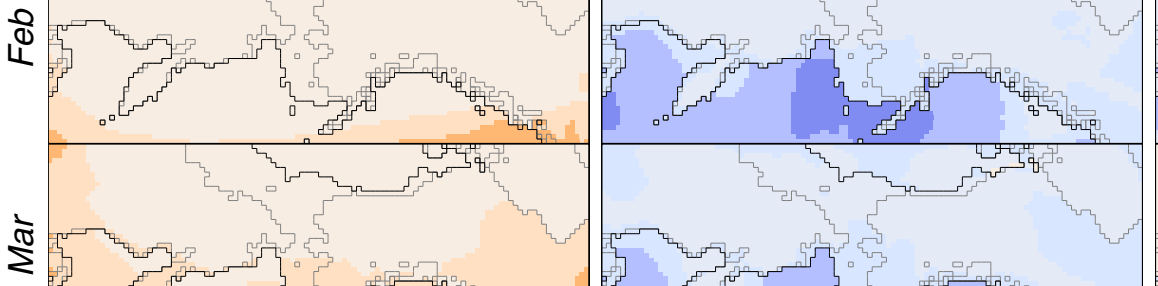

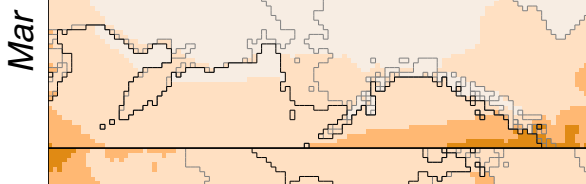

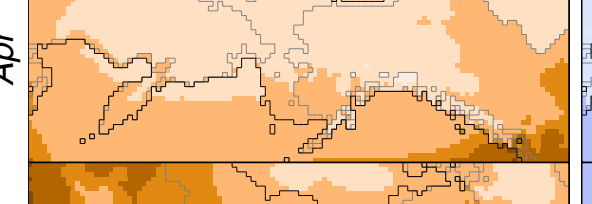

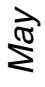

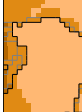

y
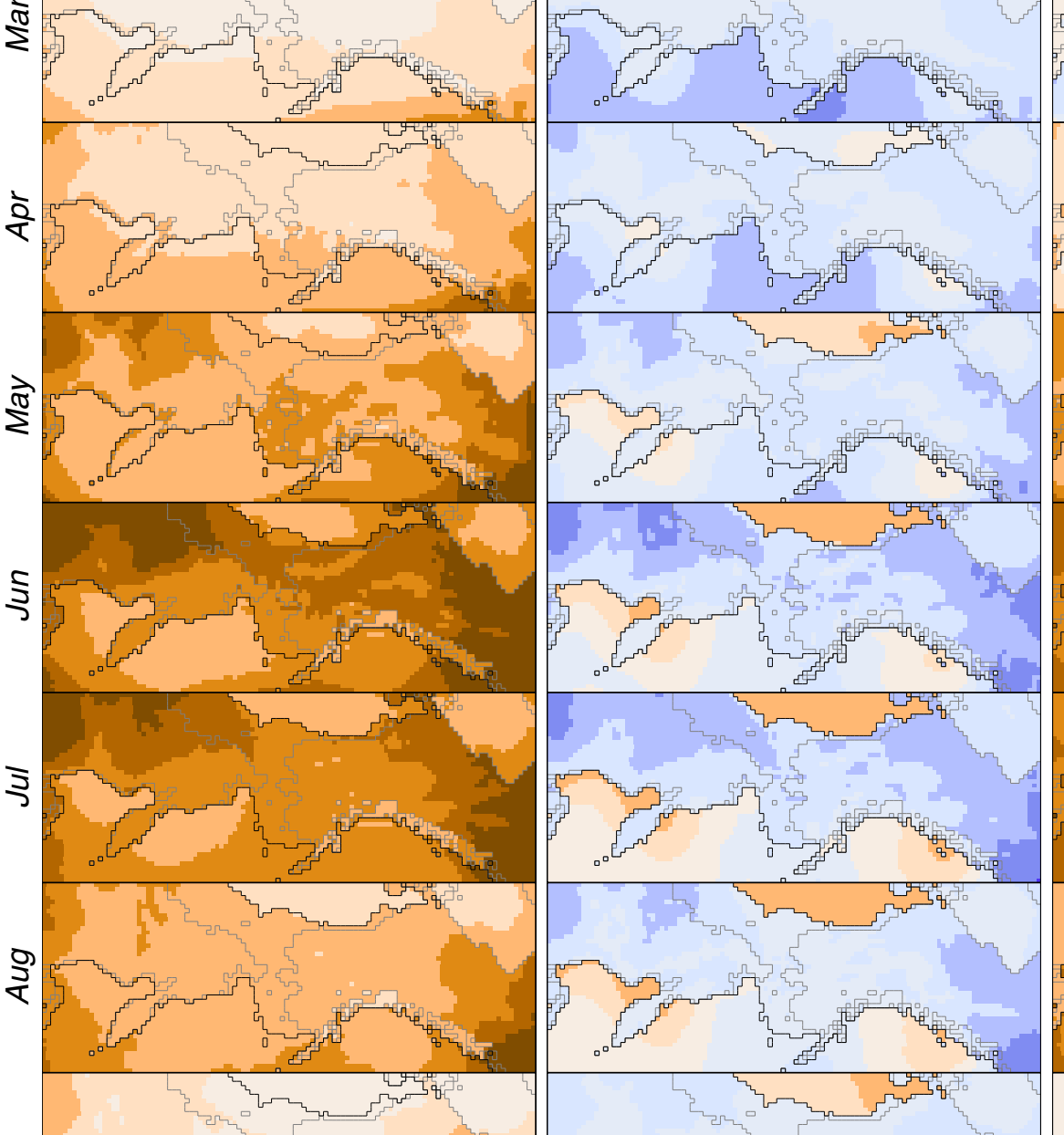

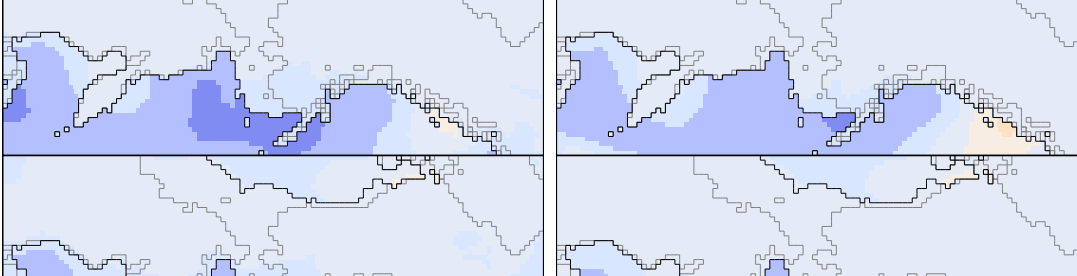

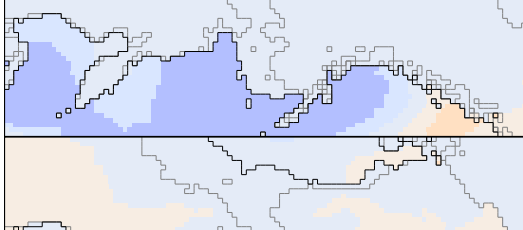

$p e-2 x$

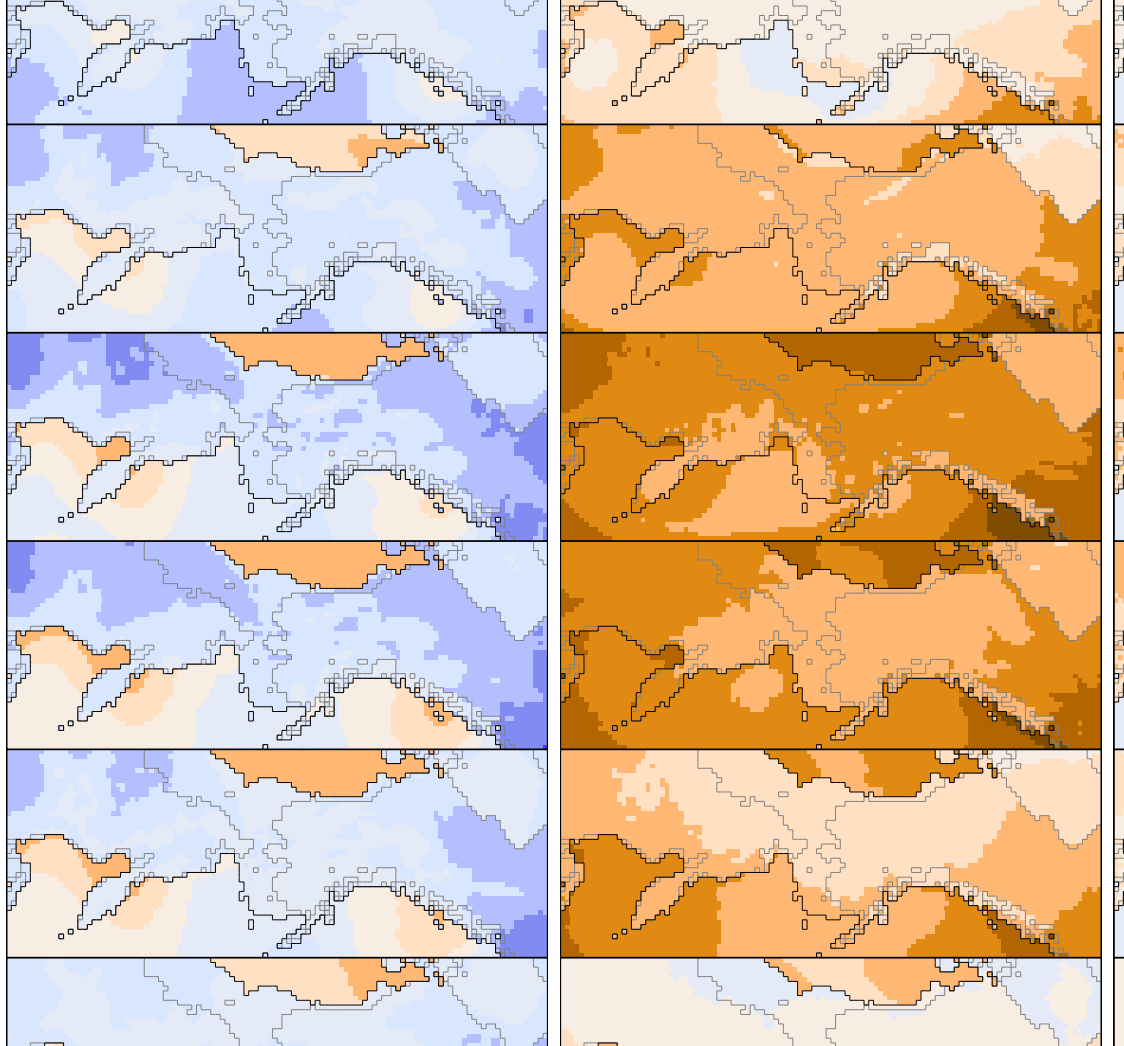

की

O)

$\overrightarrow{2}$ 8

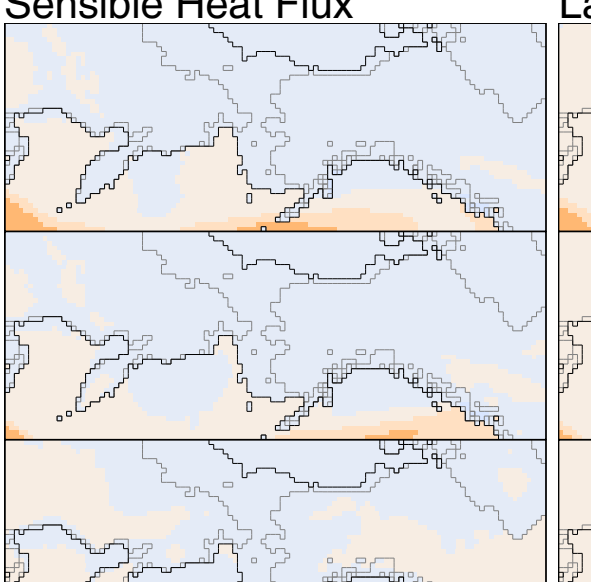

Con

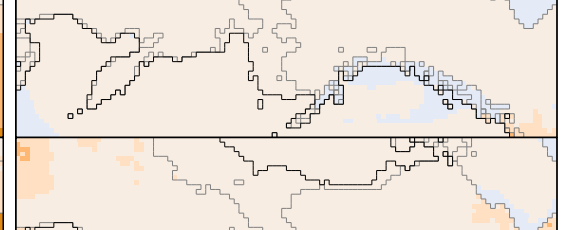

peran

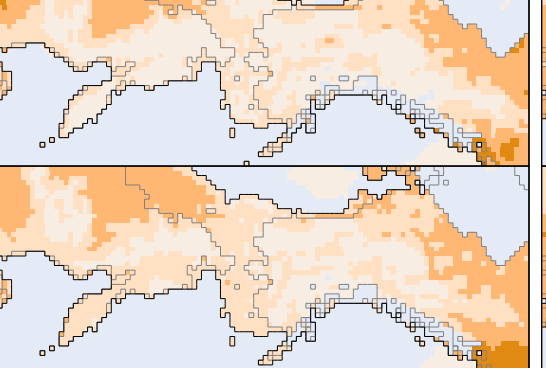

rom

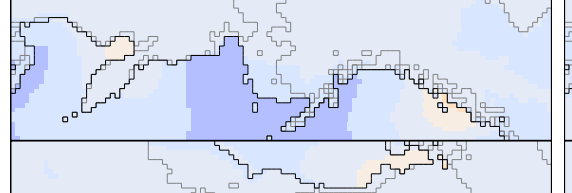

Drits

(1)

Substrate Heat Flux

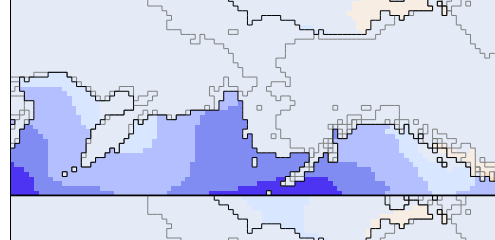

$12 y-1, y=4$ perting

renting

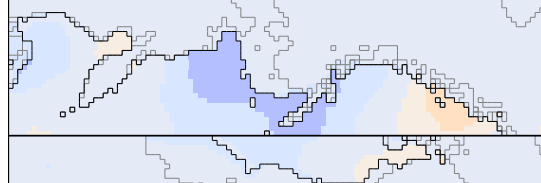

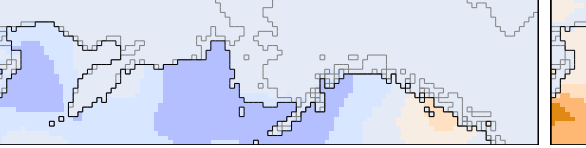

Denty

(1)

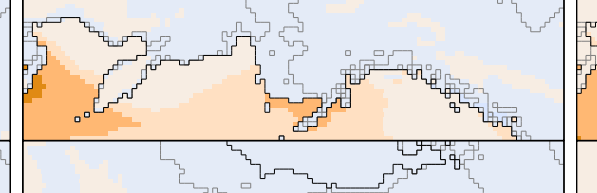

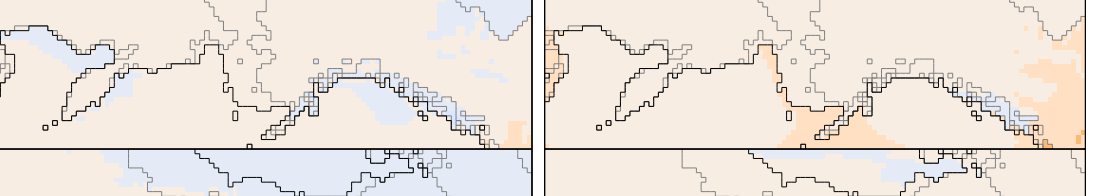

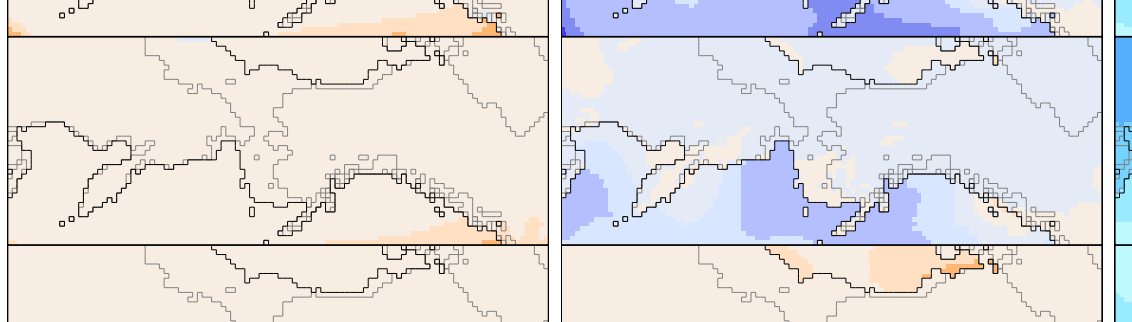

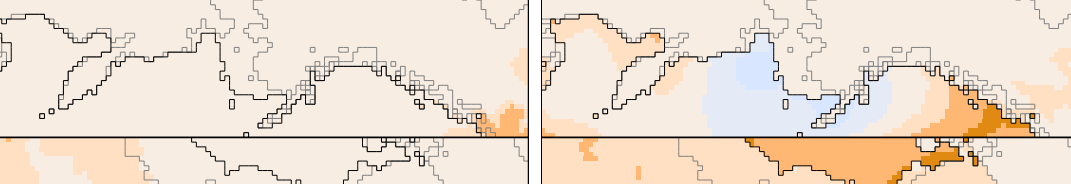
F
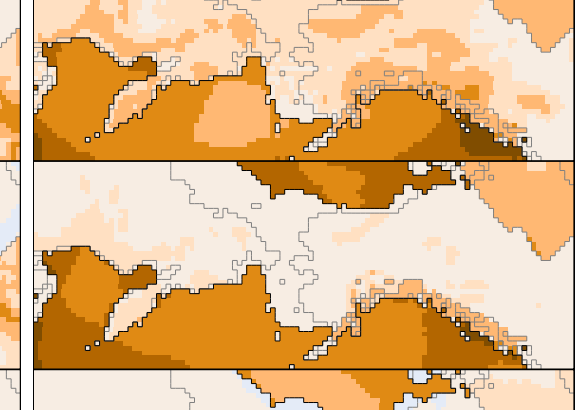
$P(4)$ 10.4 2.

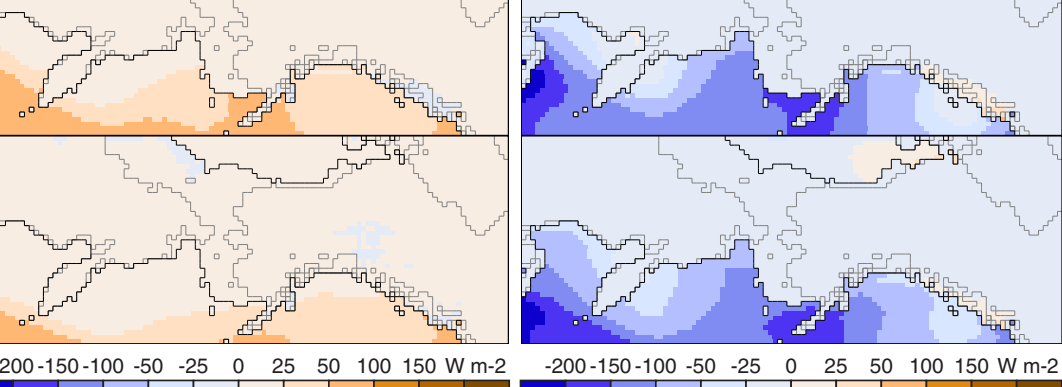

Long-Term Means 2-m Air Temperature

3 of of

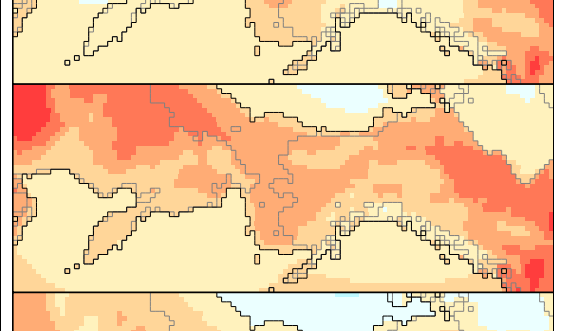
ar

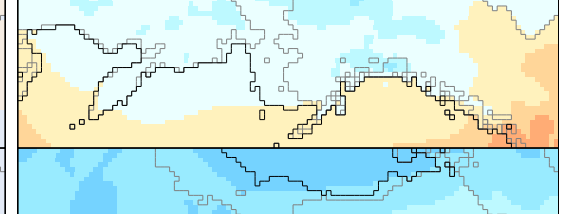

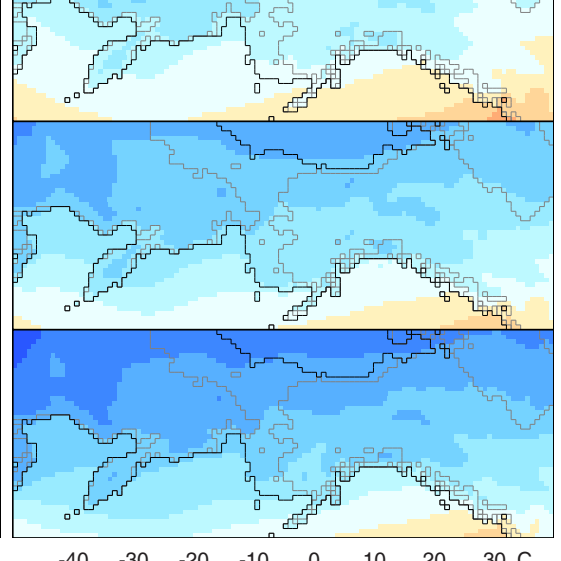




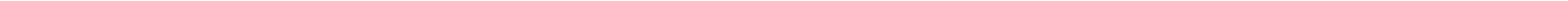




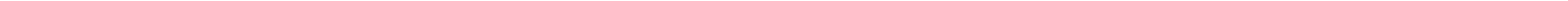


11 ka Control Simulation - Present-Day Simulation (with 11 ka Continental Outlines)

Net Shortwave Radiation Net Longwave Radiation Net Radiation $\quad$ Sensible Heat Flux Long-Term Mean Differences

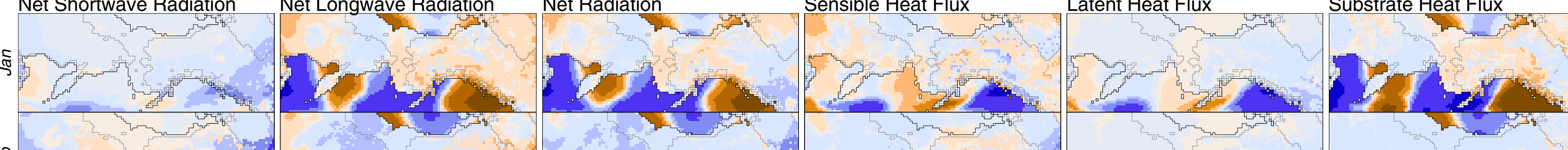

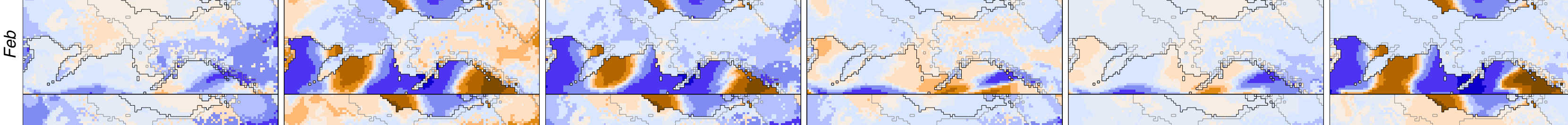

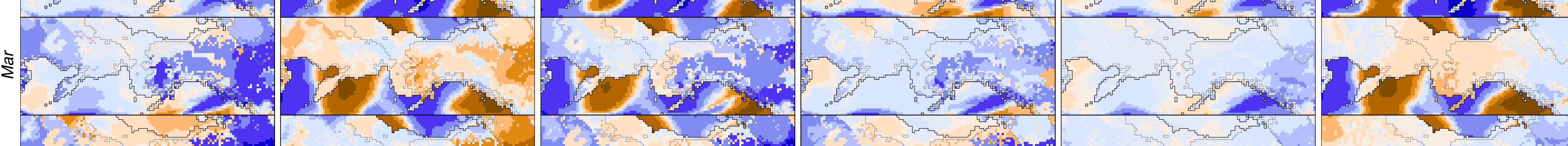
Fo

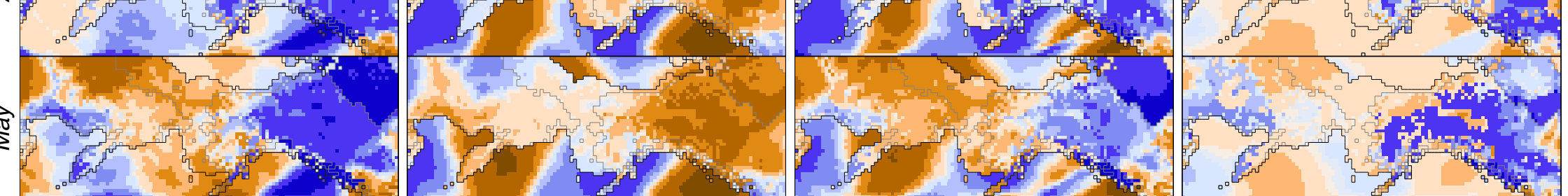

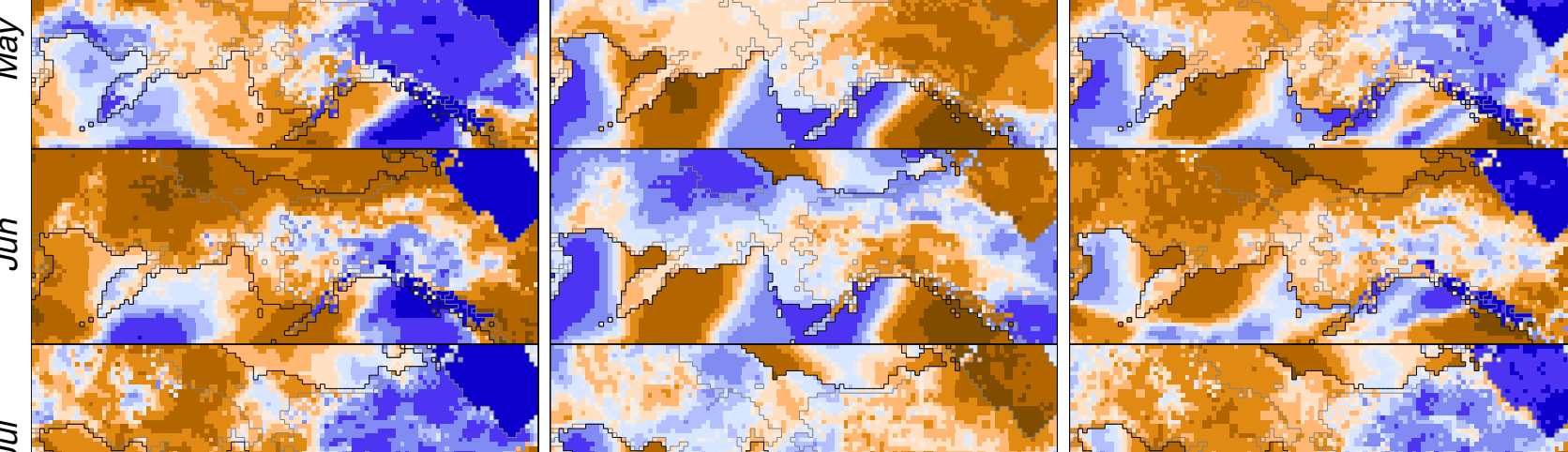
. xtex

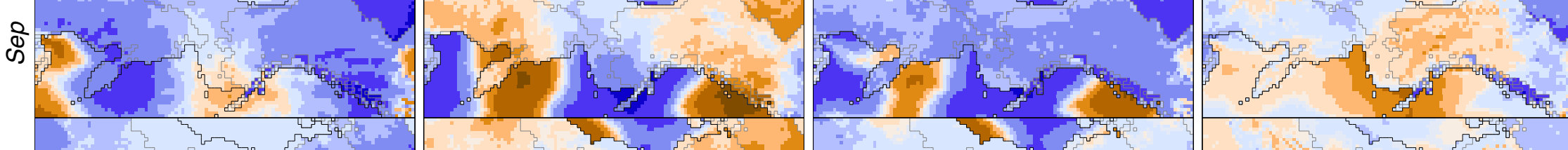
30 Tince Etore : nowinte spen pera

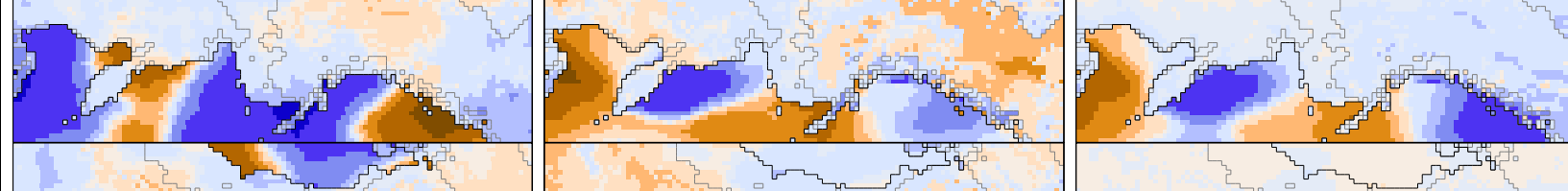

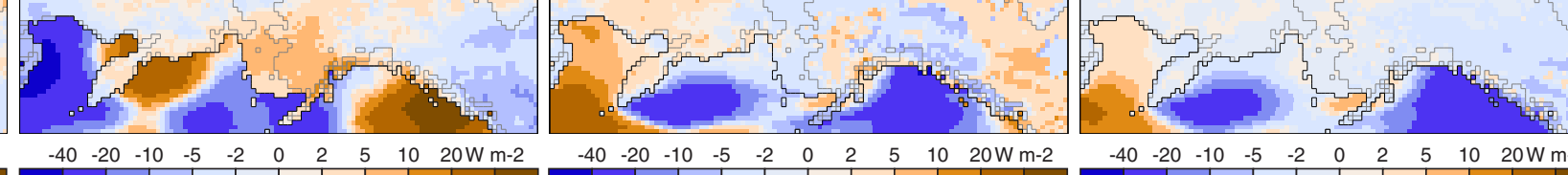

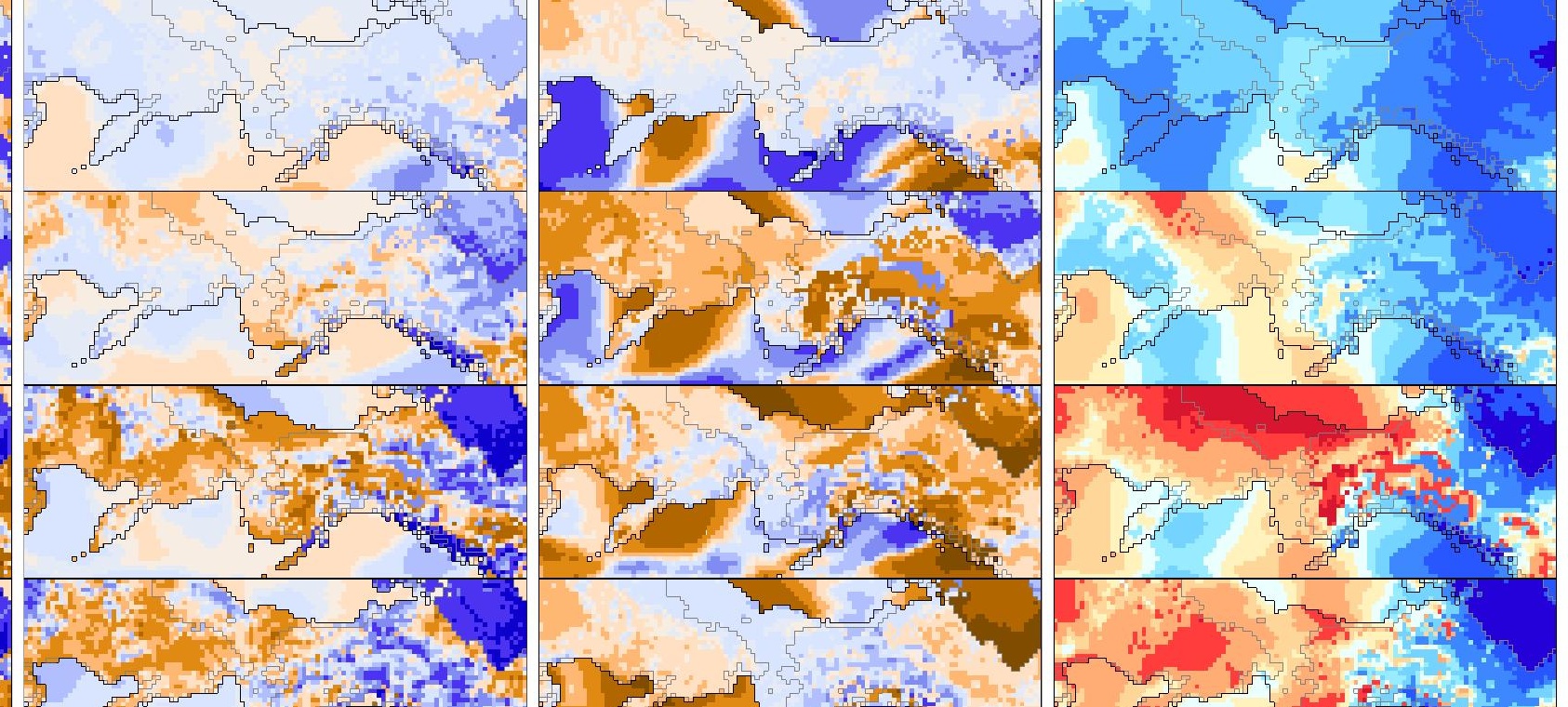
1. $4 x+5$ incents

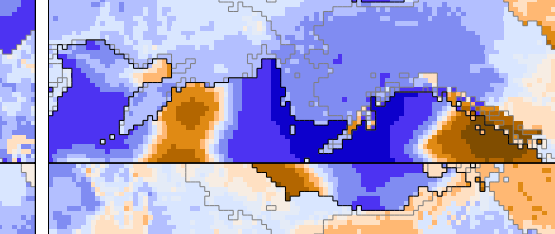

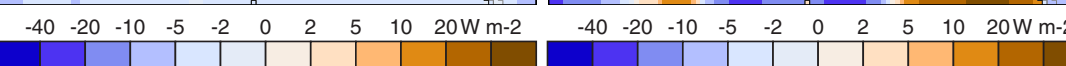

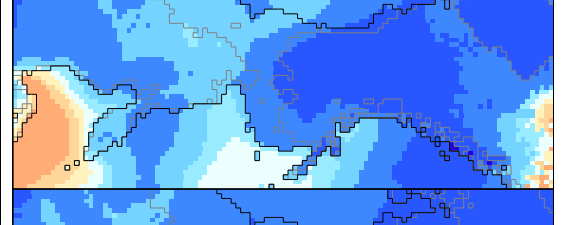
$x^{2}+x^{2}$ bon 
11 ka Sea-Level Simulation

Net Radiation 2-m Air Temperature

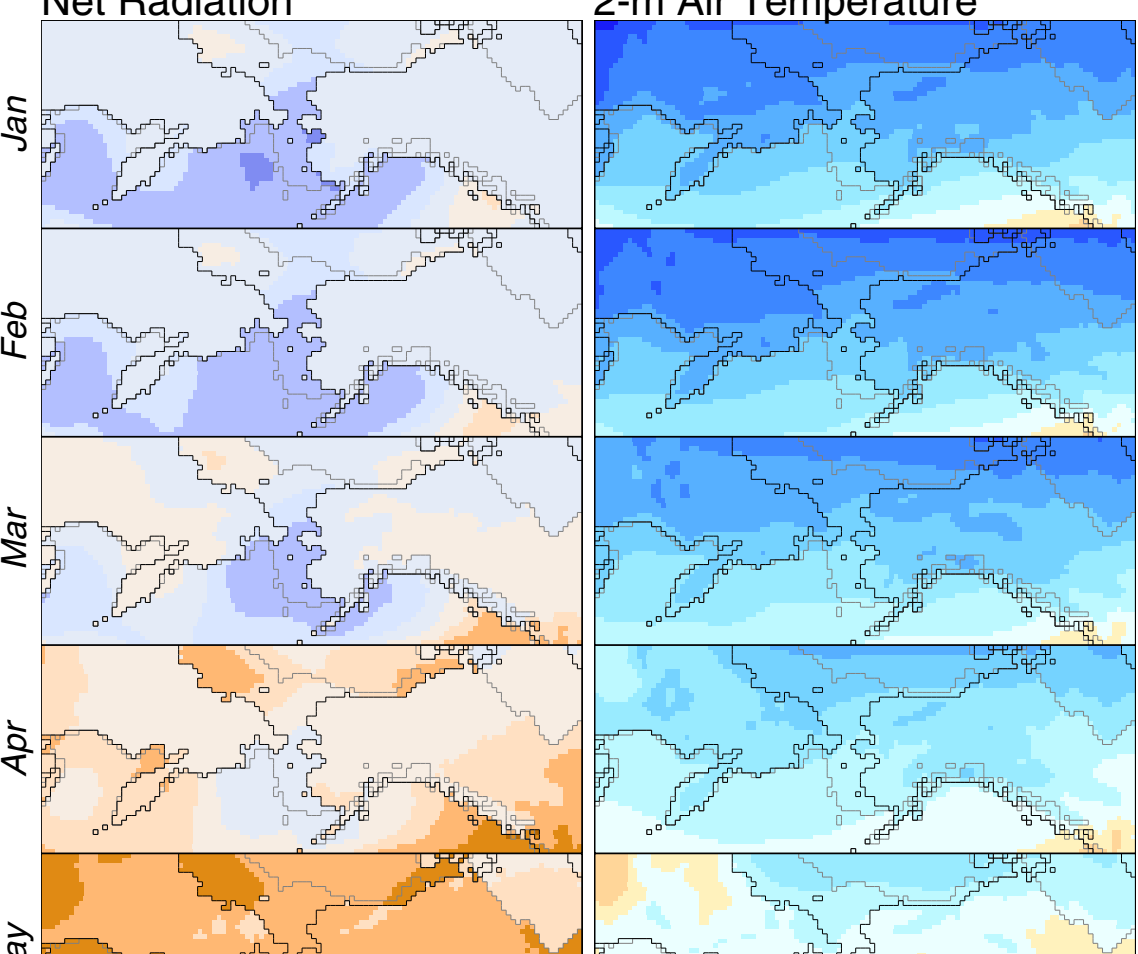

要

S

5

(3)

की

8.

2
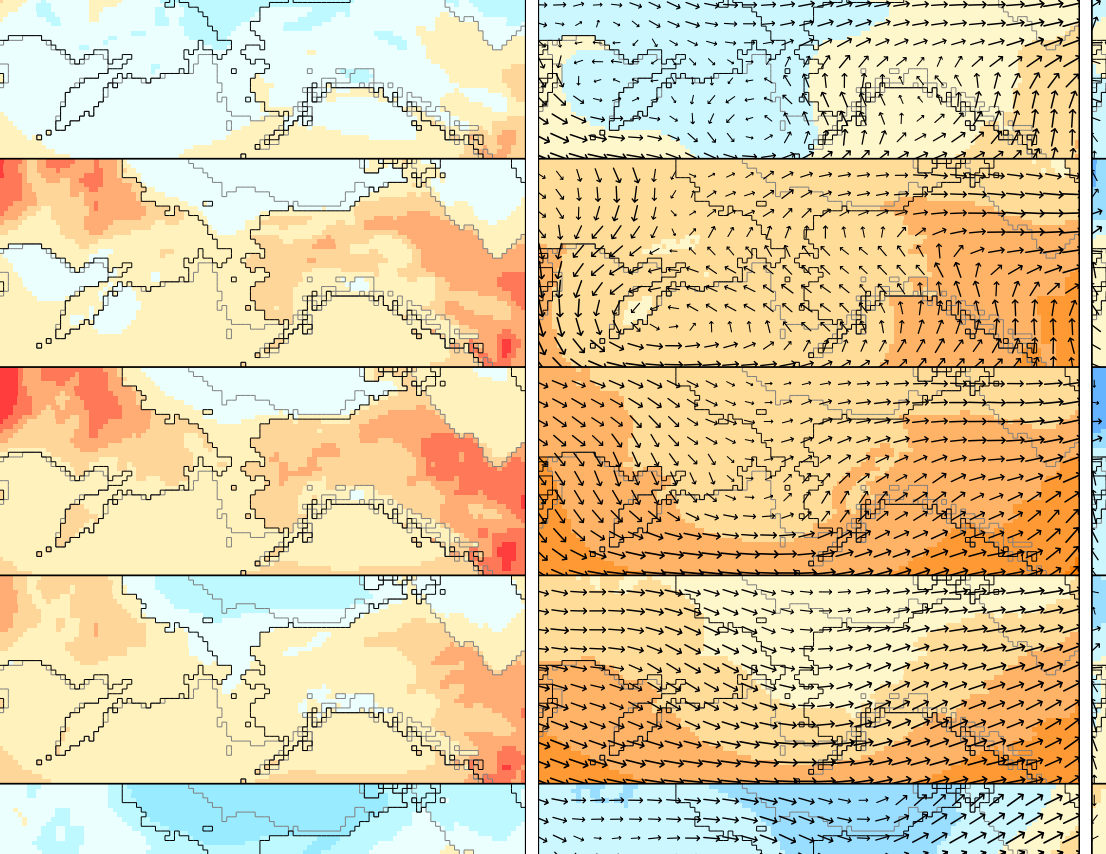

500hPa Heights \& Winds Sea-Level Pressure \& Winds Total Cloud Fractior

Long-Term Means
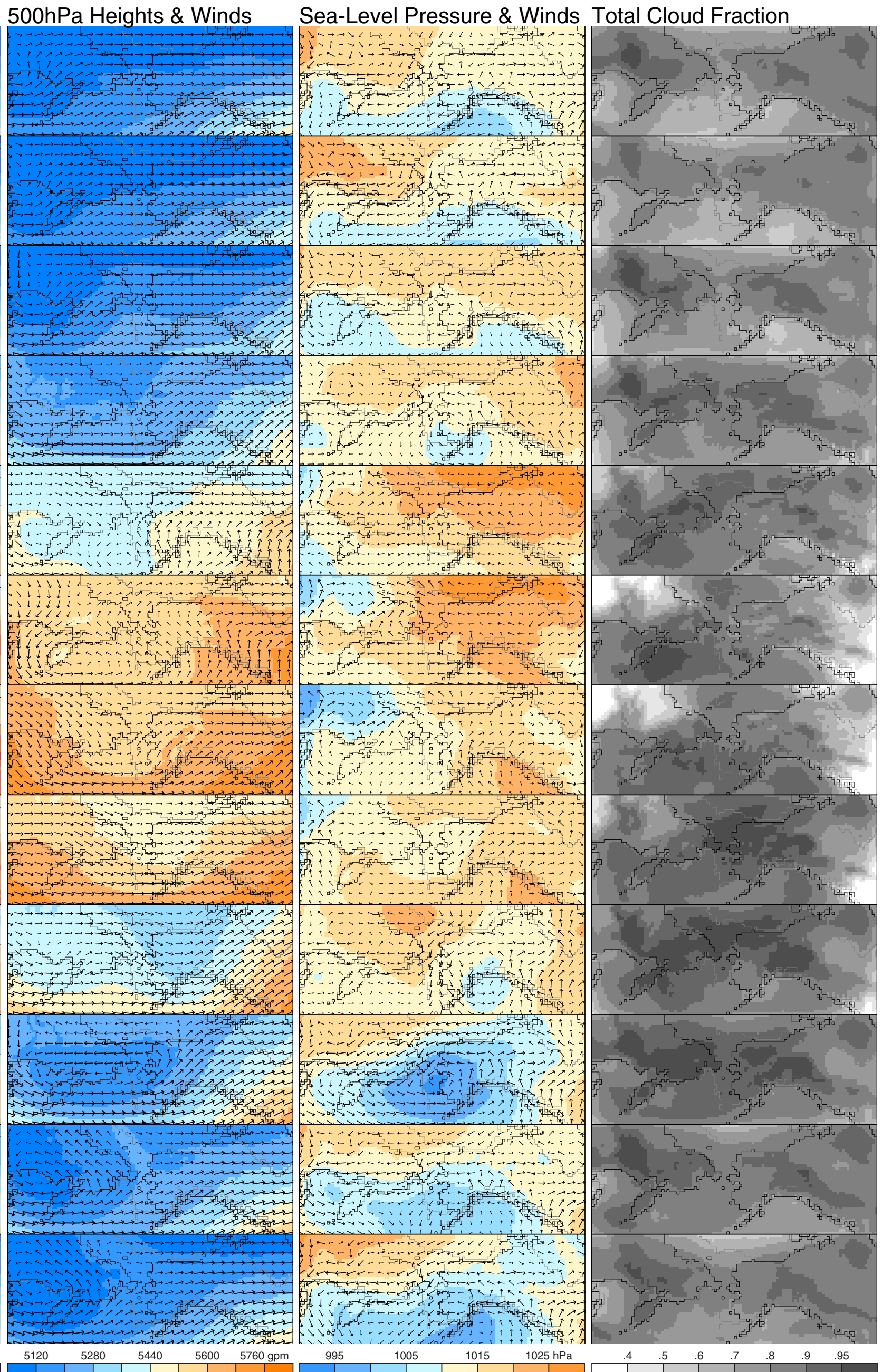

Precipitation Rate Soil Moisture
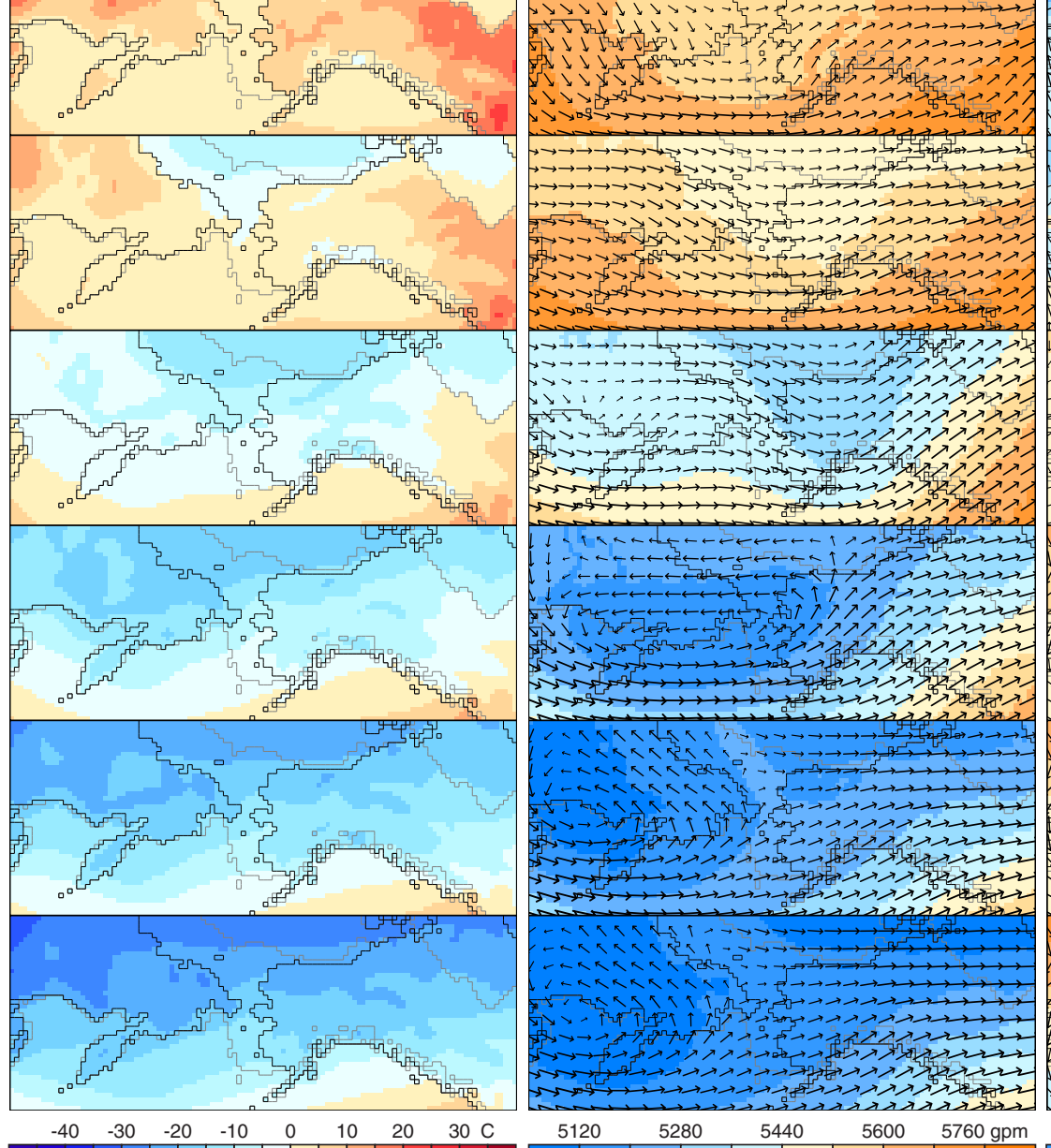

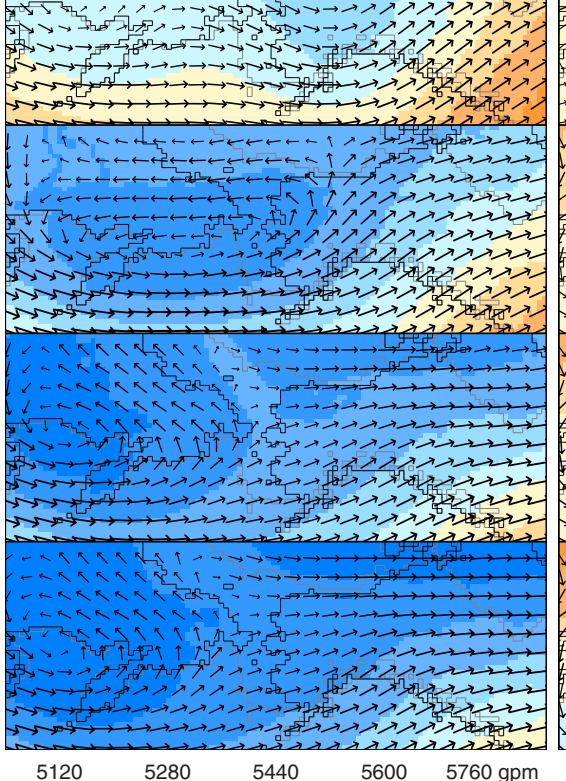

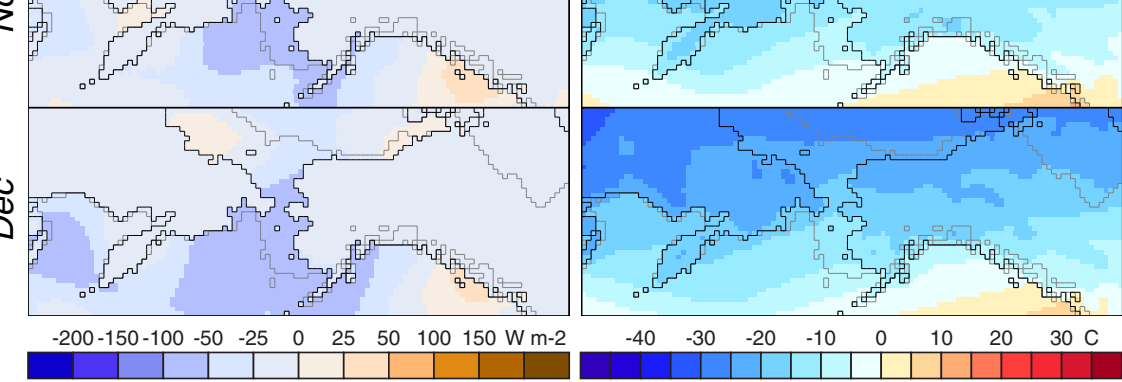

: 
11 ka Sea-Level Simulation

Net Shortwave Radiation Net Longwave Radiation

Net Radiation

Sensible Heat Flux

Long-Term Means

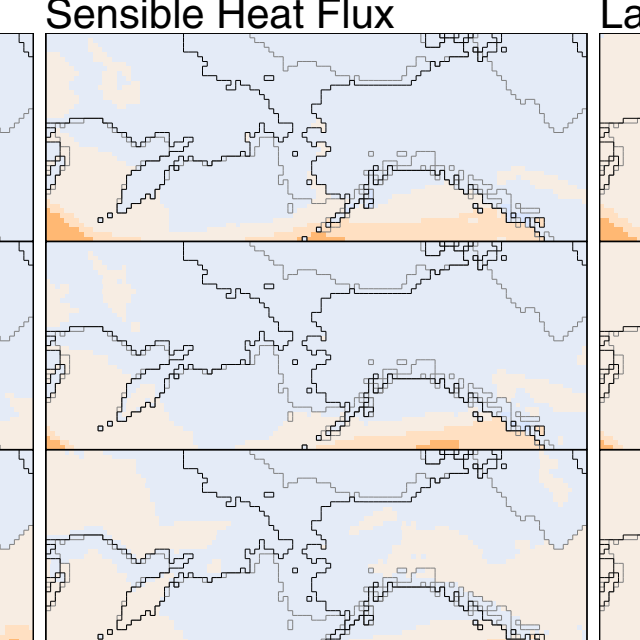

Substrate Heat Flux

Ty $17+y$

$\stackrel{\varpi}{\Sigma}$

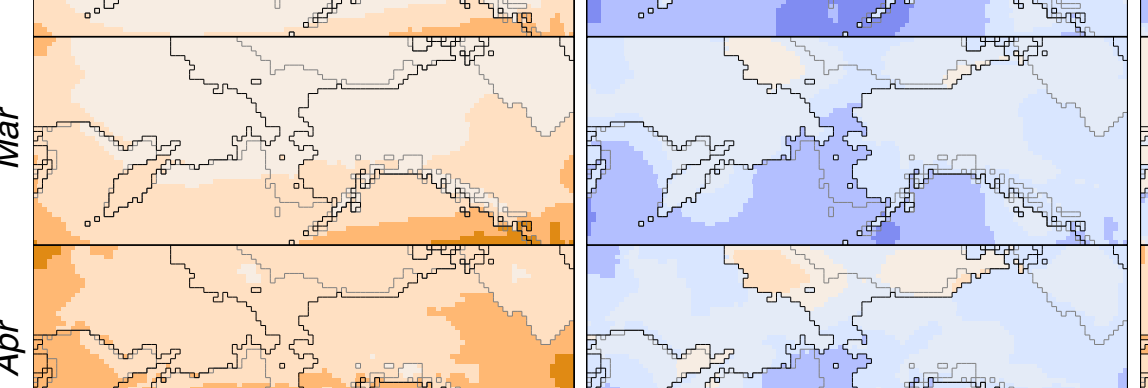

(a)

ले

.

-

.

.

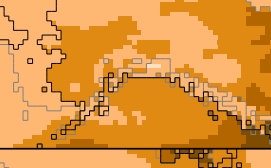

.

S

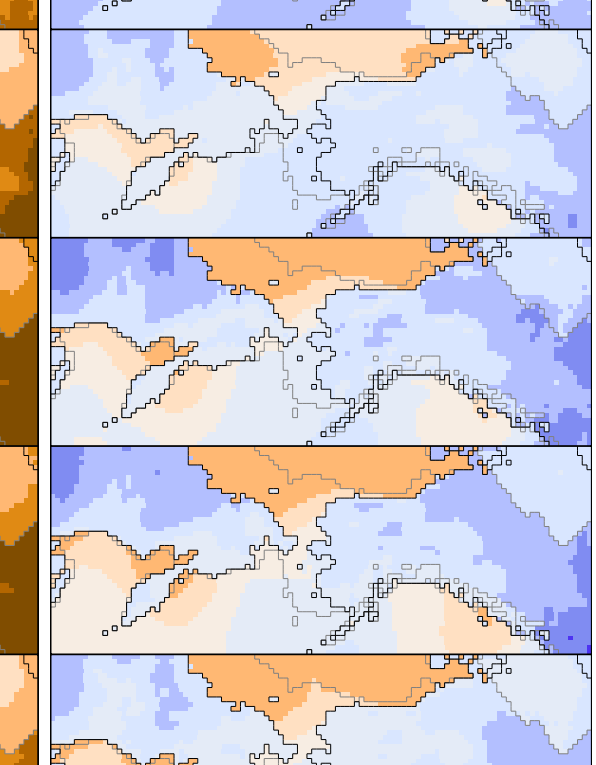

(n)
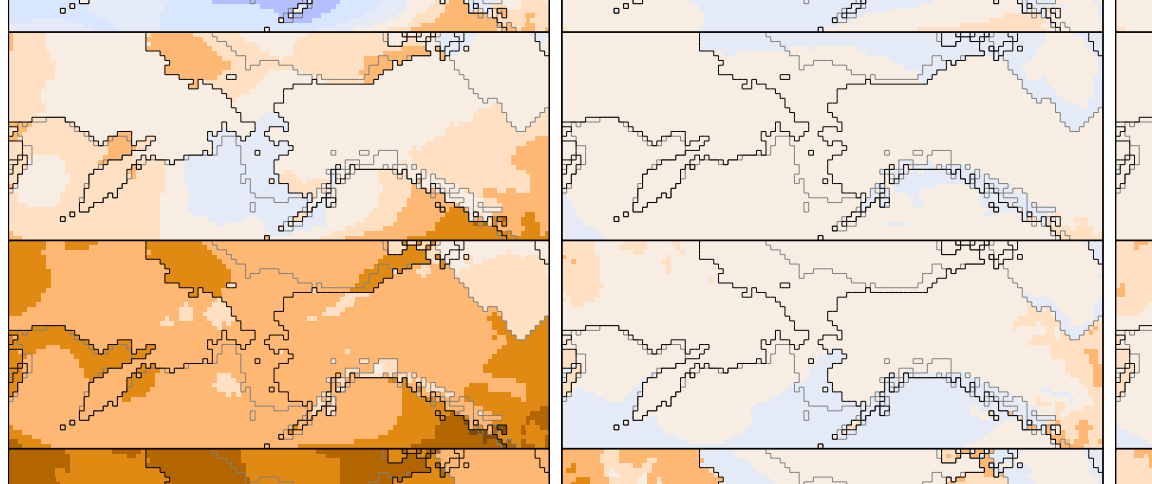

की
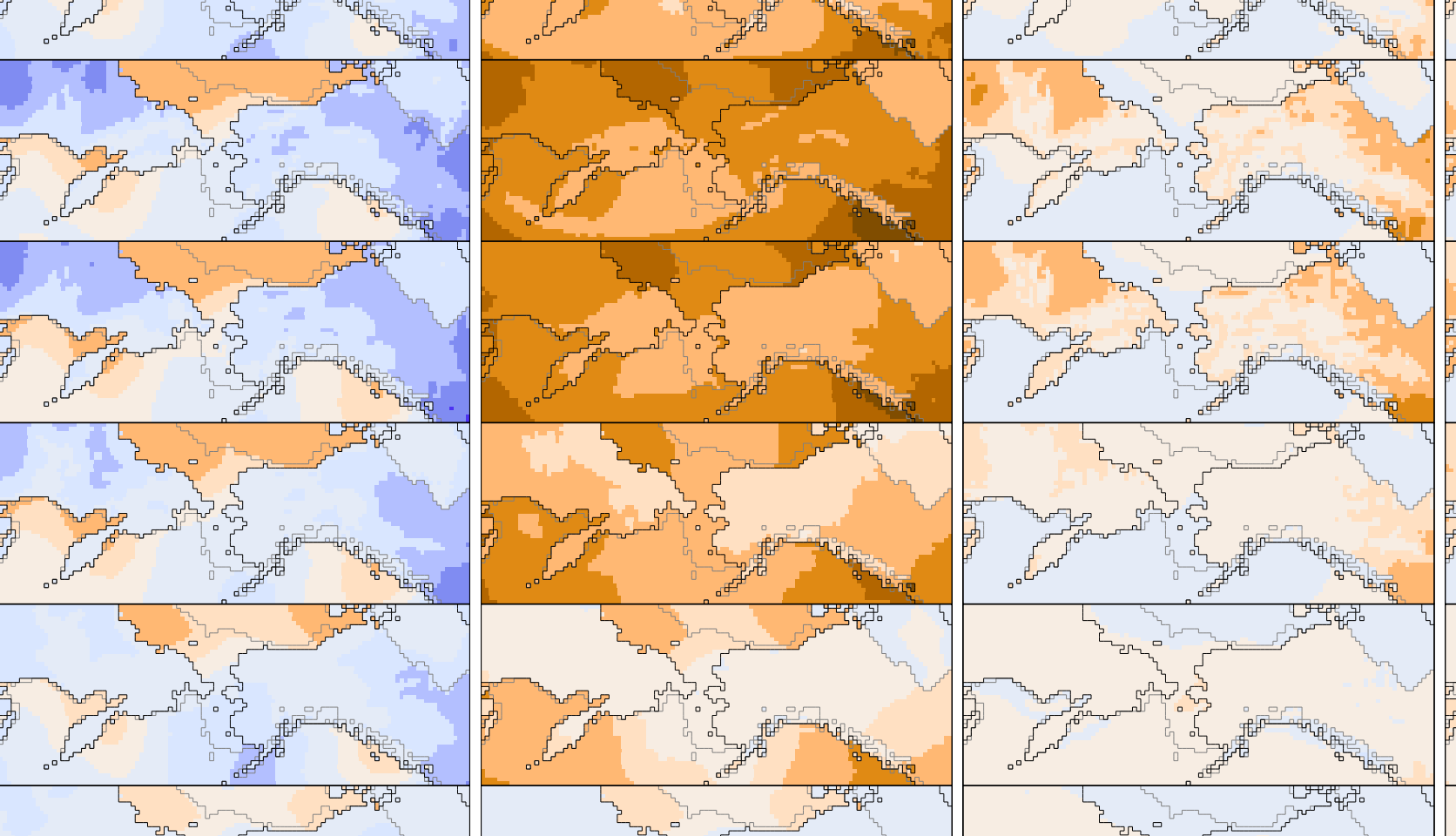

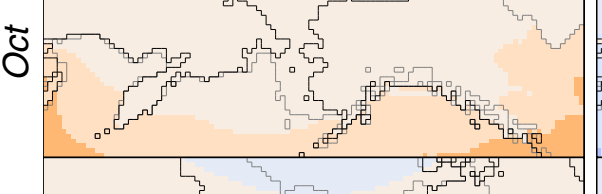

管

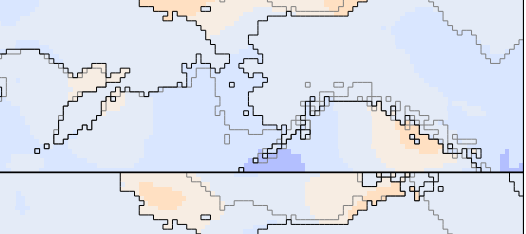

8

$\begin{array}{ccccccc} & \\ -200-150-100-50 & -25 & 0 & 25 & 50 & 100 & 150 \mathrm{Wm}-2\end{array}$
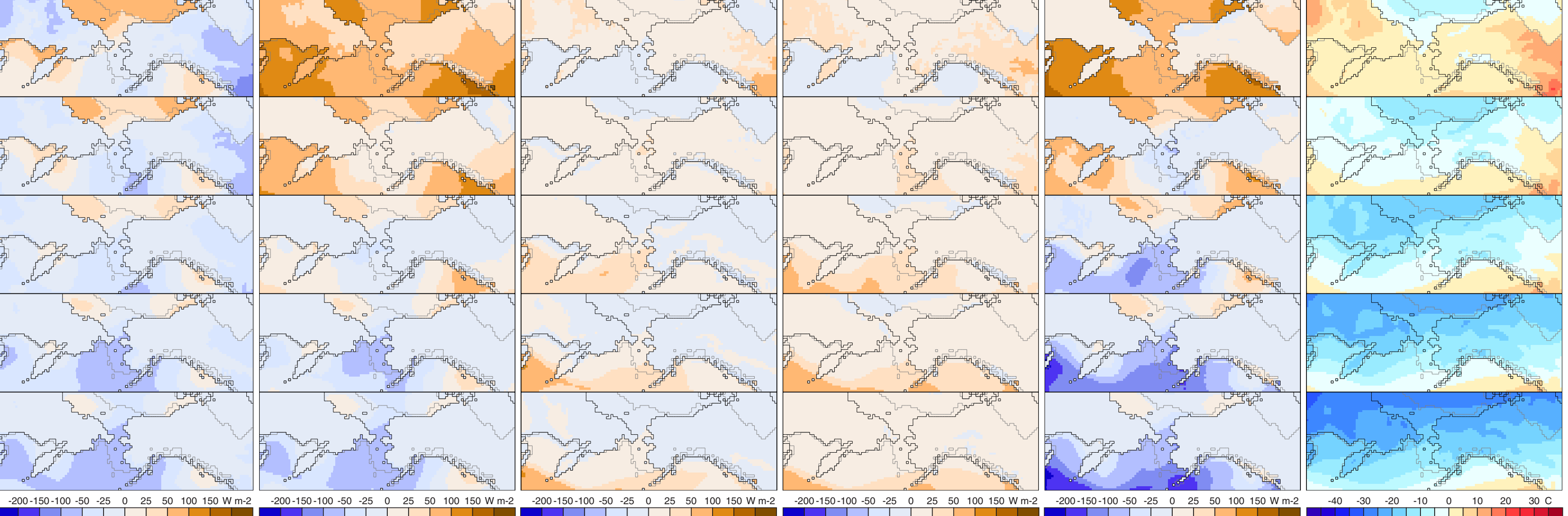
11 ka Sea-Level Simulation - 11 ka Control Simulation

Net Shortwave Radiation Net Longwave Radiation Net Radiation

(1)

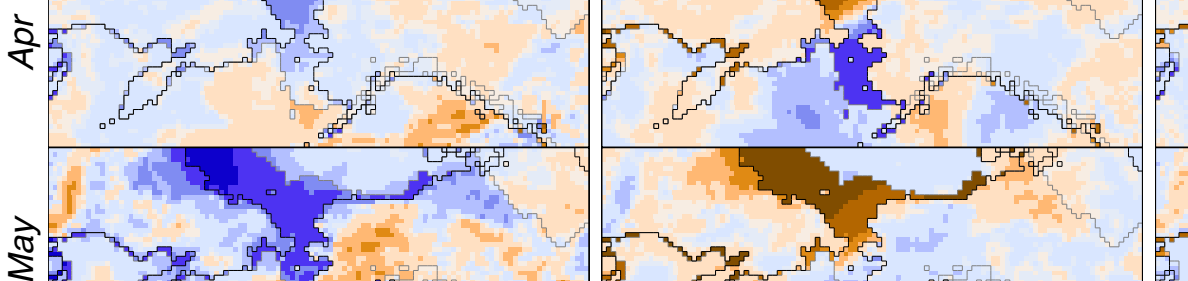

का $y^{2}$

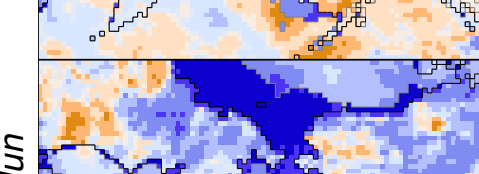
Sensible Heat Flux

Long-Term Mean Differences
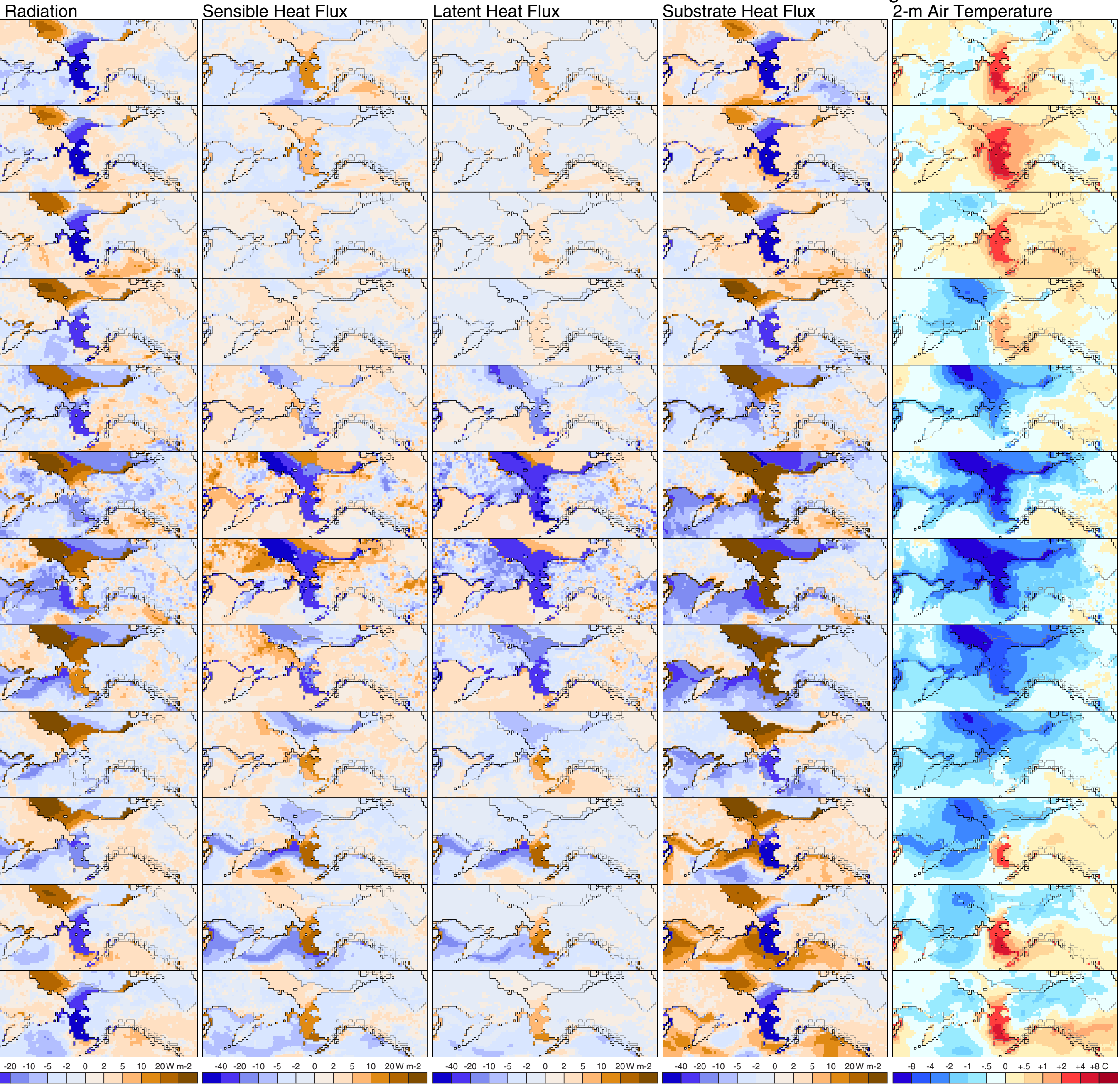


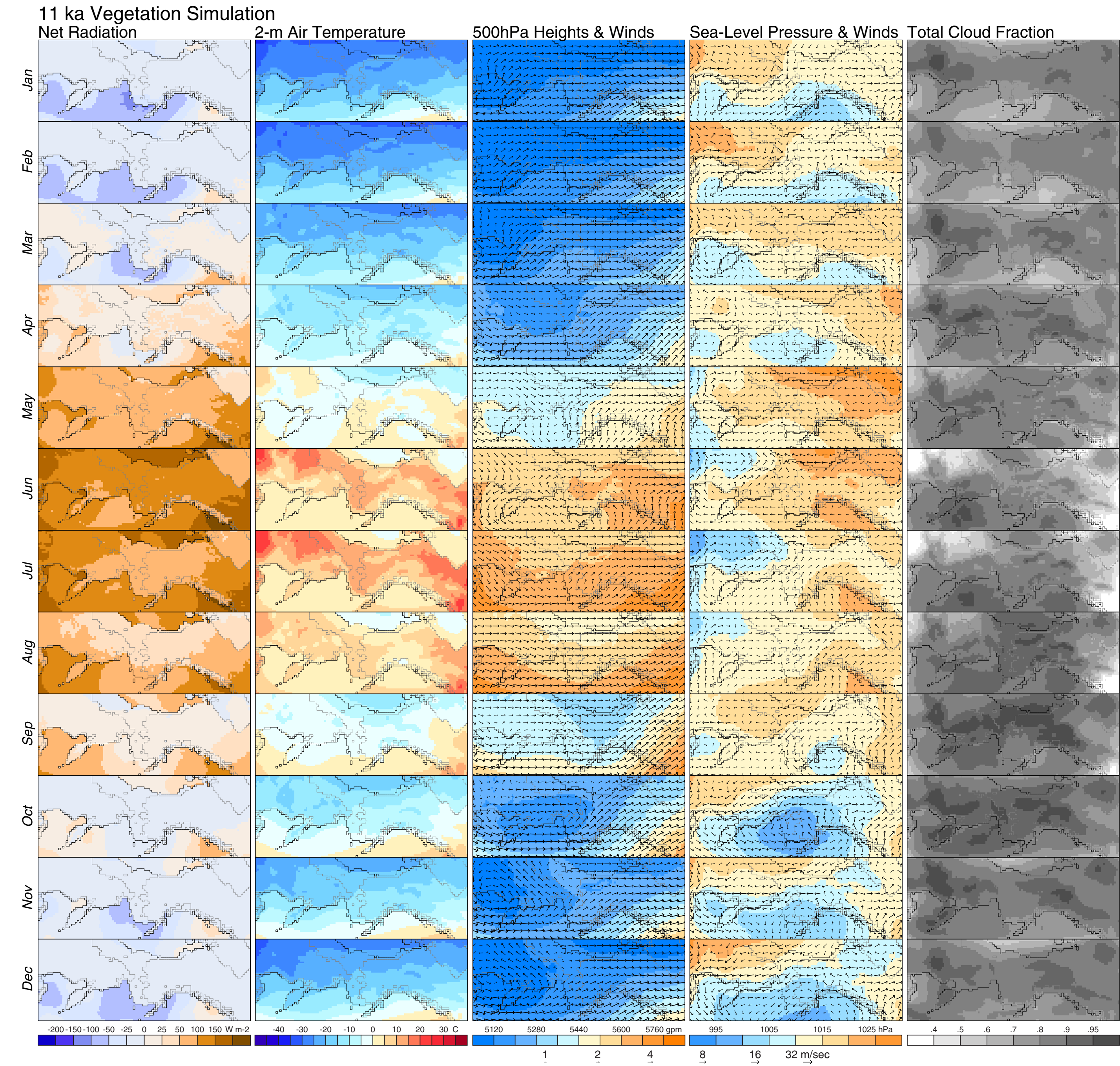

Precipitation Rate

Long-Term Means

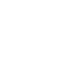

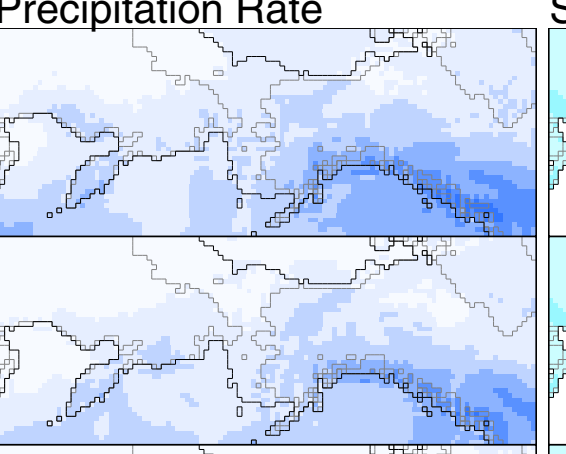

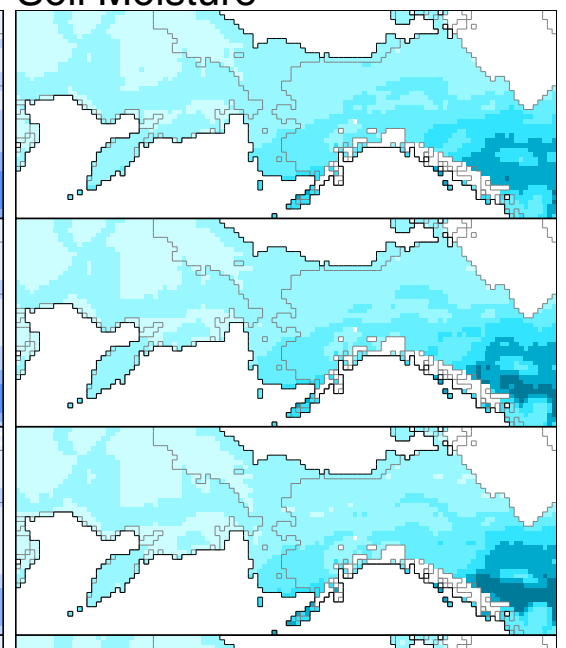

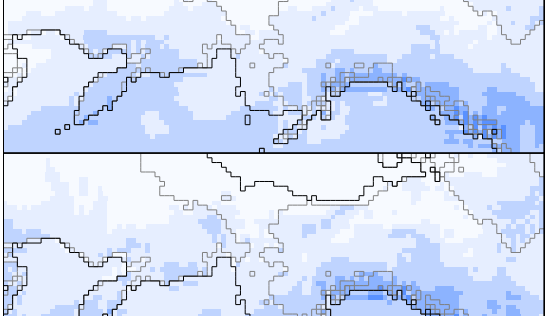

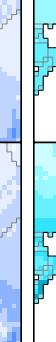

b y

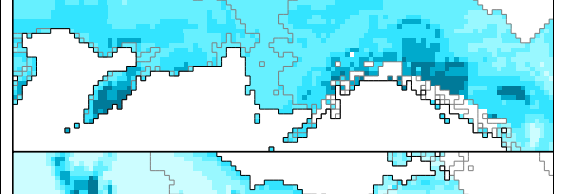
(4)

4

4,

$y_{3}$
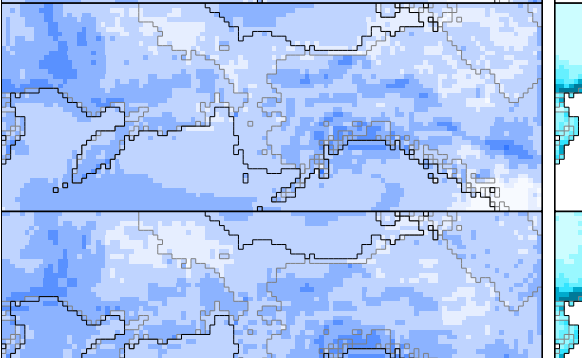

$4 y^{2}$

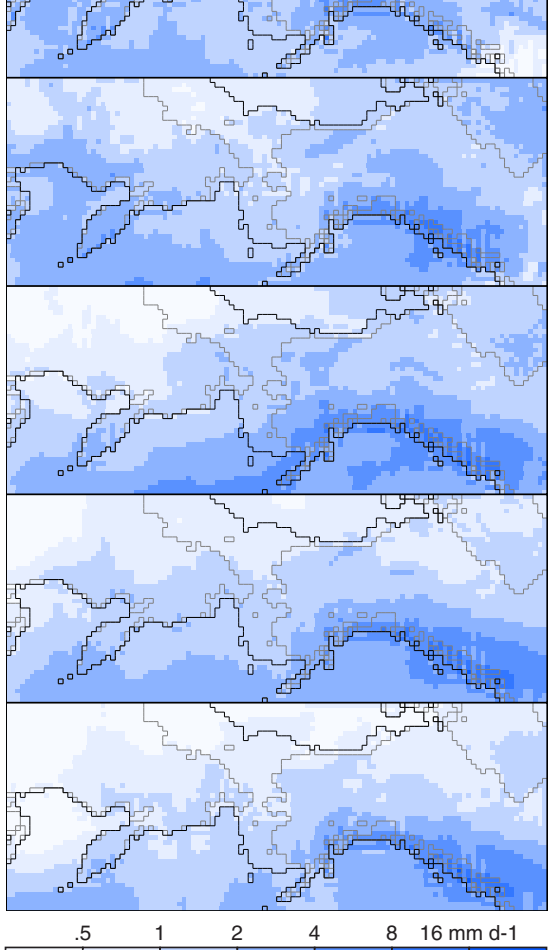

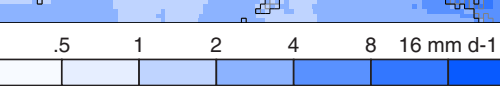

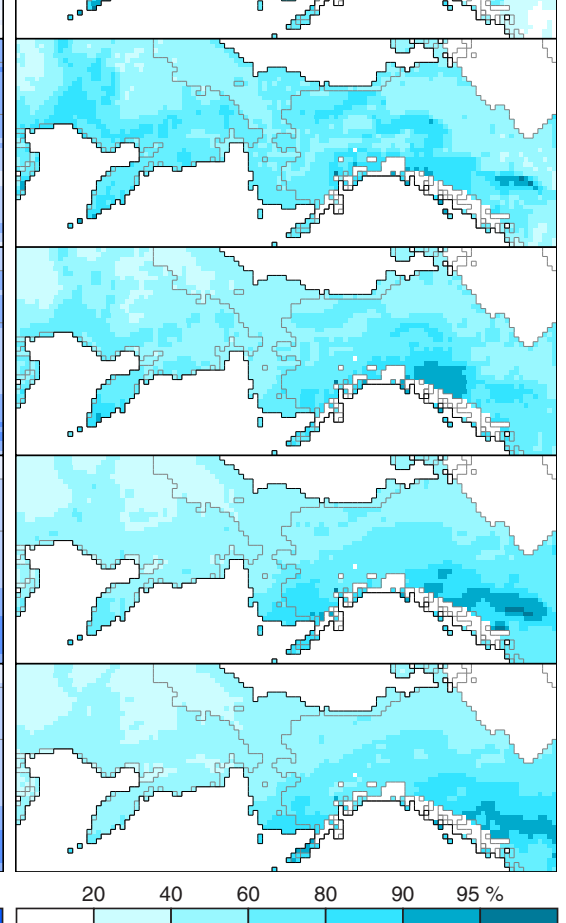

Suppl. Fig. 9A 
11 ka Vegetation Simulation - 11 ka Control Simulation

2-m Air Temperature

Pa Heights \& Winds

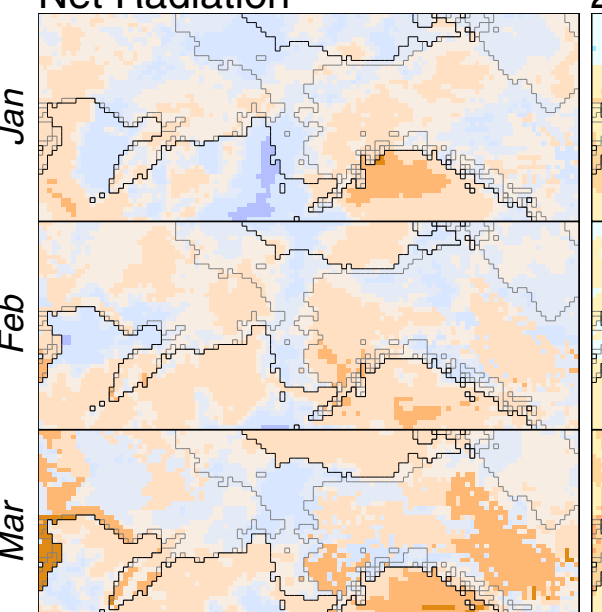

7 o

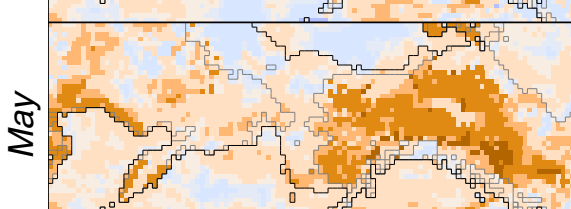

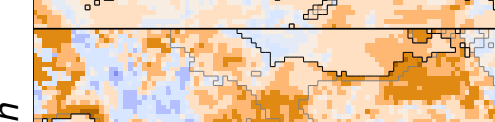

$\$$

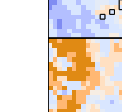

$\$$

$\frac{1}{3}$

की

O)

2

$\begin{array}{llllllllllll}4 & -20\end{array}$ -m Air Temperature $\quad 500$
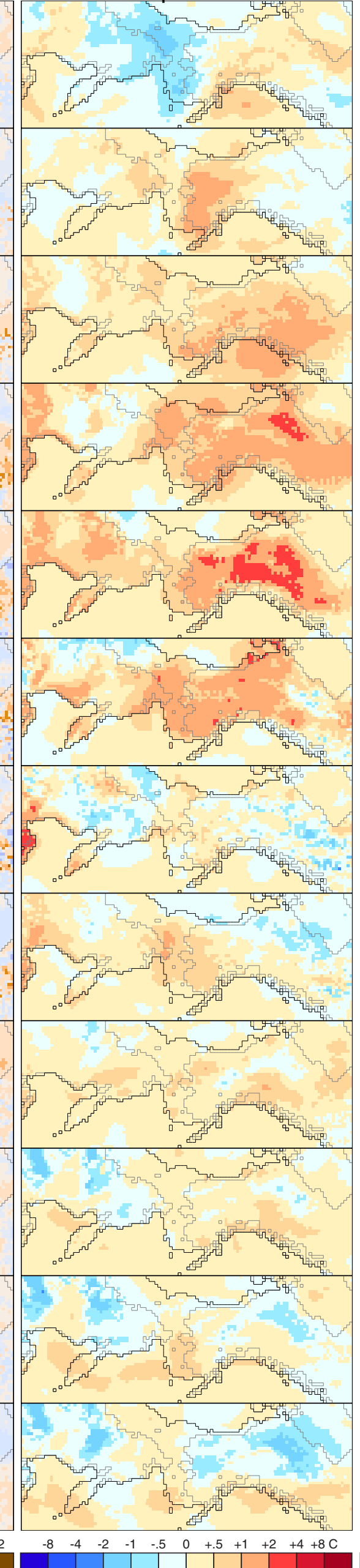

Sea-Level Pressure \& Winds Total Cloud Fraction

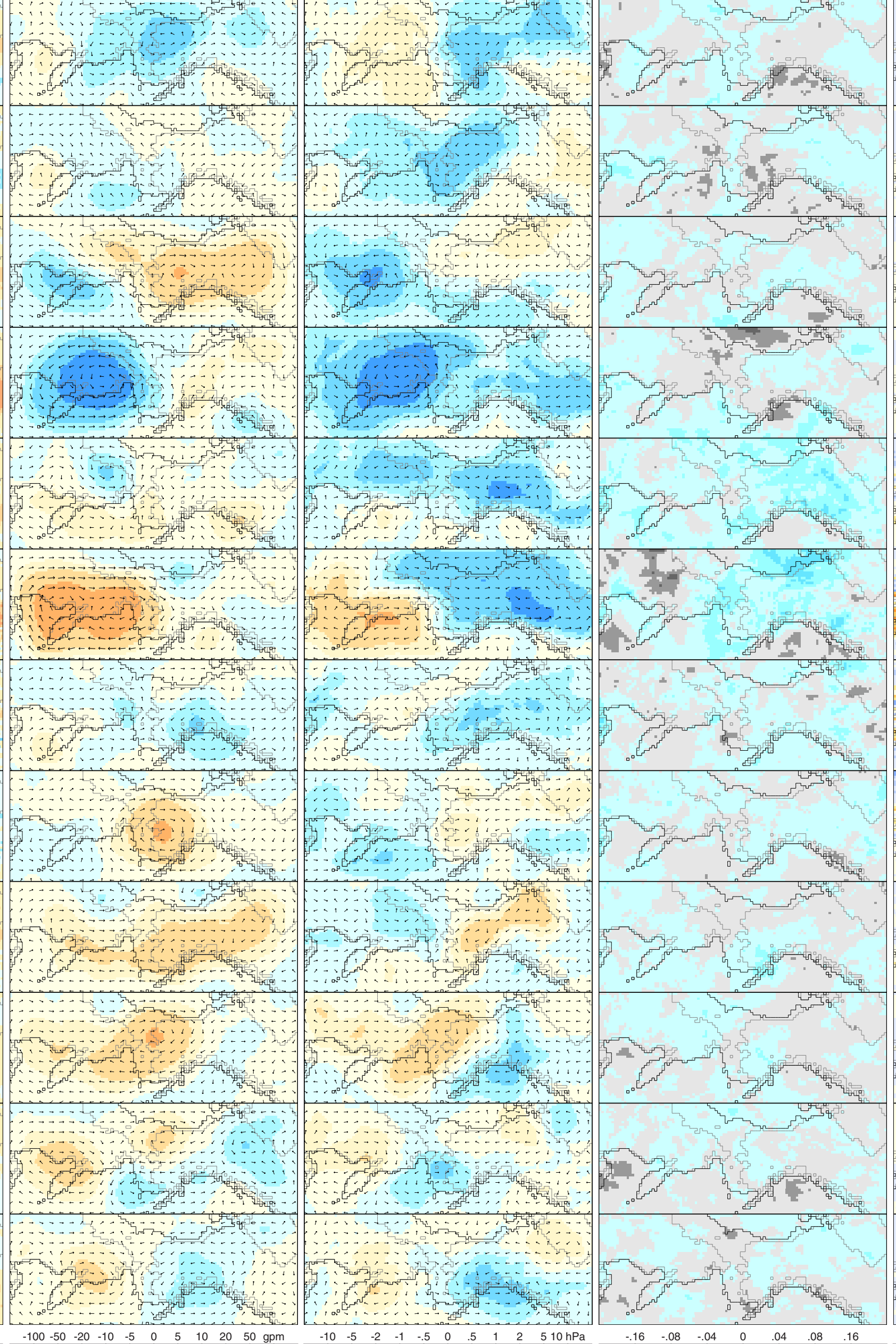

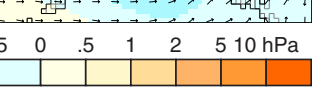

\section{Precipitation Rate}

ong-Term Mean Differences

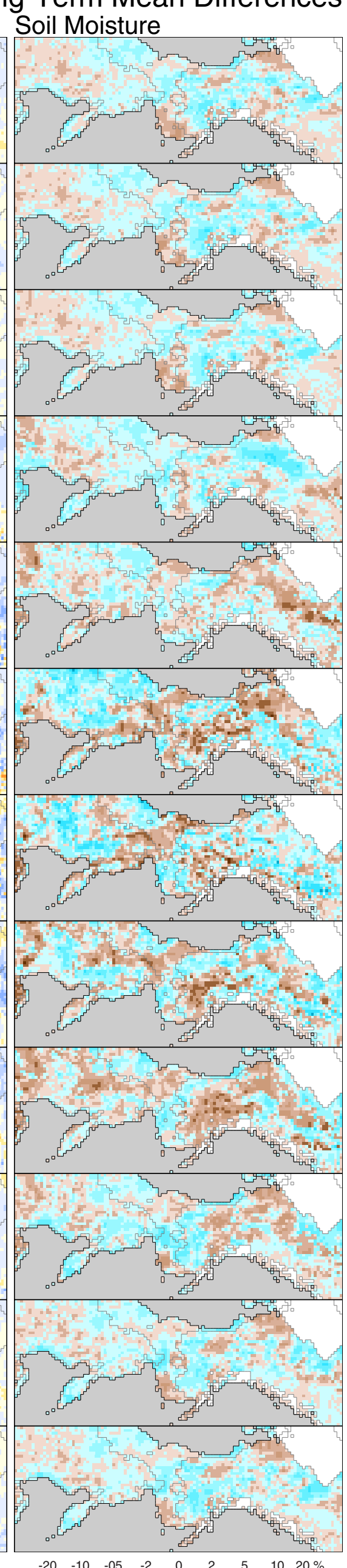


11 ka Vegetation Simulation - 11 ka Control Simulation

Net Shortwave Radiation Net Longwave Radiation Net Radiation

Net Shortwave Radiation Net Longwave Radiation Net Radiation

(5)

$\sum_{0}^{2}$

$\frac{3}{4}=3$.

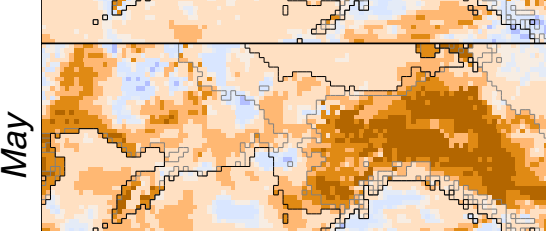

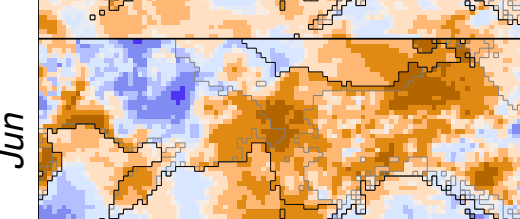

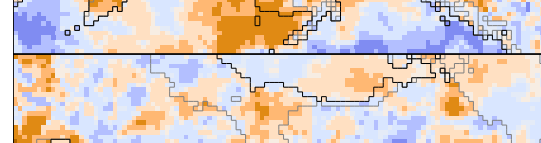

s

急

का

o

2 .

8.
Sensible Heat Flux
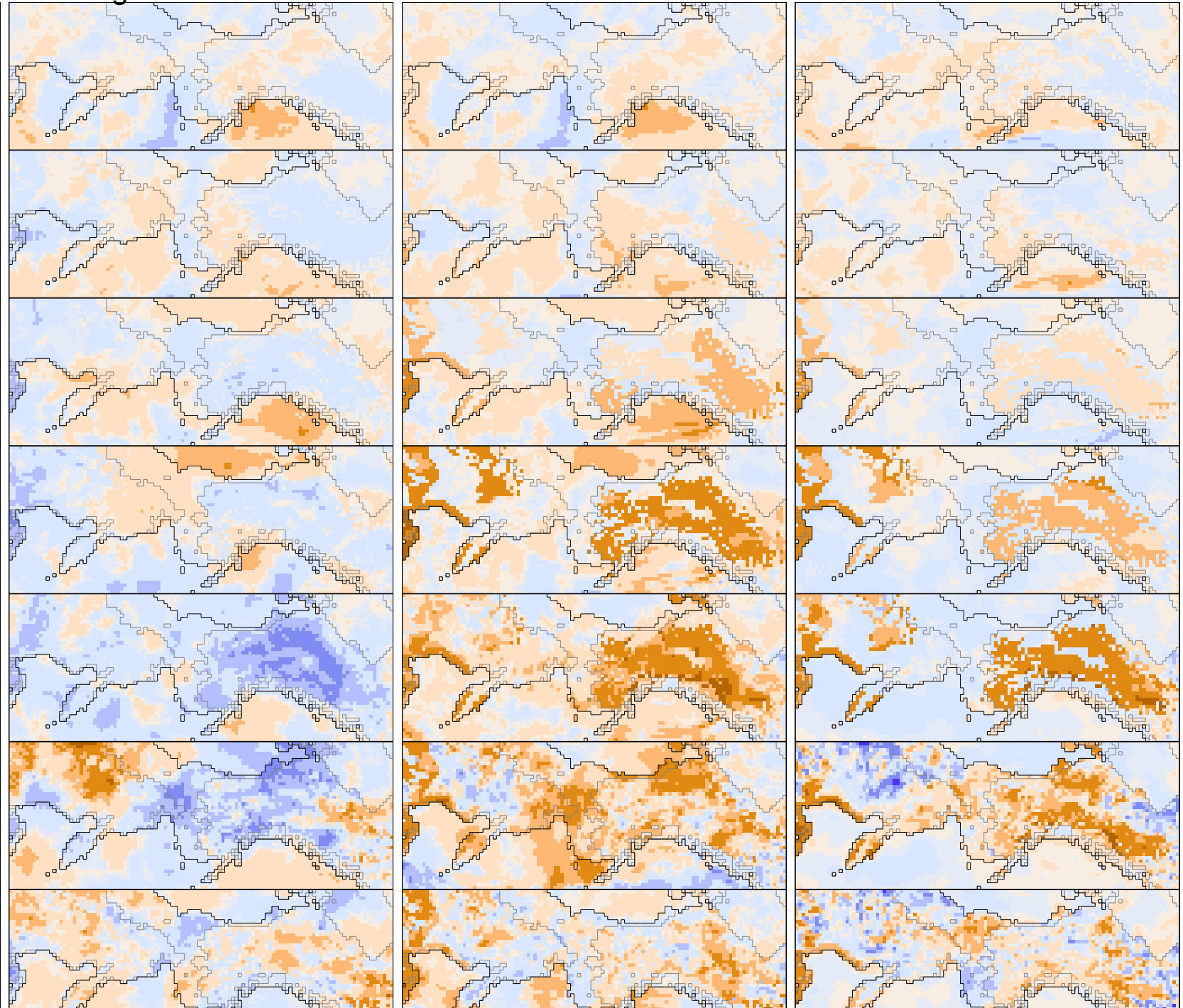

7 F
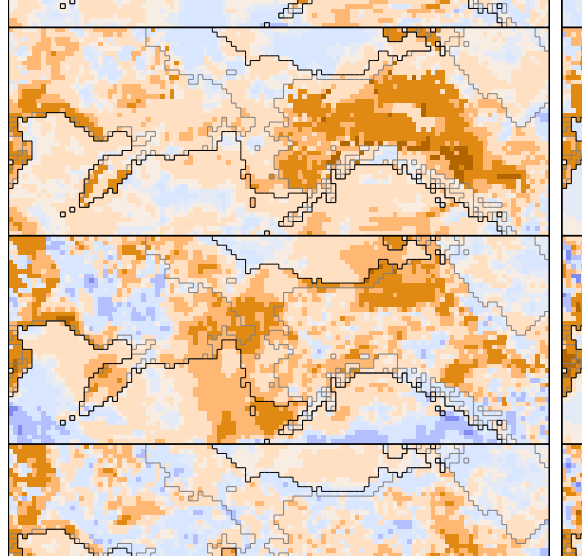

bis

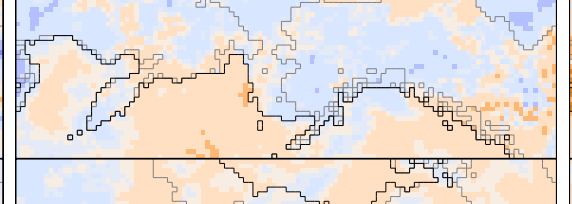

D.

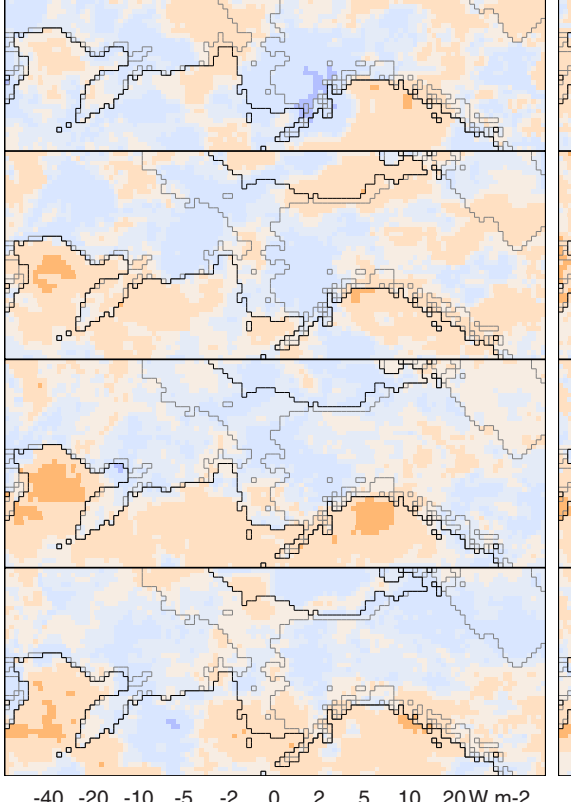

Latent Heat Flux

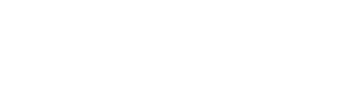

Substrate Heat Flux

Long-Term Mean Differences

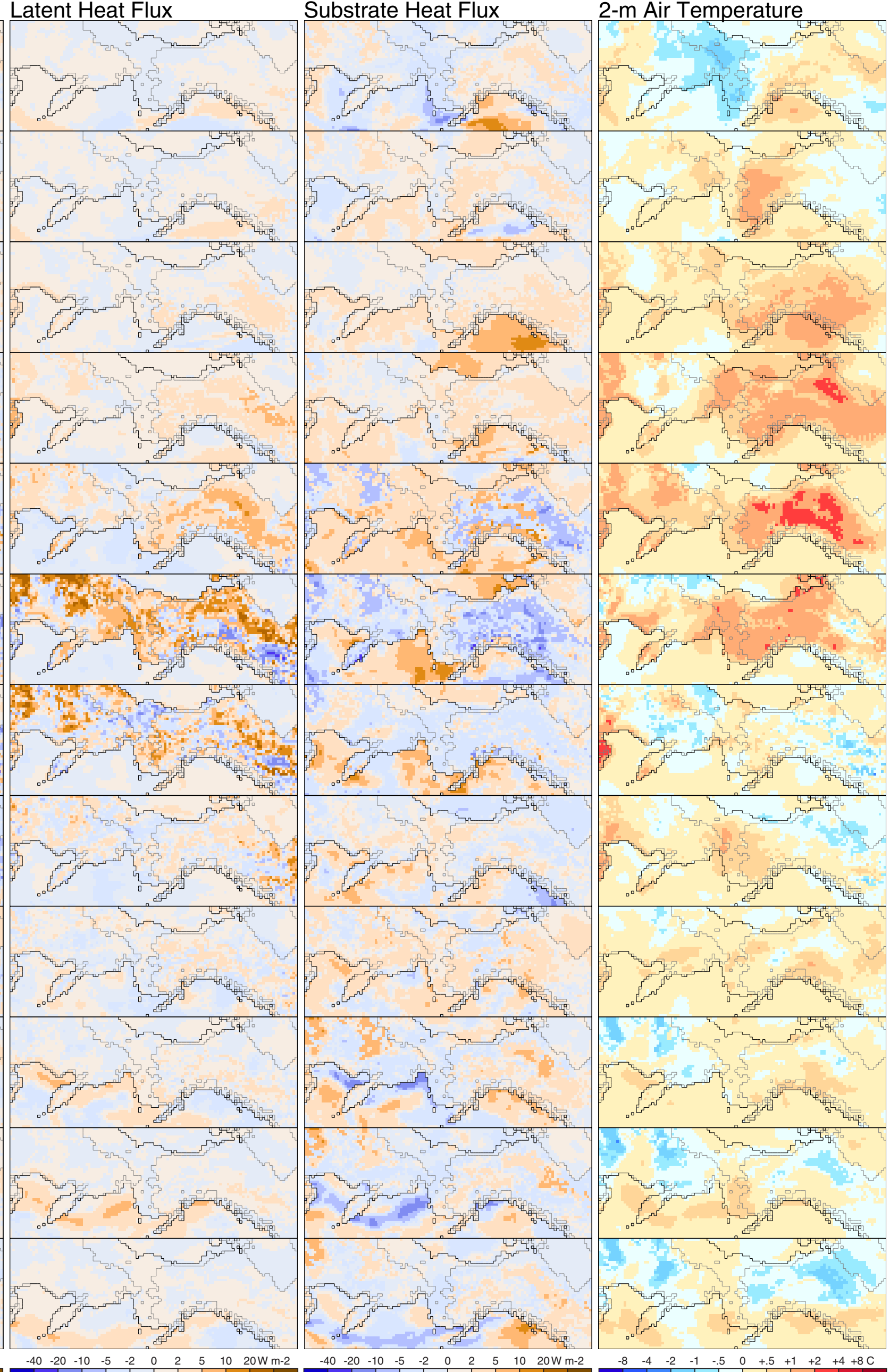




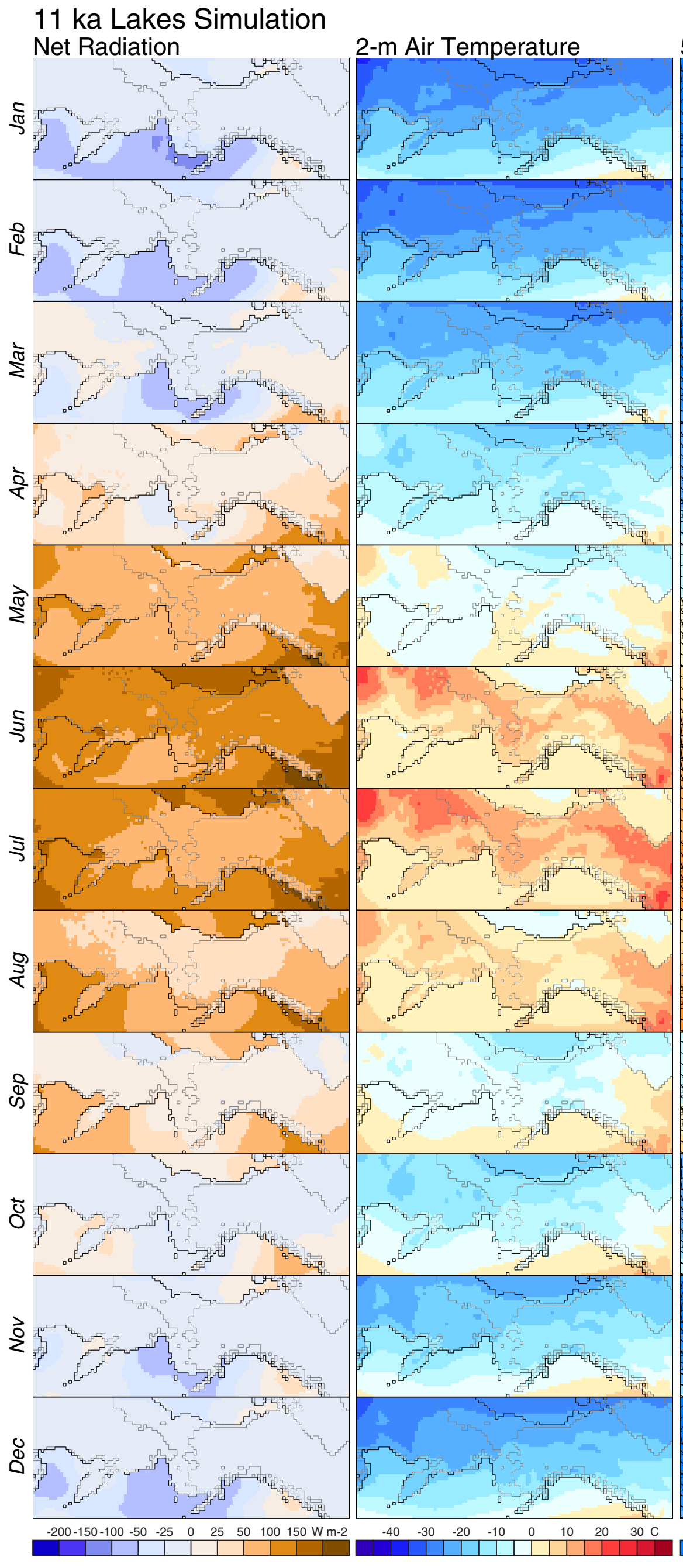

500hPa Heights \& Winds Sea-Level Pressure \& Winds Total Cloud Fraction
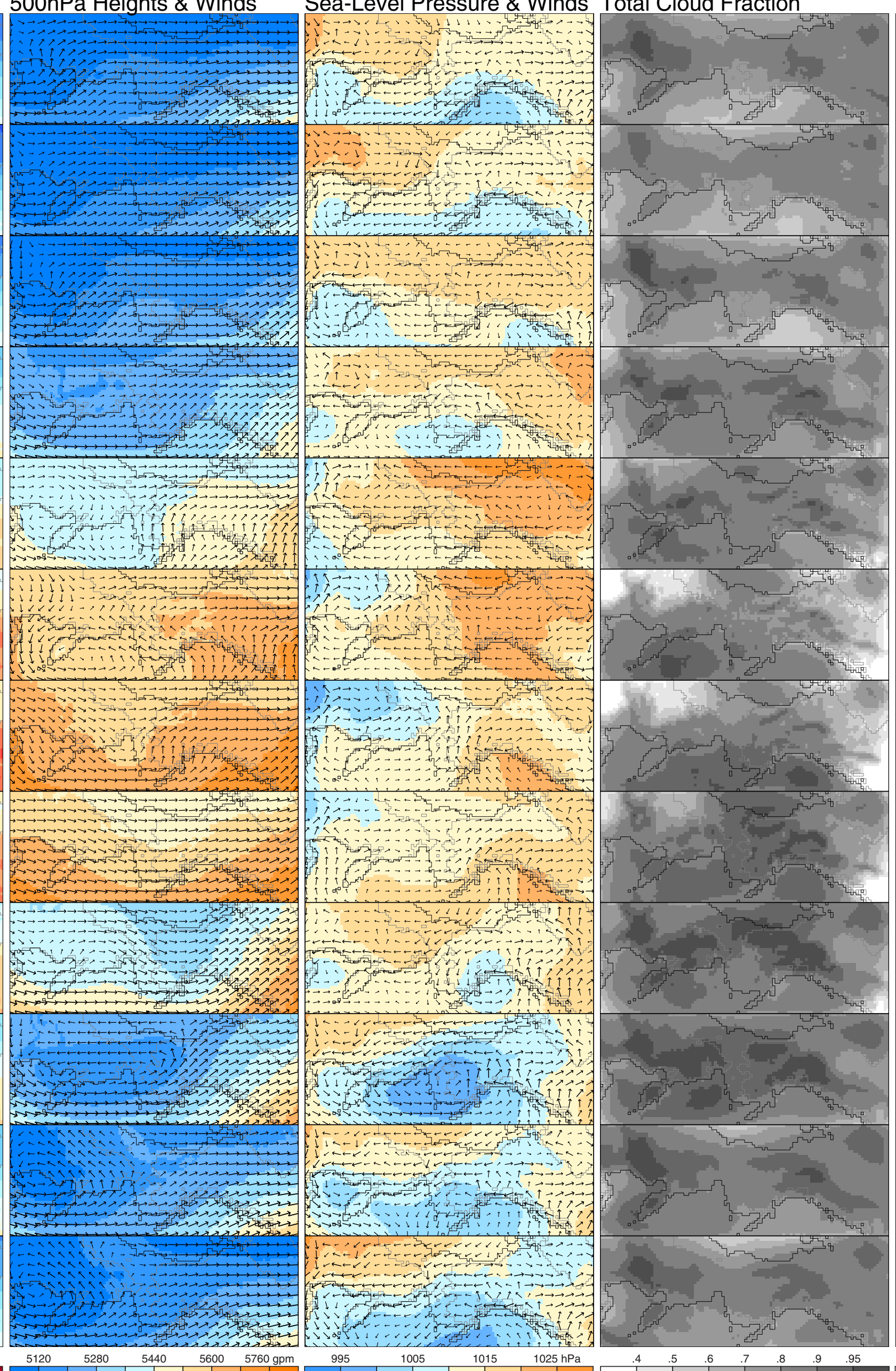

Precipitation Rate

Long-Term Means

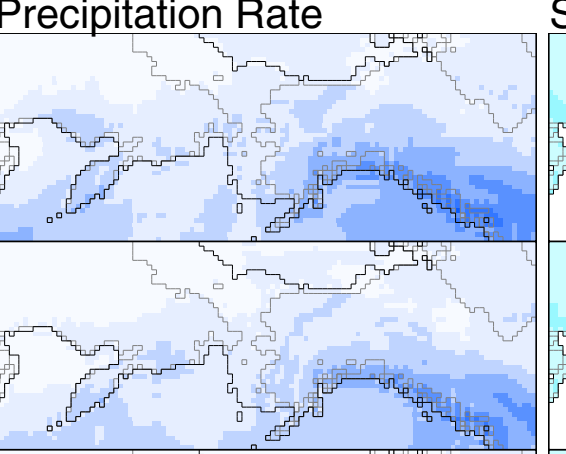

Soil Moistur

(1)
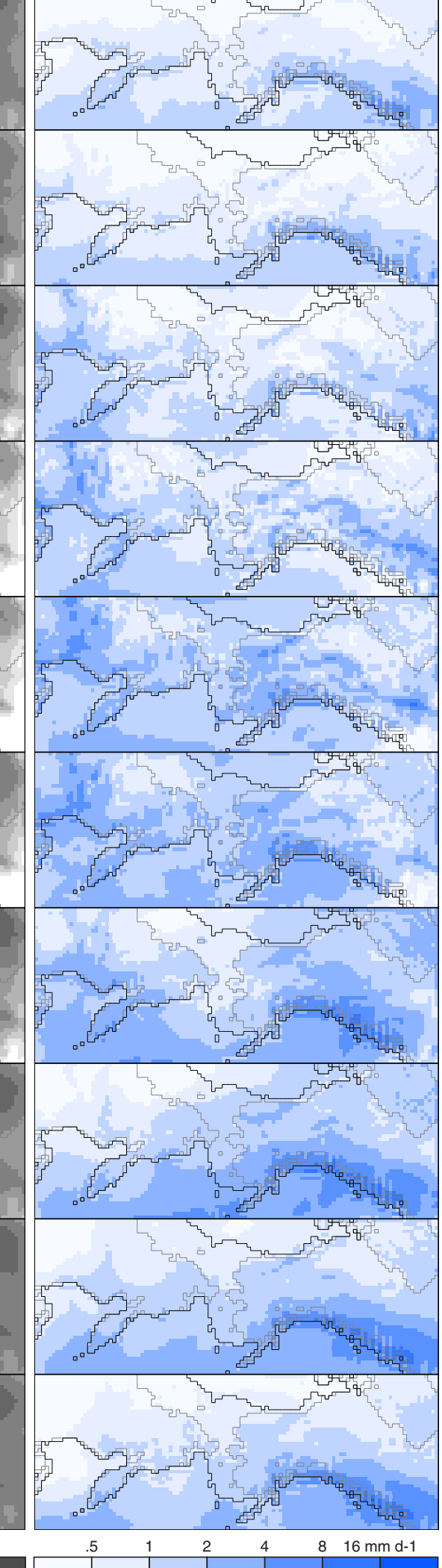

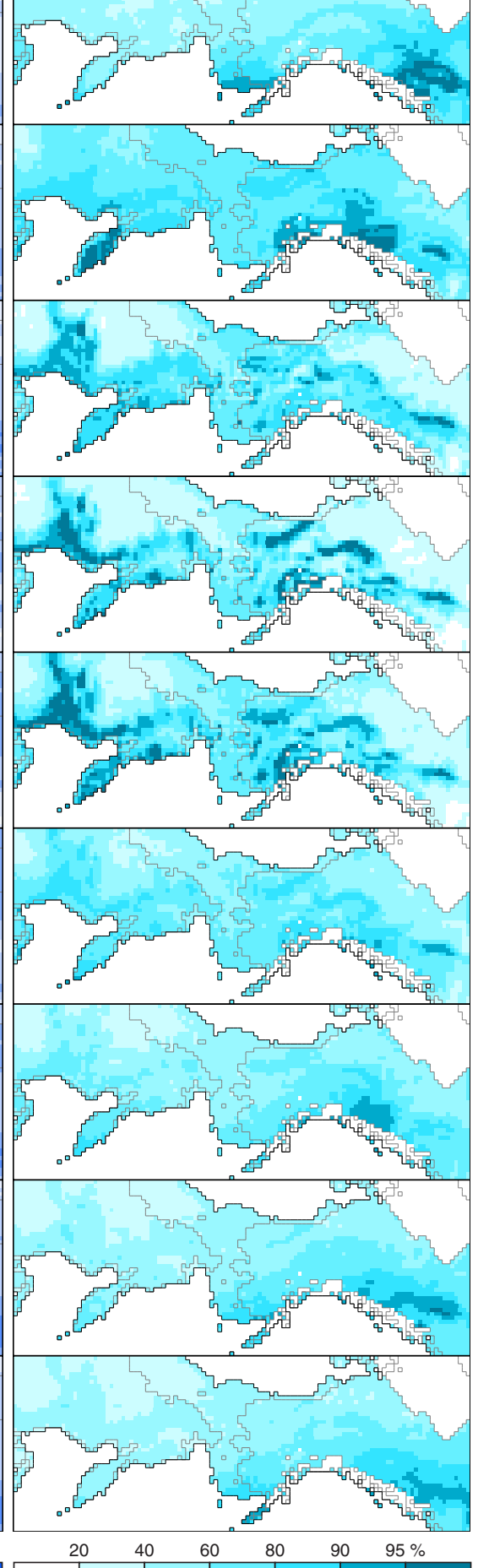
Suppl Fig $11 \mathrm{~A}$ 


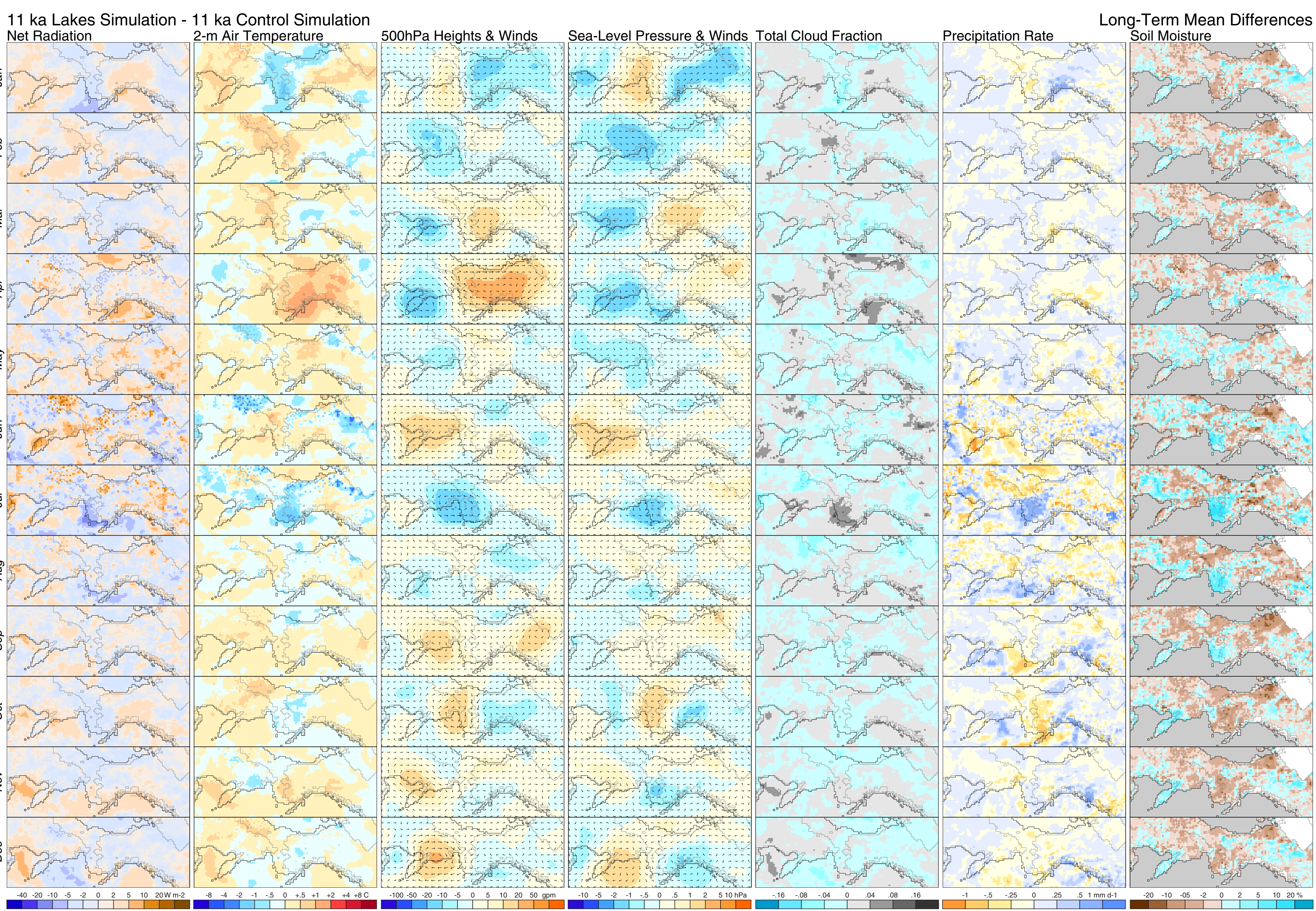
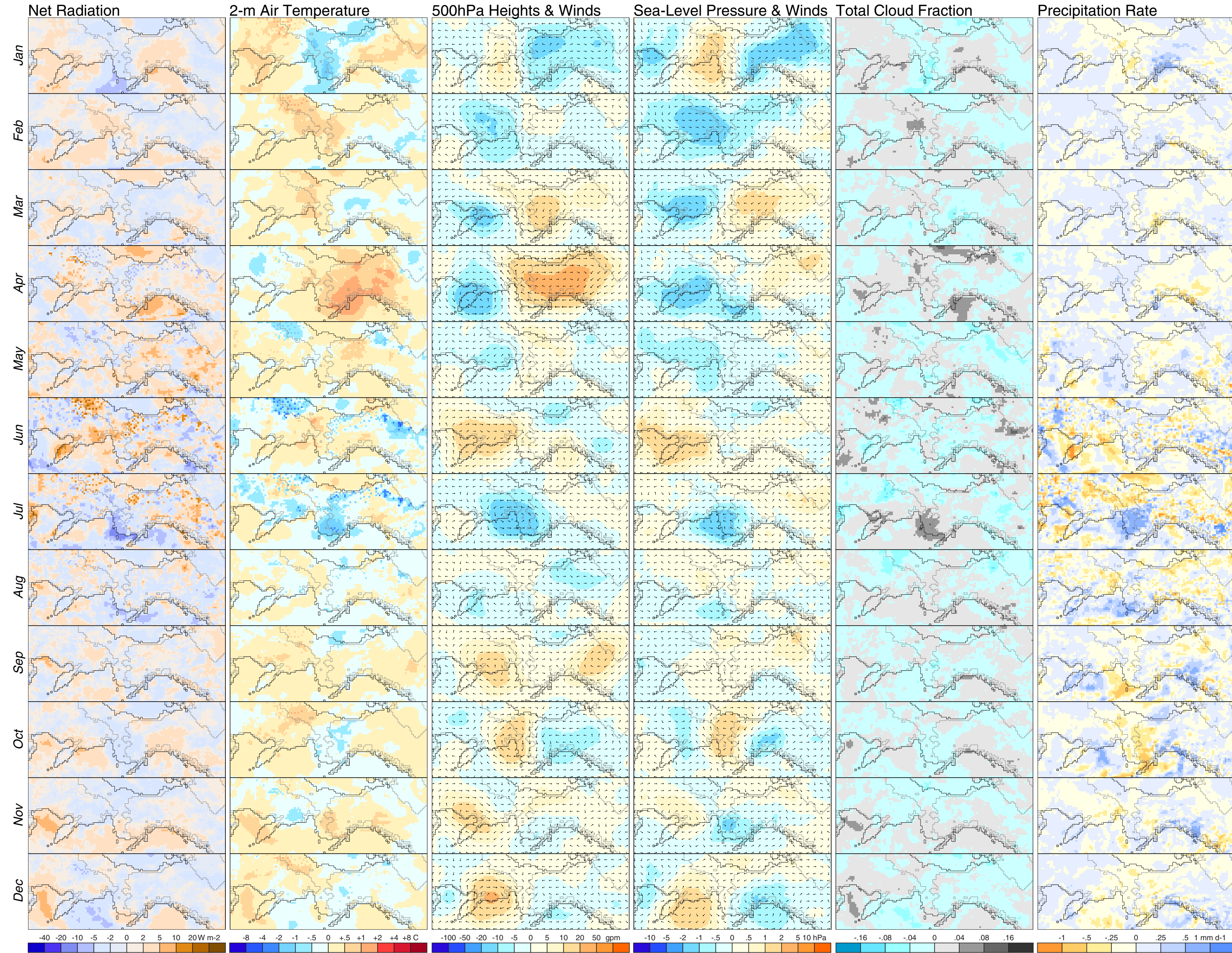

$16 \quad 32 \mathrm{~m} / \mathrm{sec}$ 


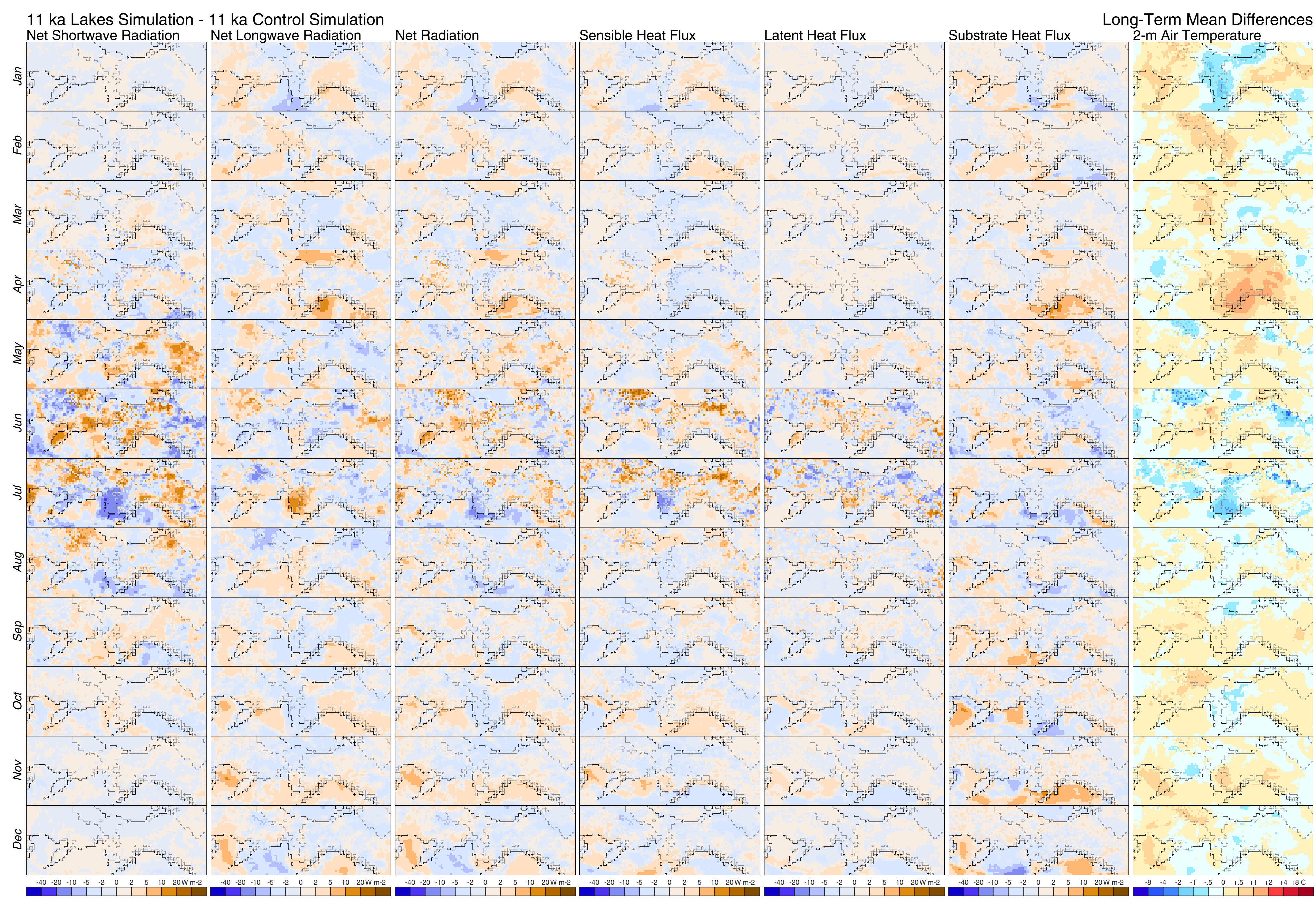


11 ka All Simulation

Net Radiation

2.

\$

事

की

O.

2 b

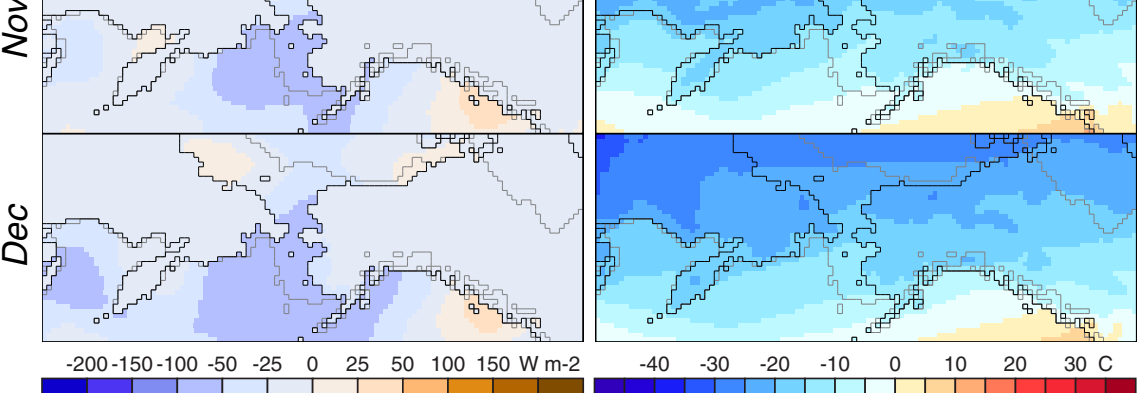

500hPa Heights \& Winds Sea-Level Pressure \& Winds Total Cloud Fraction
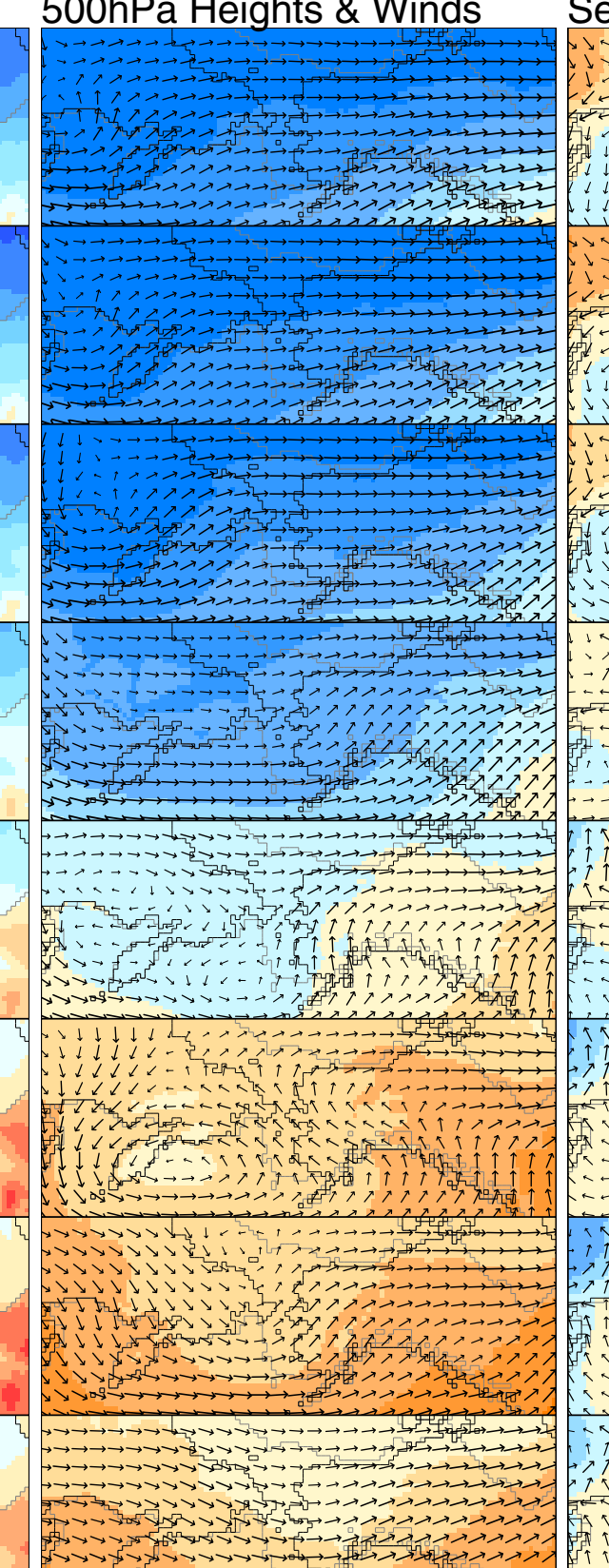

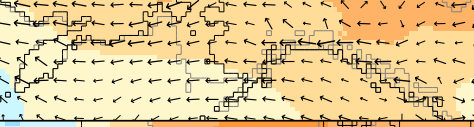

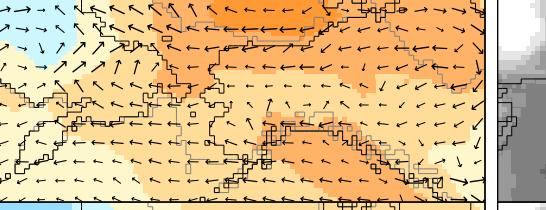

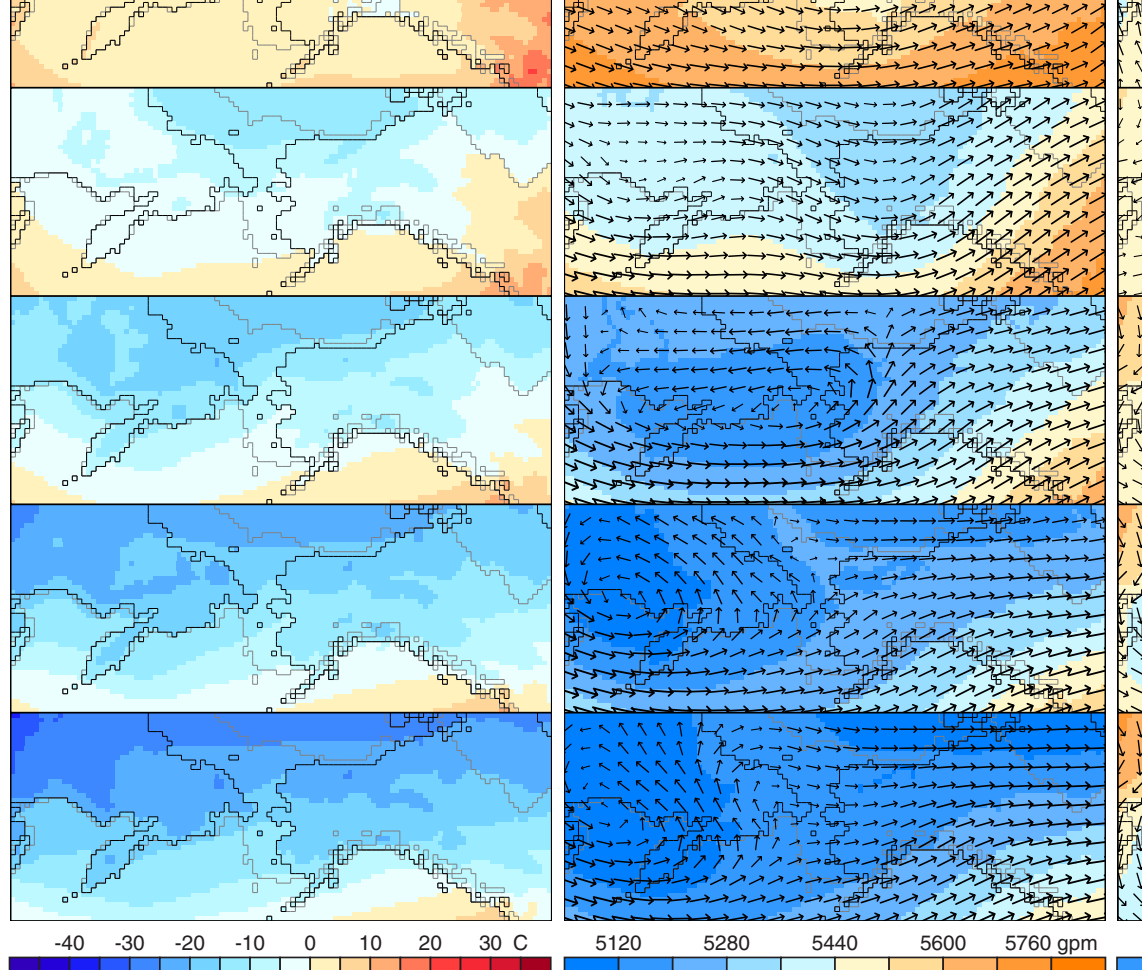

Precipitation Rate

Long-Term Means Soil Moistur ans

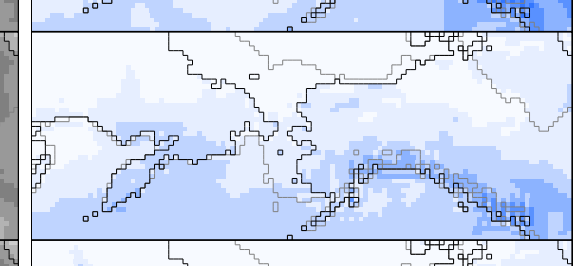

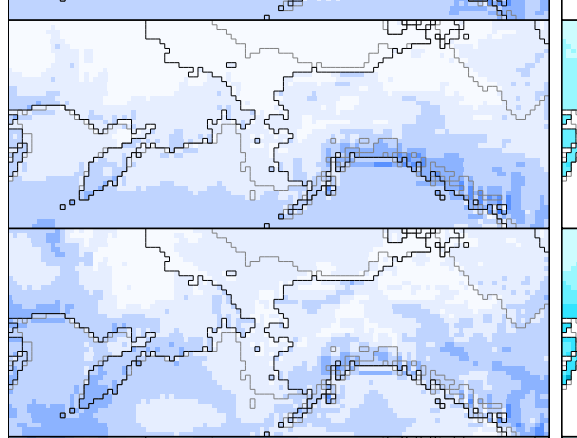

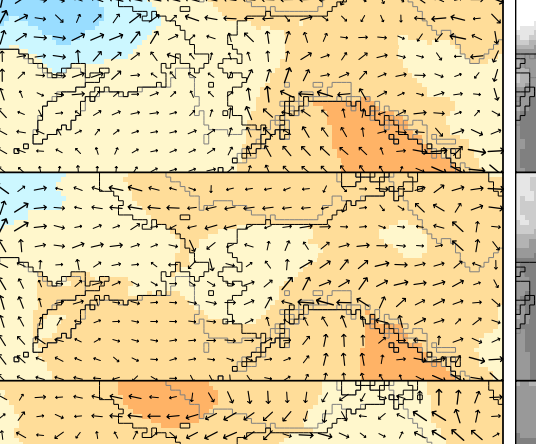

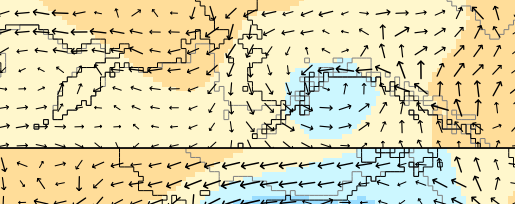

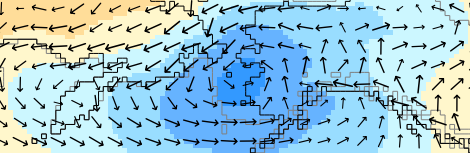

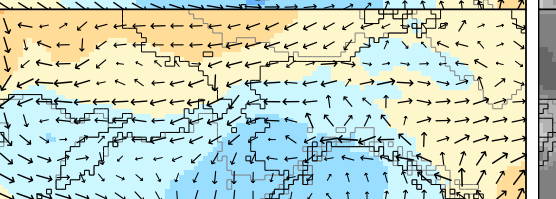

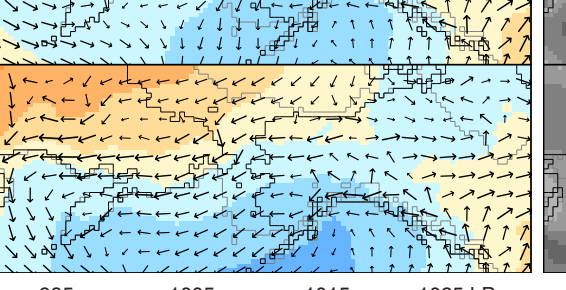

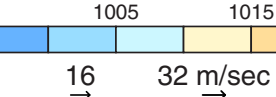
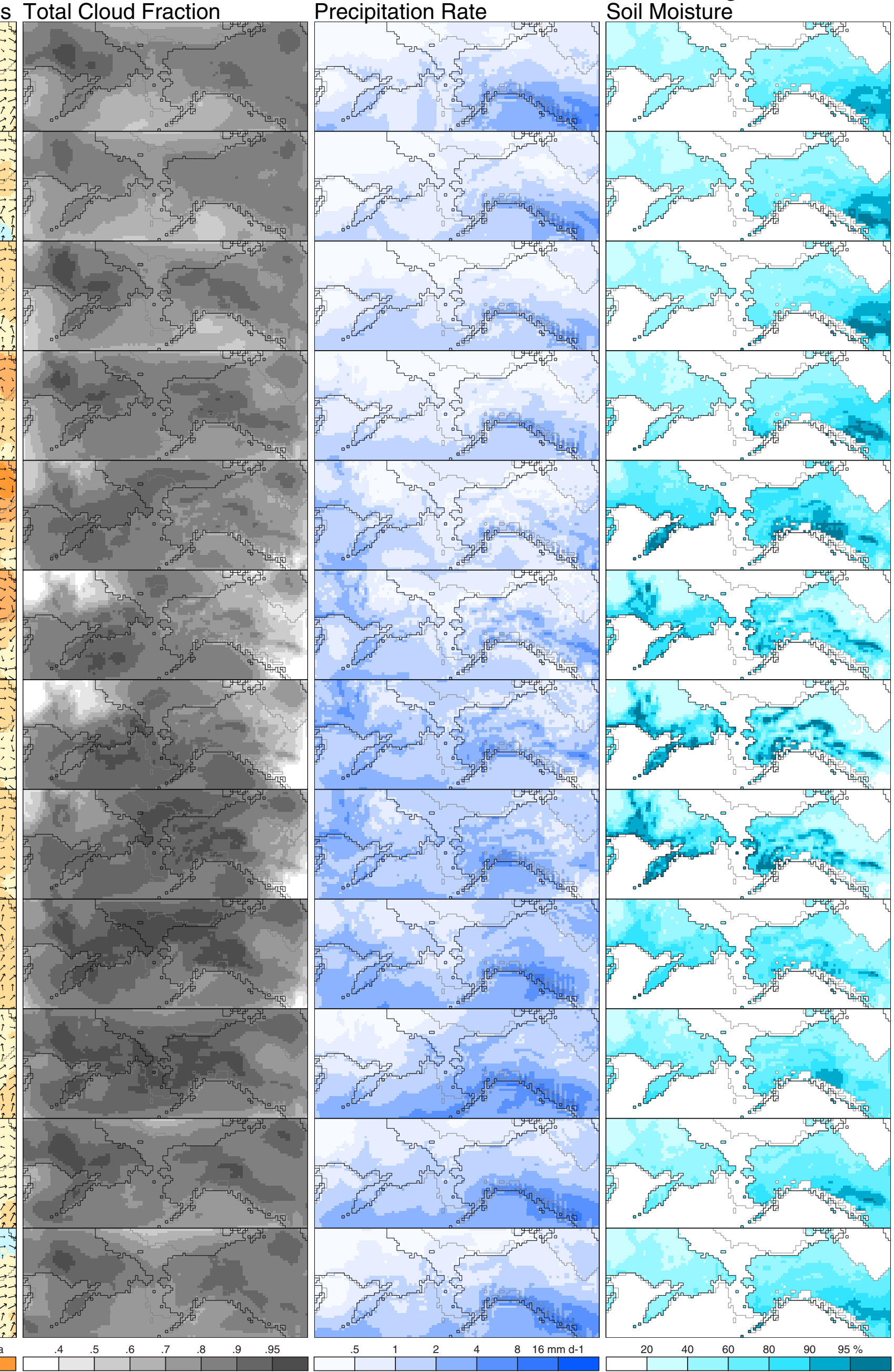

uppl. Fig $13 \mathrm{~A}$ 
11 ka All Simulation

Net Shortwave Radiation

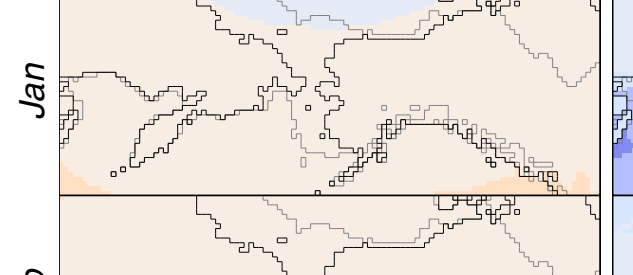

造

$\sum^{2}$

文

$\frac{\pi}{2}$

.

§

Par.

5

O

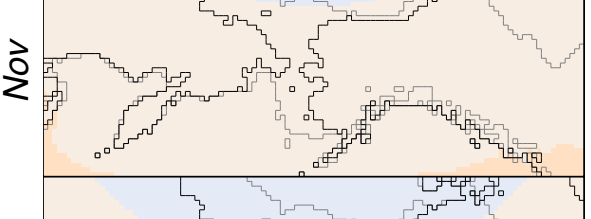

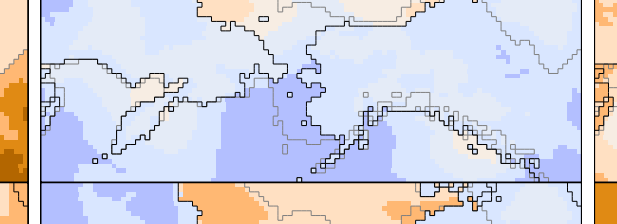

$\frac{70^{2}}{f^{2}}$
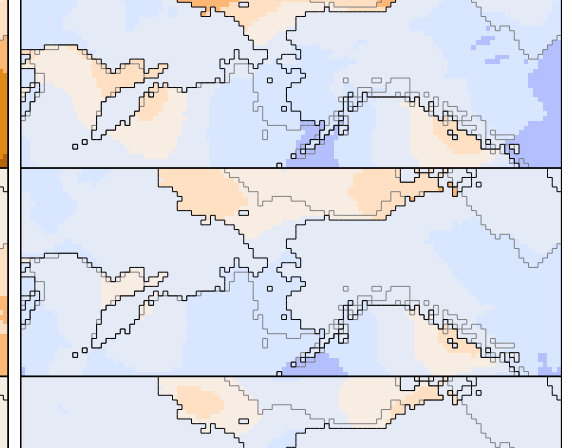

1)

Net Longwave Radiation Net Radiation

Radiation Sensible Heat Flux

(1)
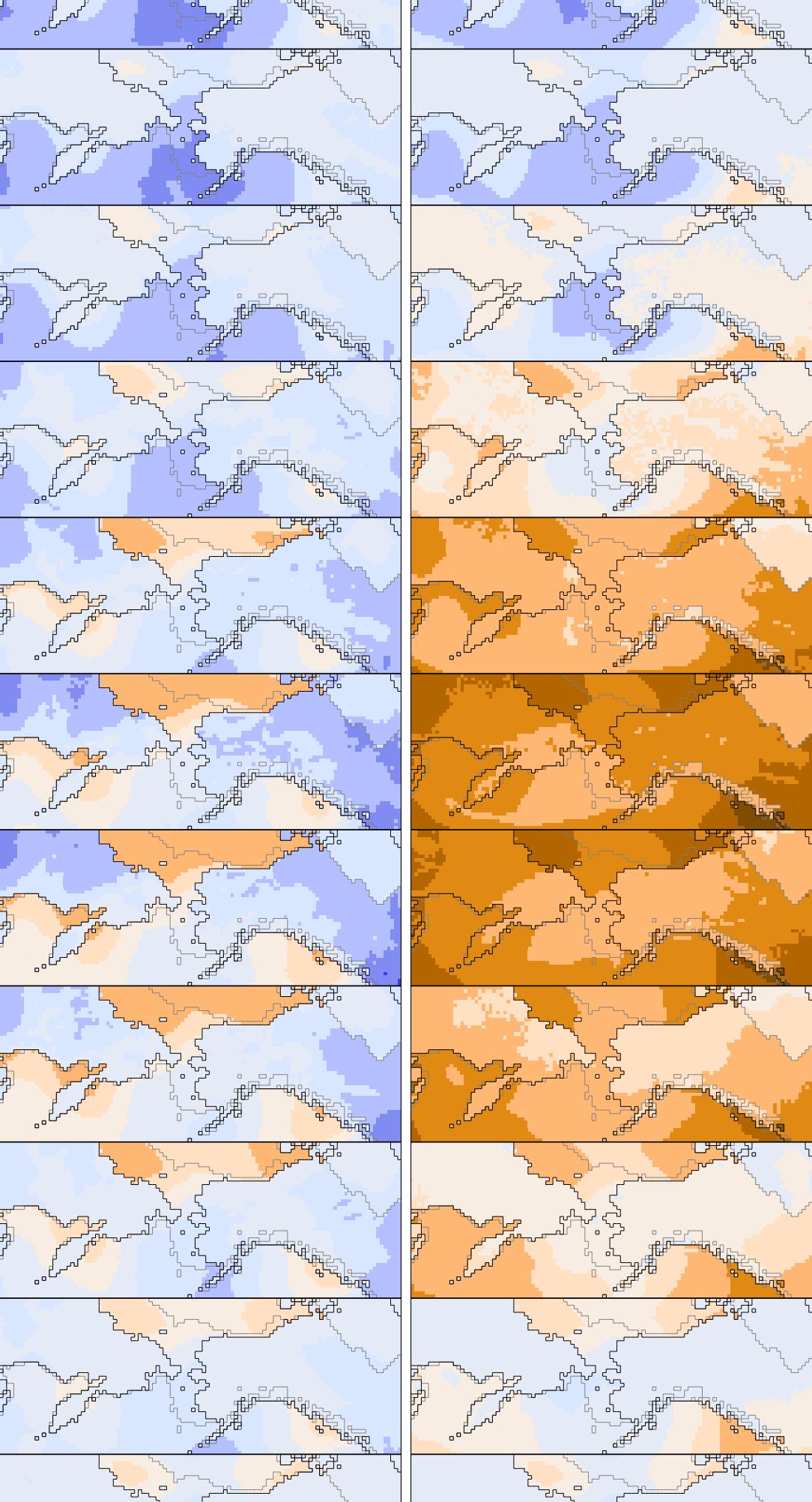

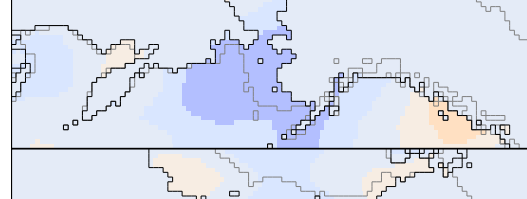

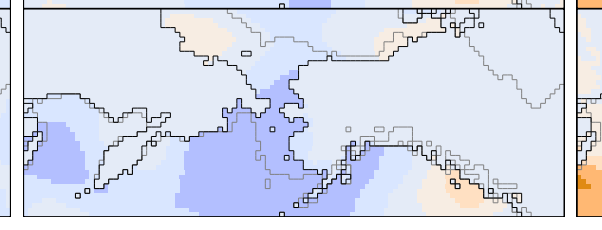

Substrate Heat Flux

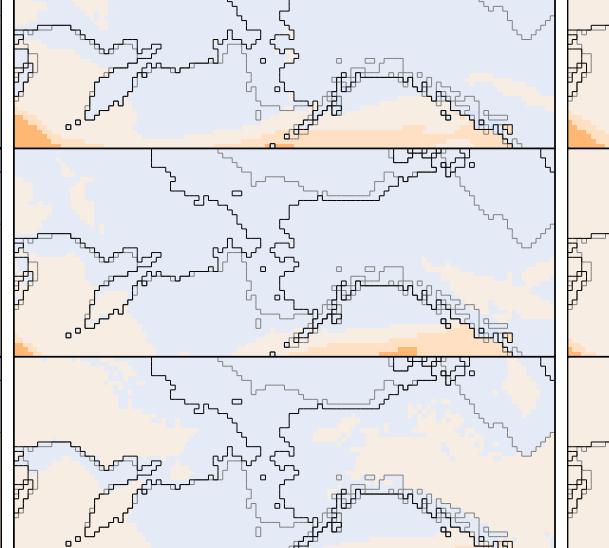

(2)

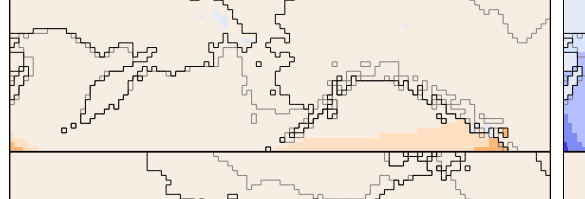

$y^{2} y^{2}$

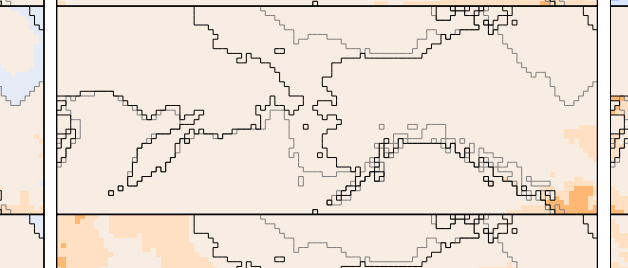

$2 y^{2}$

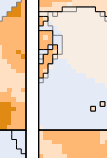

$2 \frac{1}{20}$

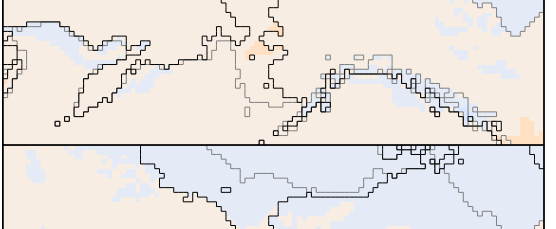

D.

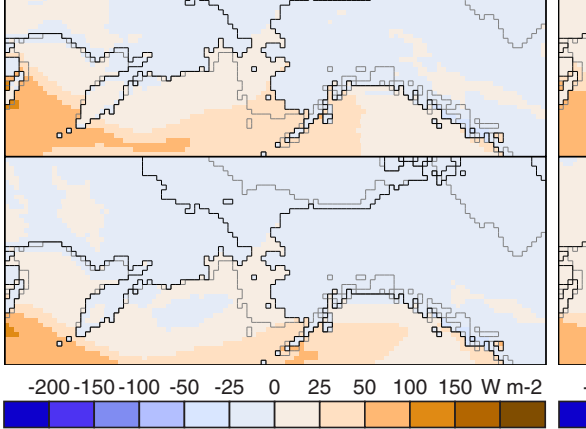

ton

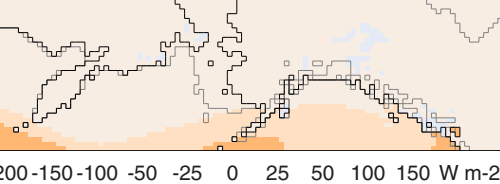

Long-Term Means (n) (7) (2) .
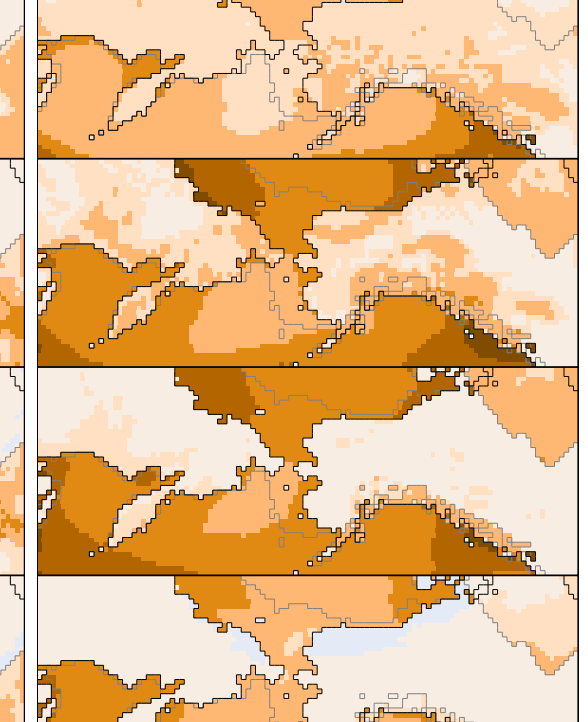

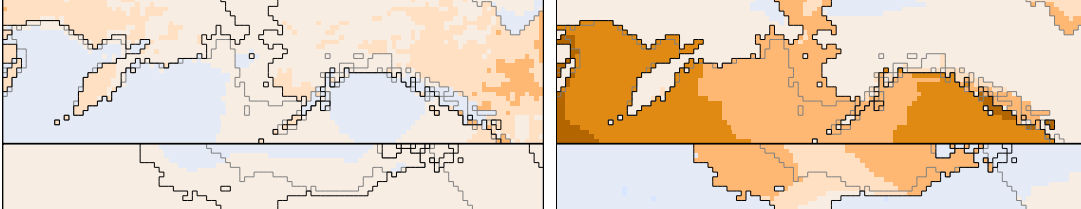
年

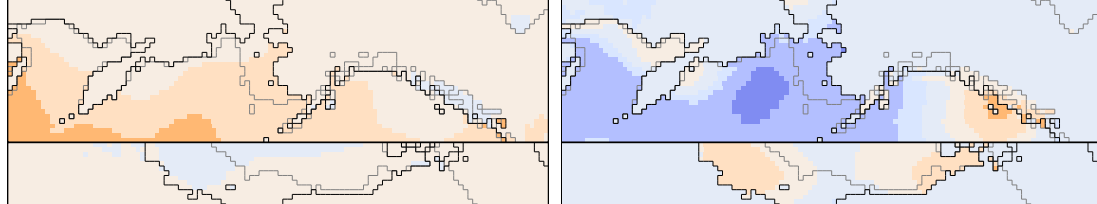

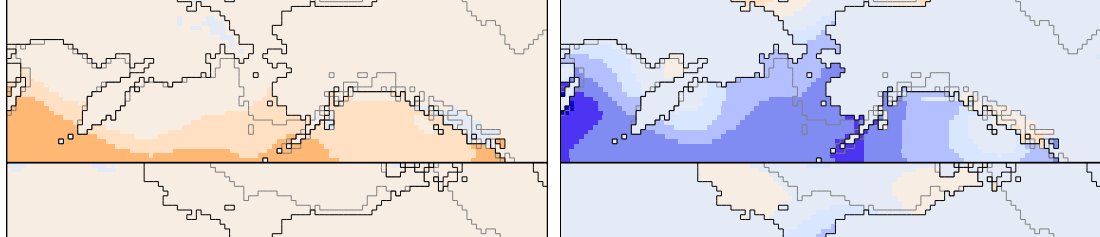
2. $200-150-100-50-25025 \quad 50100150 \mathrm{Wm}$ -m Air Temperature

N

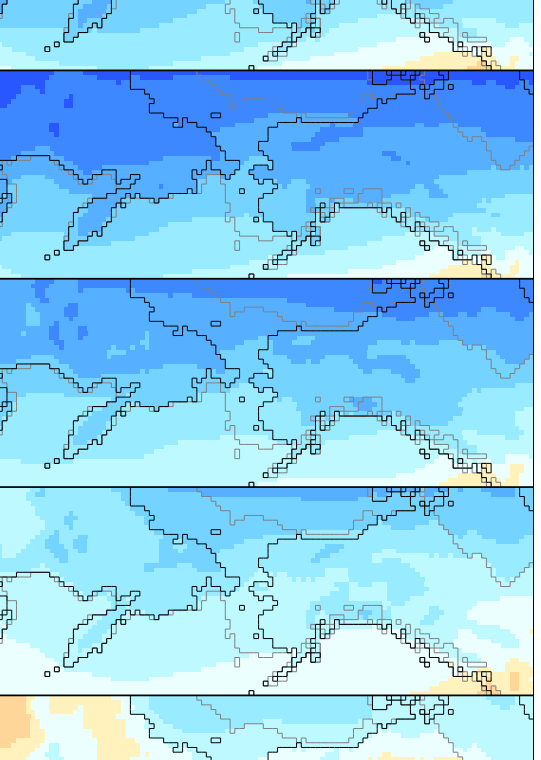

7)
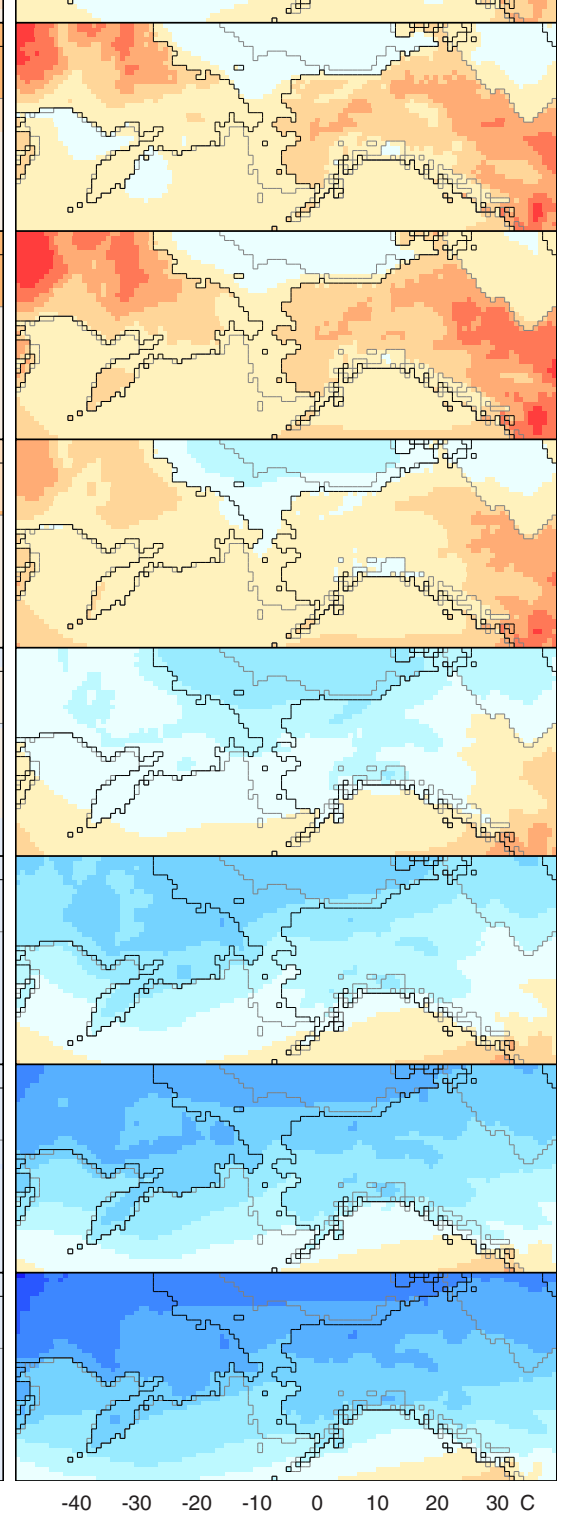

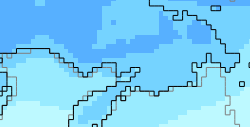


11 ka All Simulation - 11 ka Control Simulation

2-m Air Temperature

I 3

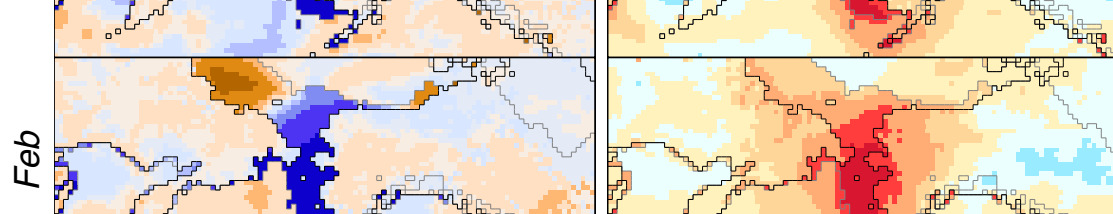

21

$\mathrm{P}^{2} \mathrm{C}$

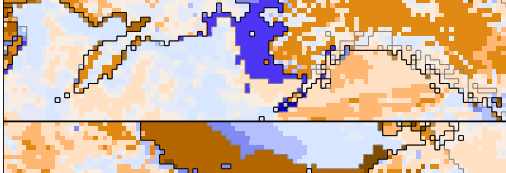

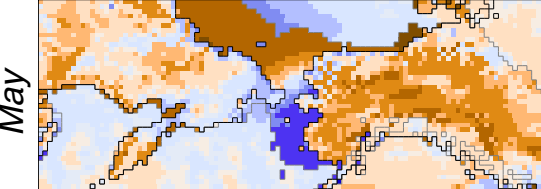

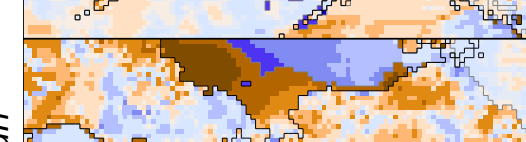

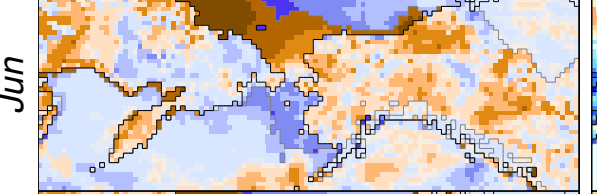

Pat $(x)$

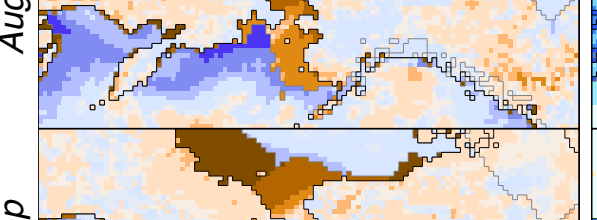

s.5

$\overleftarrow{t}, 4$

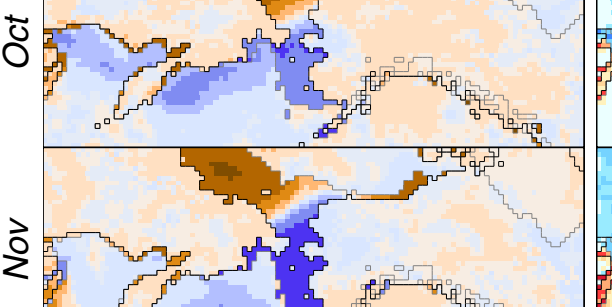

D
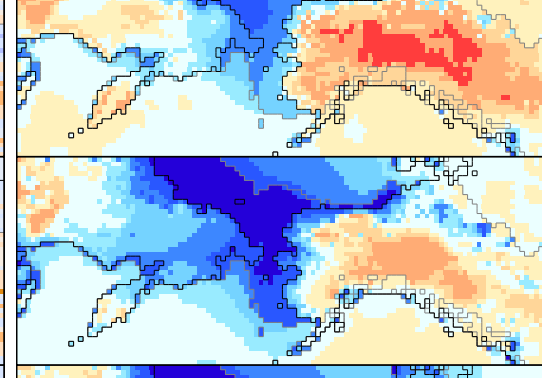

$\rightarrow$
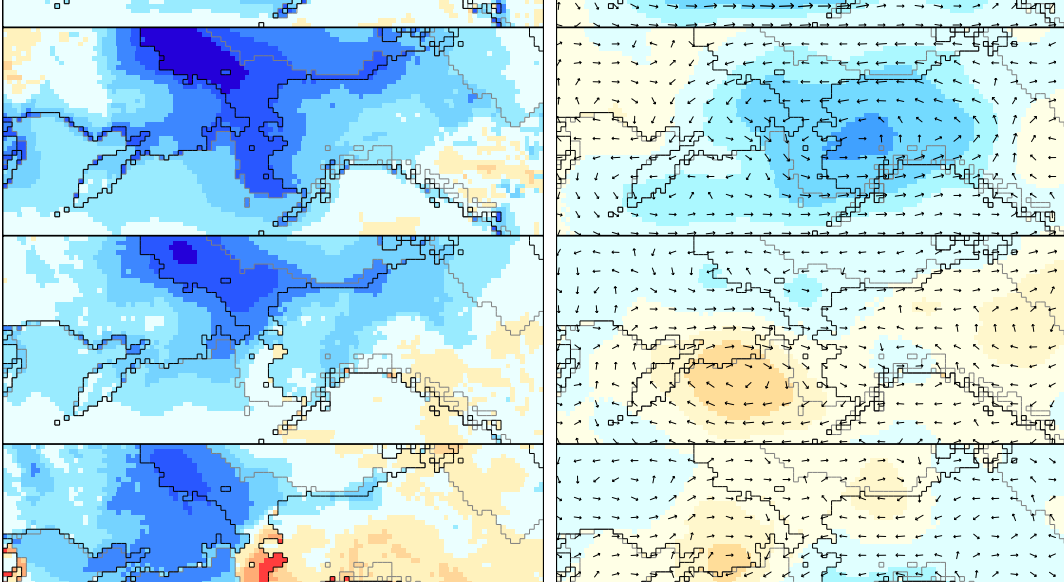

1
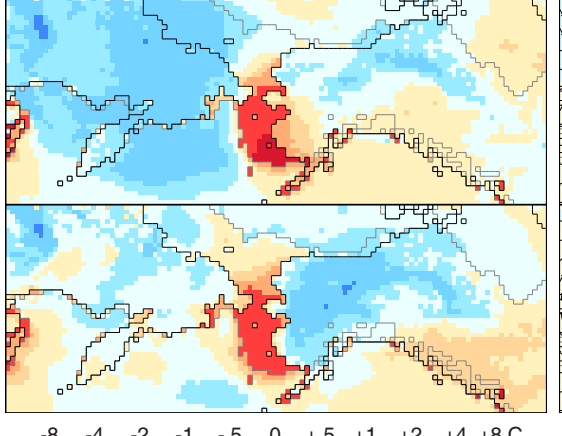

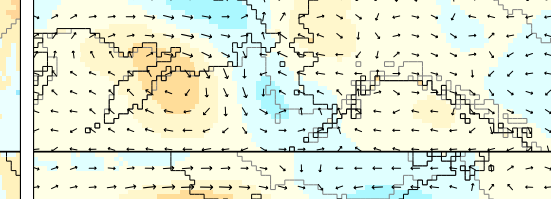

h 年
Sea-Level Pressure \& Winds Total Cloud Fraction

Long-Term Mean Differences

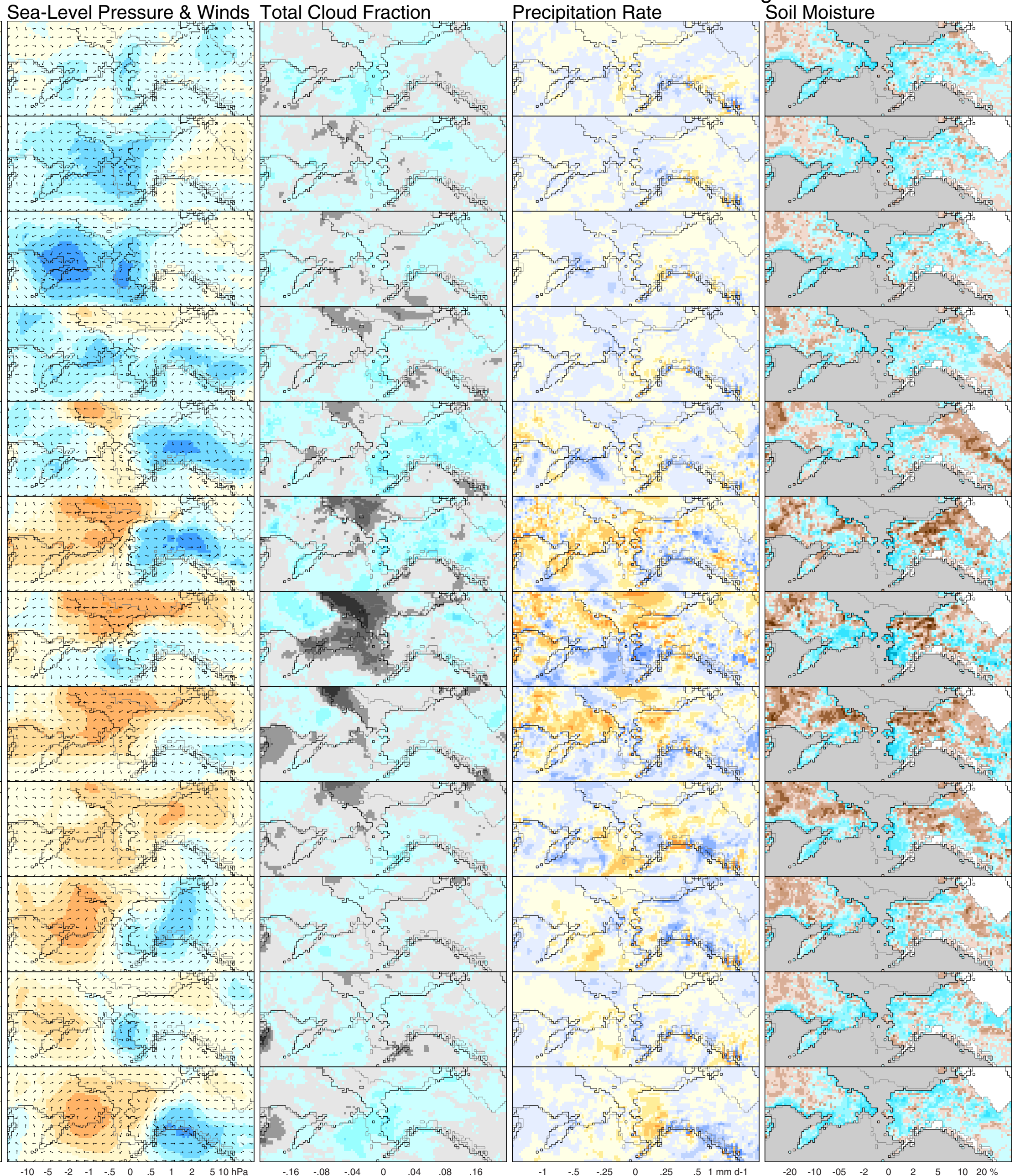


11 ka All Simulation - 11 ka Control Simulation Net Longwave Radiat

7 . 87 $-140$

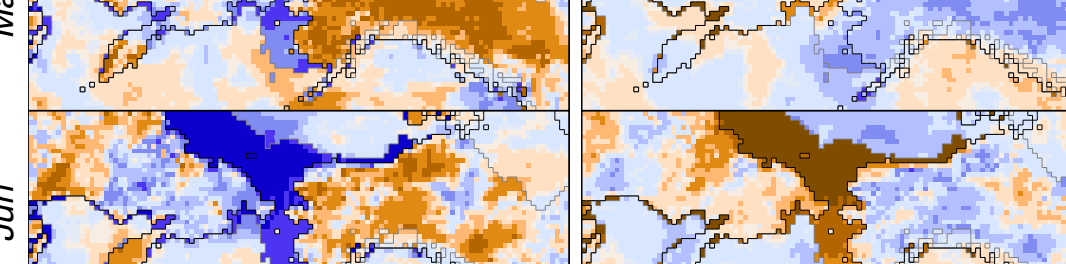

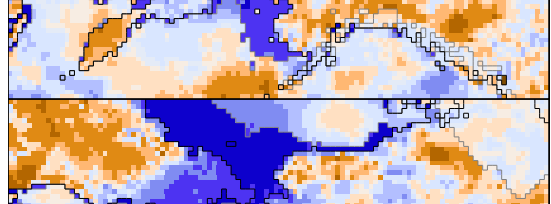

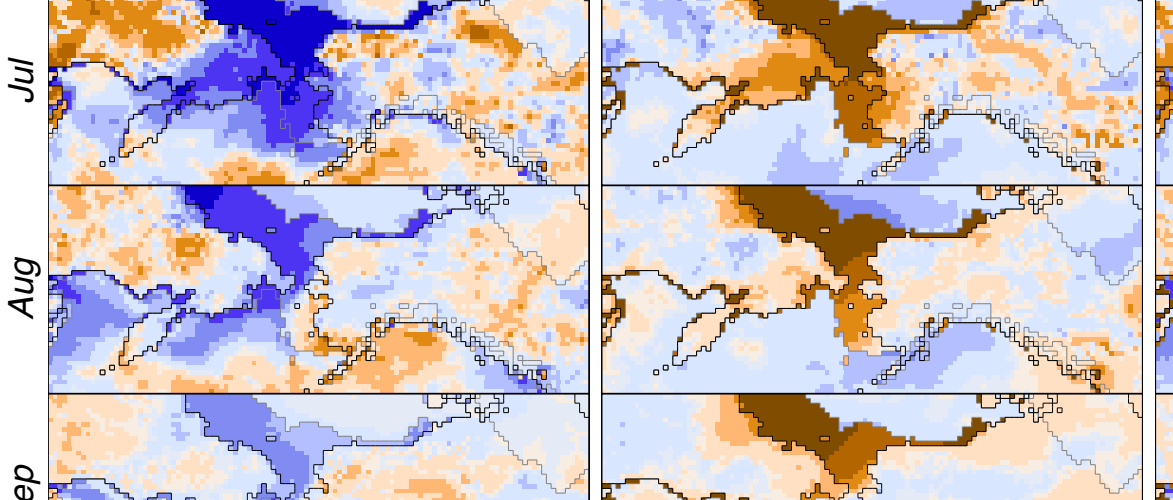

क

$\delta$ O

$\stackrel{2}{2}$

2

8.

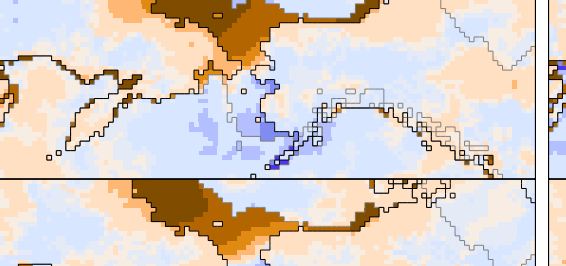

$\frac{7}{2}+\frac{1}{2}$ (2) 2)

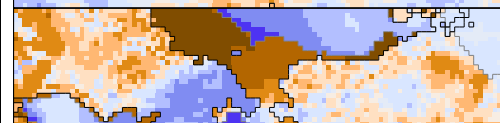

$12+2$
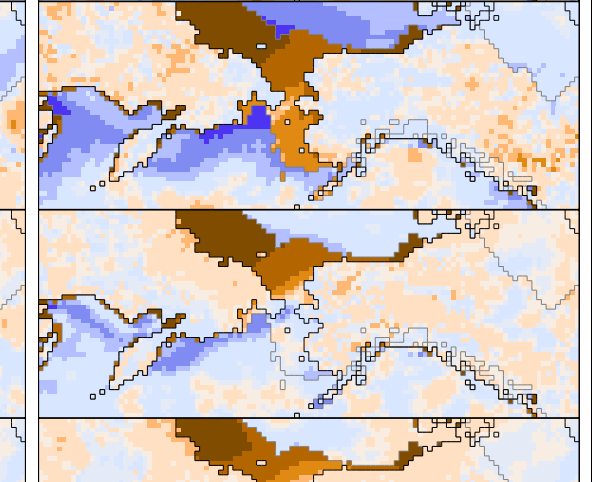

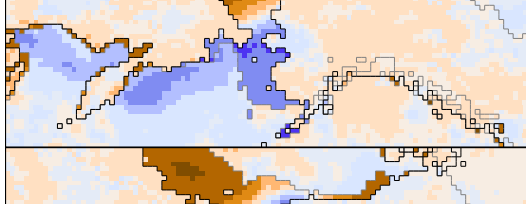

${ }^{2}$

$2{ }^{2}$

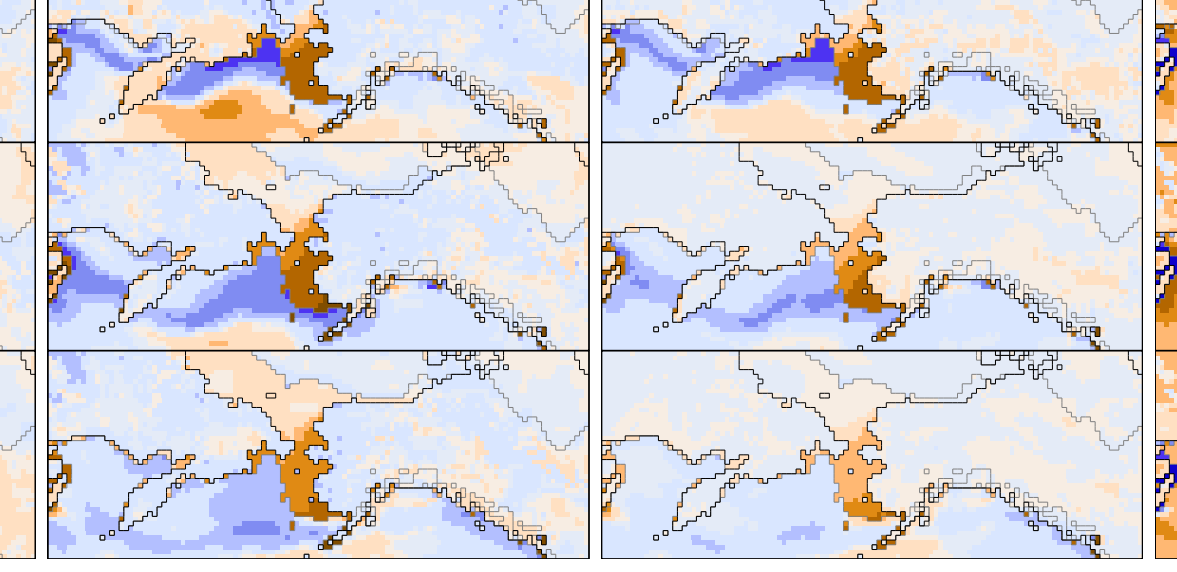
$y+2, y+2$ $y \geq y^{2}, y+1$ $y^{3} y^{2}-y^{2} x^{2}$ 3.

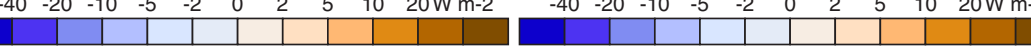

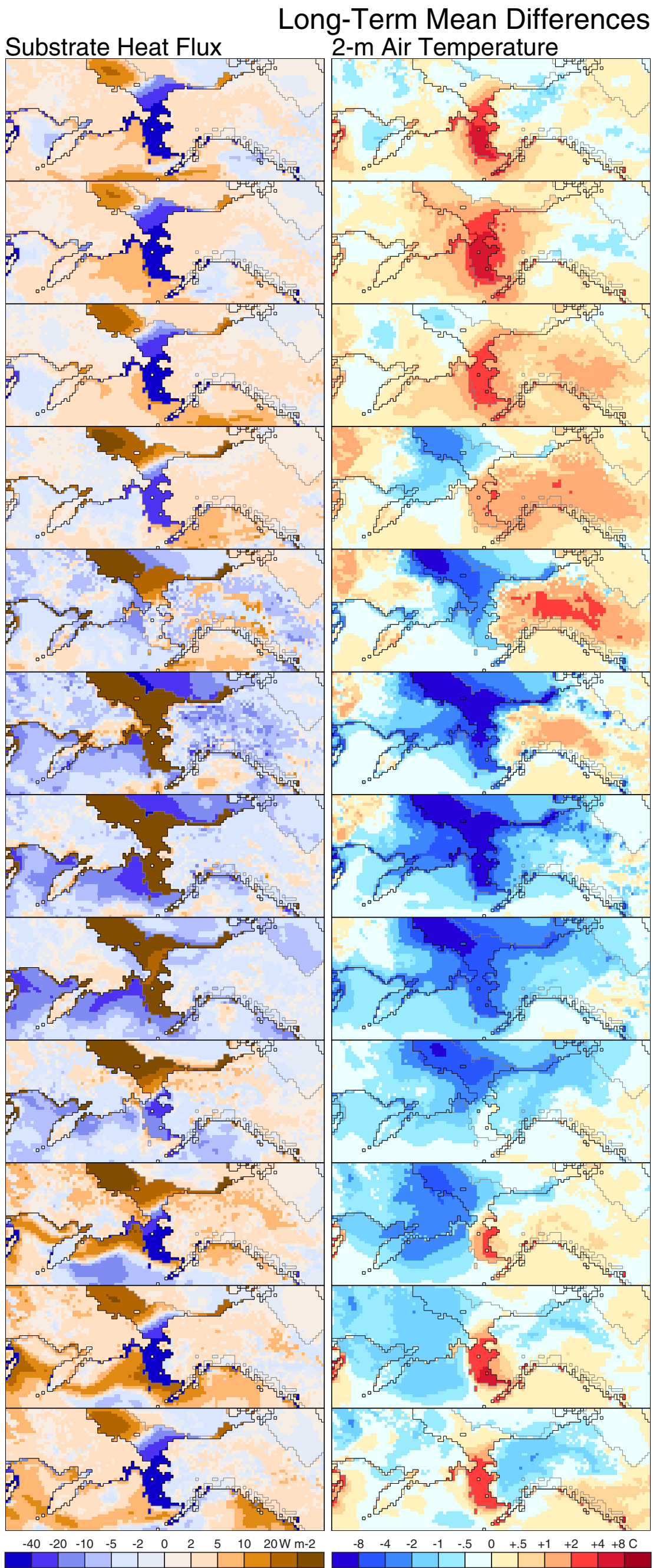

Long-Term Mean Differences

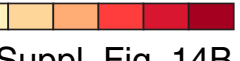




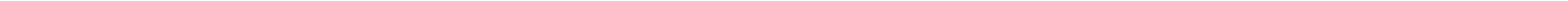




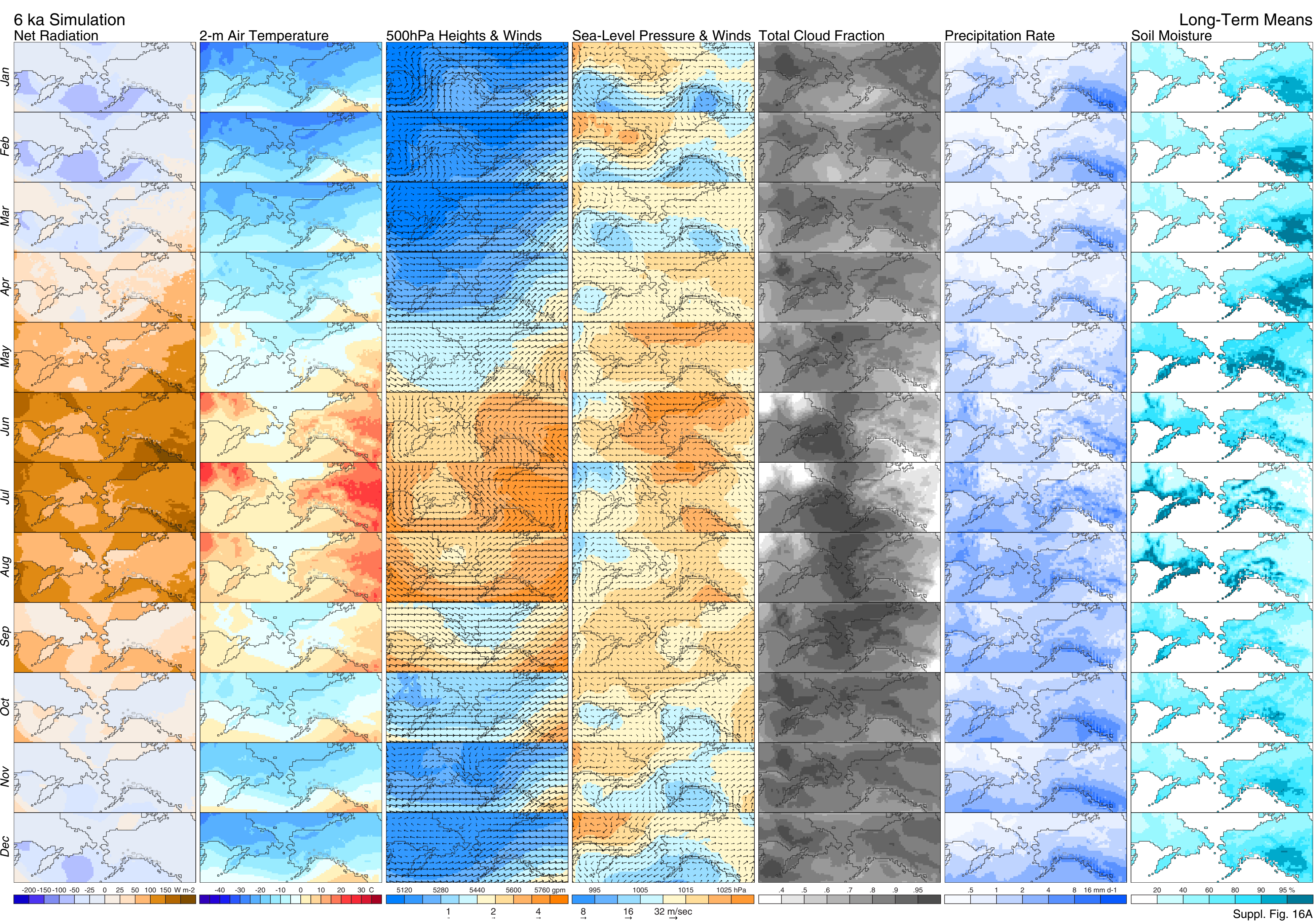




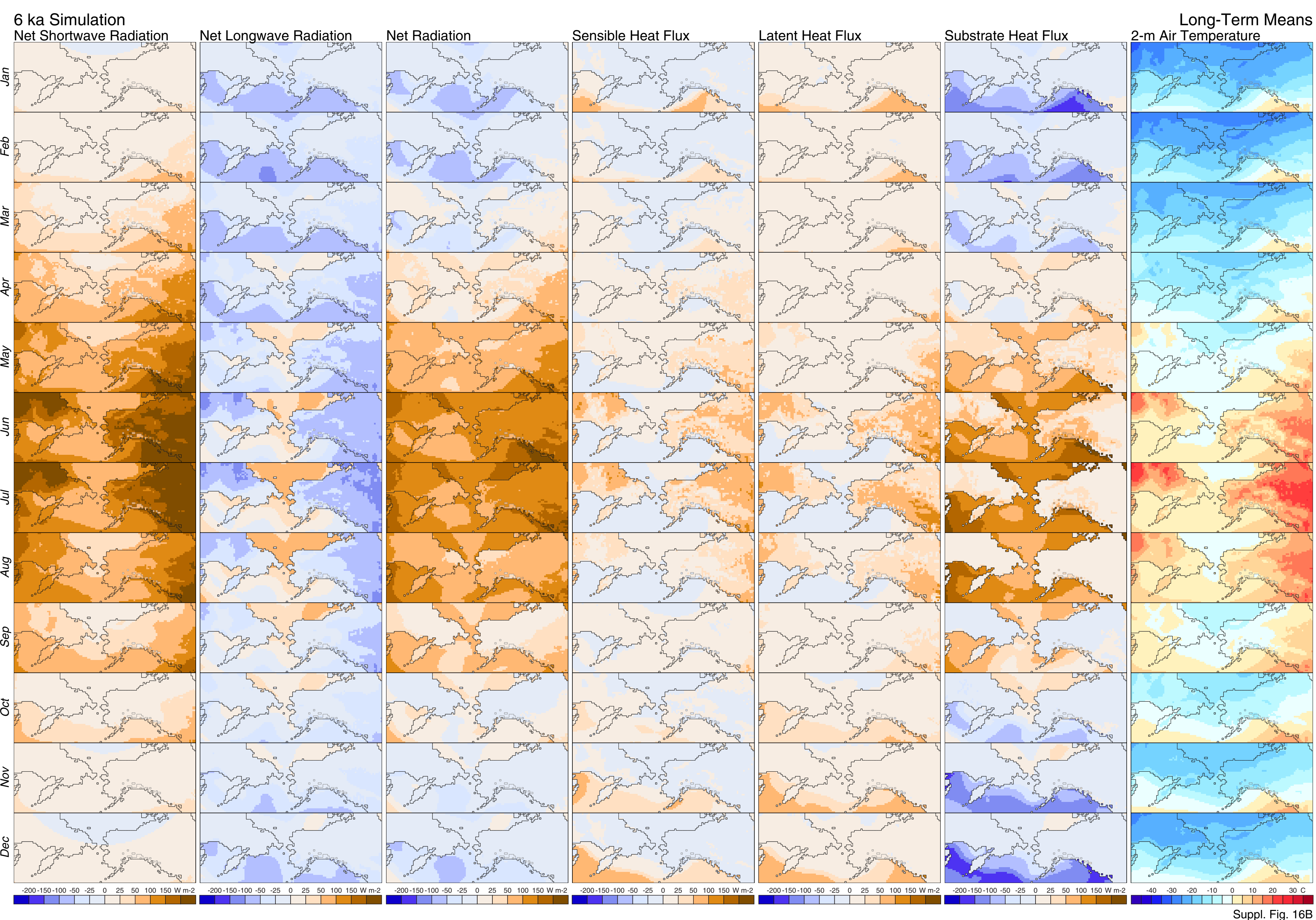

Suppl. Fig $16 B$ 


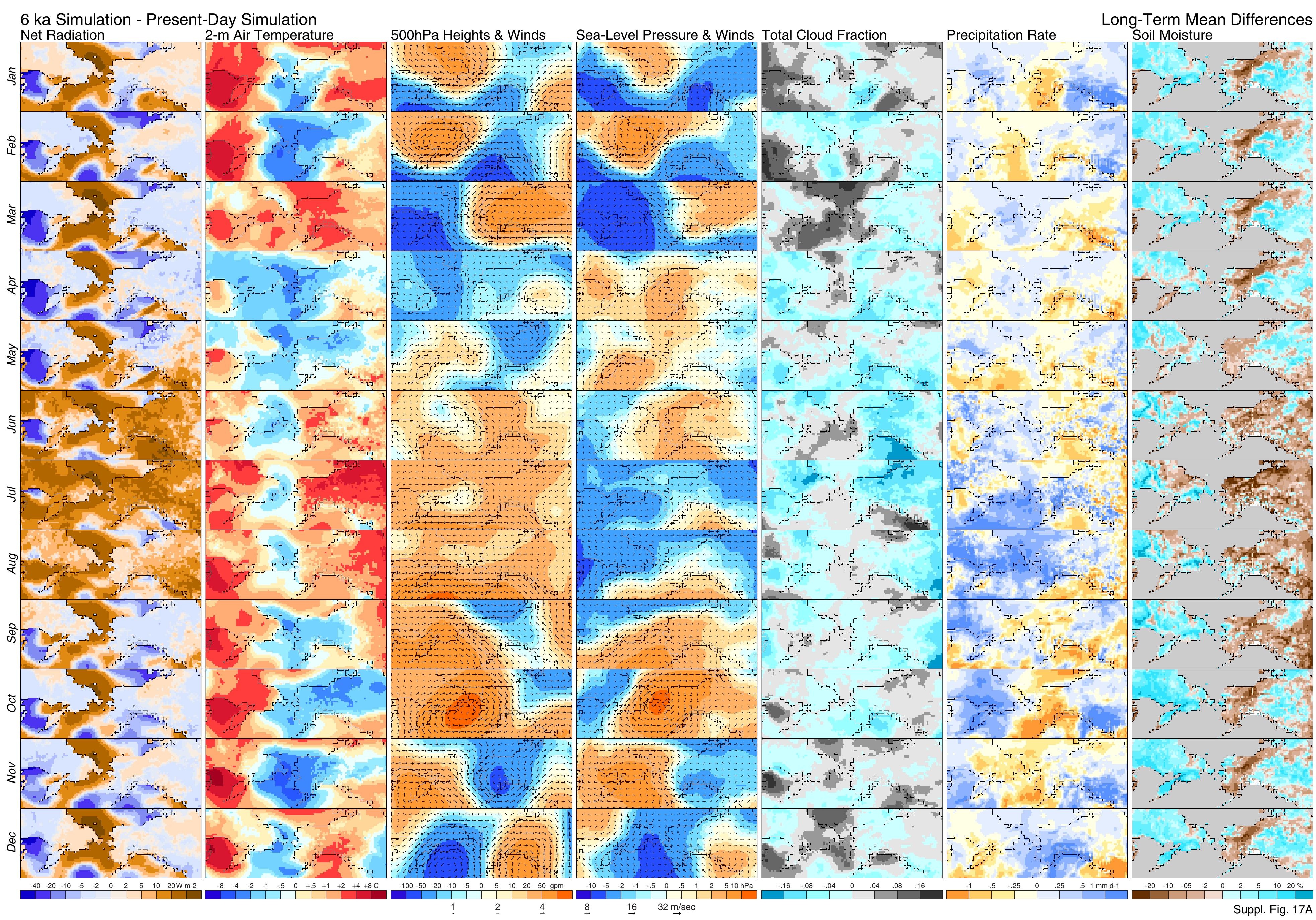




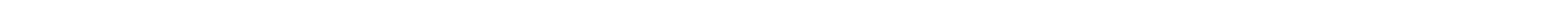




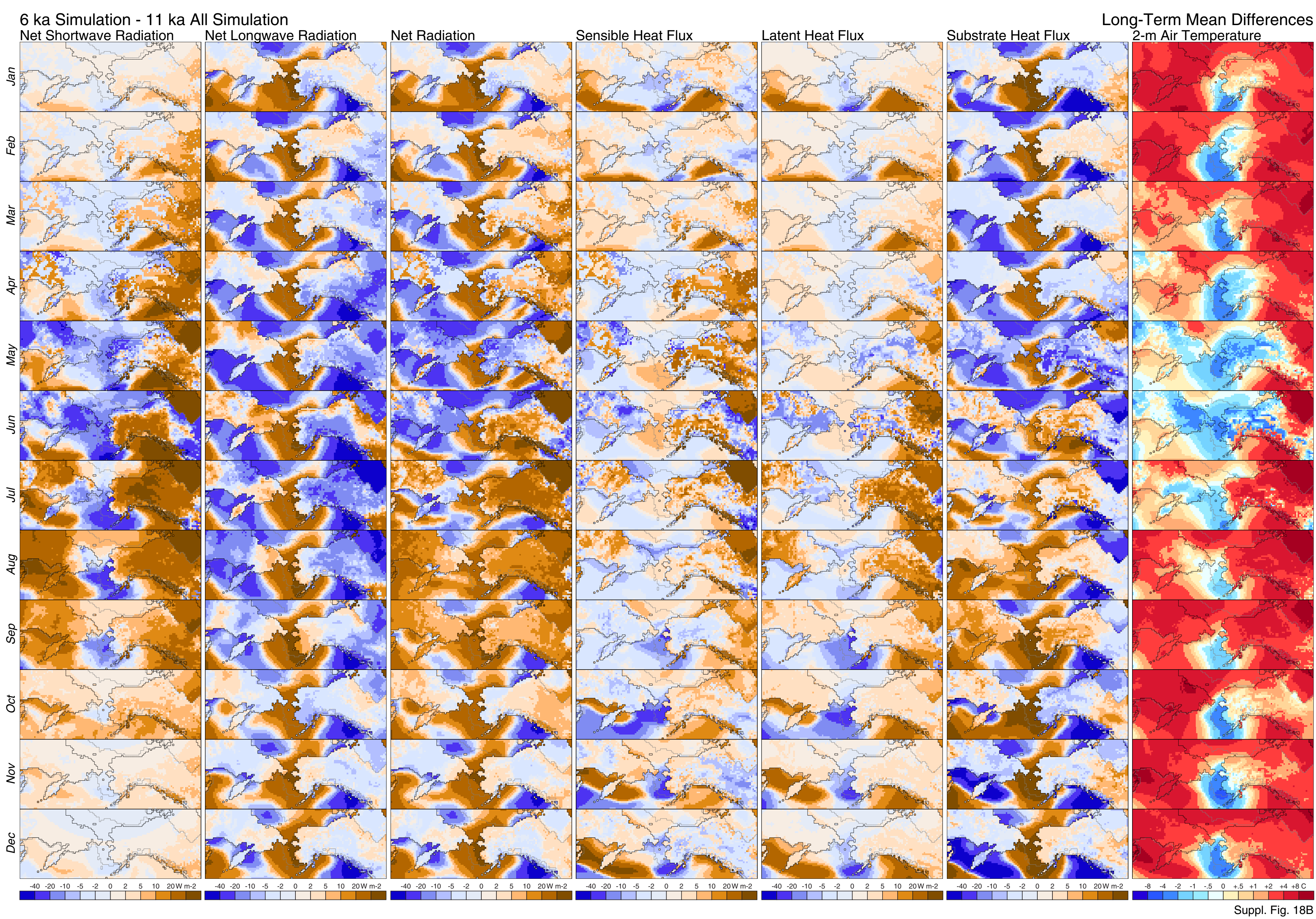

